\title{
I. Die Verfasstheit der Wiener Germanistik
}

\author{
I.1. Kategorien der Ordnung - \\ Lehrstuhlbesetzungen 1848-1912
}

In der Habsburgermonarchie erfolgte die Institutionalisierung der Germanistik als universitäres Fach im Zuge der Universitätsreform von 1848/49. Innerhalb kürzester Zeit wurden an allen Universitäten des Landes Lehrkanzeln für Deutsche Sprache und Literatur eingerichtet, die sowohl den Bedarf an Philologen für das höhere Schulwesen abdecken sollten als auch nationalpolitischen Interessen des Vielvölkerstaats zu genügen hatten. ${ }^{1}$ Mangels akademisch ausgebildeter Germanisten wurden diese Lehrstühle in der Konsolidierungsphase des Faches mit nicht-habilitierten Privatgelehrten oder mit Wissenschaftlern anderer Fachrichtungen besetzt. In Wien berief Leo Graf von Thun-Hohenstein, der 1849 das neu geschaffene Ministerium für Kultus und Unterricht übernommen hatte, 1850 den germanistischen Autodidakten und Bibliothekar an der Wiener Hofbibliothek Theodor Georg von Karajan als Professor für Deutsche Sprache und Literatur. ${ }^{2}$ Karajan trug jedoch nur bedingt zum Aufbau des Faches bei, da er aufgrund konfessioneller Auseinandersetzungen an der Fakultät bereits drei Semester später die Universität wieder verließ. ${ }^{3}$ Zum Nachfolger

1 Zur Gründungsphase des Fachs in Österreich vgl. Thaler: „Die so sehr aus Leben und Zeit herausgefallene deutsche Philologie" [erscheint 2016]; Michler/SchmidtDengler: Germanistik in Österreich (2003), S. 193-201; Egglmaier: Die Einrichtung von Lehrkanzeln für Deutsche Philologie in Österreich nach der Universitätsreform der Jahre 1848/49 (1981); Fuchs: Die Geschichte der germanistischen Lehrkanzel von ihrer Gründung im Jahre 1850 bis zum Jahre 1912 (1967). - Zur Beziehung zwischen Universität und (Deutsch-)Lehrer-Ausbildung im 19. Jahrhundert vgl. Gönner: Die Lehrerbildung in Österreich von der Aufklärung bis zum Liberalismus (1974); für Preußen vgl. Meves: „Wir armen Germanisten ..." (1991). - Einen Überblick über die Geschichte der Wiener Germanistik bietet Grabenweger: Germanistik an der Universität Wien (2015).

2 Ernennungsdekret des Ministeriums für Kultus und Unterricht vom 12. Jänner 1850; UAW, Phil. Fak., Zl. 306 ex 1849/50, PA 3844 Theodor Georg von Karajan. - Zur Besetzungspolitik an den österreichischen Universitäten in der Ära Thun vgl. Zikulnig: Restrukturierung, Regeneration, Reform (2002).

3 Nachdem der Protestant und Klassische Philologe Hermann Bonitz im Juli 1851 zum Dekan gewählt worden war, verhinderte das Professorenkollegium der 
Karajans ernannte Thun den habilitierten Klassischen Philologen Karl August Hahn, der die Wiener Professur noch im Wintersemester 1851 antrat und sie bis zu seinem Tod 1857 behielt. In Hahns Amtszeit fielen die ersten Promotionen im Fach Deutsche Philologie; und auch die erste Habilitation erfolgte. ${ }^{4}$ Trotzdem war auch Hahns Nachfolger noch kein habilitierter Universitätsgermanist, sondern der Privatgelehrte Franz Pfeiffer, der in München Medizin studiert und dort ohne formalen Abschluss auch germanistische Vorlesungen besucht hatte. Pfeiffer lehrte sowohl Neuere deutsche als auch Ältere deutsche Literatur und setzte sich während seiner Amtszeit vehement für die Errichtung einer zweiten germanistischen Lehrkanzel ein. ${ }^{5}$ Diesem Ansinnen wurde seitens des Ministeriums 1868, im Jahr von Pfeiffers Tod, auch stattgegeben.

Insgesamt kann das Jahr 1868 als das Ende der ersten Phase der Wiener Universitätsgermanistik betrachtet werden. In dieser wurden die Lehrstühle, wie es seit 1848 üblich war, direkt vom Ministerium und ohne Fakultätsvorschlag besetzt. Die Professoren kamen nicht nur aus Österreich (Karajan), sondern auch aus der Schweiz (Pfeiffer) und aus Deutschland (Hahn); sie waren nicht nur katholisch (Pfeiffer), sondern auch griechischorthodox (Karajan) und protestantisch (Hahn); und sie waren keine ausgebildeten Germanisten, sondern entweder Vertreter eines anderen universitären Fachs oder Privatgelehrte. Dieser speziellen Ausgangssituation ist es auch zuzuschreiben, dass sich in den ersten knapp zwanzig Jahren kein fachlicher oder schulischer Zusammenhang bei Berufungen erkennen lässt. Nach 1868 änderten sich die Kriterien der Professorenfolge jedoch grundlegend. Die nationale und konfessionelle Offenheit und die fachliche

theologischen Fakultät die Einsetzung von Bonitz mit der Begründung, dass dadurch der katholische Charakter der Universität, der durch den Stiftsbrief verbürgt war, verletzt werde. Karajan kündigte daraufhin seine Stellung, da er als nichtkatholischer, sondern griechisch-orthodoxer Professor mit dieser, wie er selbst betonte, „nur Pflichten auf sich genommen [hatte], aus denen er keinerlei Rechte ableiten durfte“. Zit. n. Fuchs: Die Geschichte der germanistischen Lehrkanzel von ihrer Gründung im Jahre 1850 bis zum Jahre 1912 (1967), S. 14. Zu Karajan vgl. außerdem Faerber: Theodor Georg Ritter von Karajan (1997).

4 Die erste germanistische Habilitation in Wien war die des Neugermanisten Karl Tomaschek 1855, vgl. dazu die nachfolgenden Ausführungen.

5 Fuchs: Geschichte der germanistischen Lehrkanzel von ihrer Gründung im Jahre 1850 bis zum Jahre 1912 (1967), S. 27 -37. Zu Pfeiffer vgl. auch Scherer: Briefe und Dokumente aus den Jahren 1853 - 1886 (2005), S. 110-118, S. 372-376; Nottscheid: Franz Pfeiffers Empfehlungskarte für Wilhelm Scherer bei Jacob Grimm (2003); Kofler: Das Ende einer wunderbaren Freundschaft (1998); Bartsch: Franz Pfeiffer (1870). 
Unbestimmtheit der Professionalisierungsphase wurden von einer zunehmend strikten Nachbesetzungspraxis abgelöst, die die Wiener Germanistik bis ins Jahr 1912 prägen sollte.

1868 bildete auch insofern eine Zäsur, als zum ersten Mal nun statt einer, wie bisher, zwei Professuren für Deutsche Sprache und Literatur zu besetzen waren und die erste "Generation der professionellen Germanisten " ${ }^{\text {"6 }}$ die Ordinarien erhielt. Die neu eingerichtete, zweite Lehrkanzel wurde im März 1868 mit dem ersten Wiener Neugermanisten Karl Tomaschek besetzt, der sich 1855 für Deutsche neuere literatur auß aesthetischen gesichtspuncten habilitiert hatte. ${ }^{7}$ Mit der Differenzierung der beiden Lehrstühle vollzog die Wiener Germanistik als erste im gesamten deutschen Sprachraum die Fächertrennung in Ältere und Neuere deutsche Literaturforschung. ${ }^{8}$ Die Nachfolge Pfeiffers trat im selben Jahr ein weiterer Germanist der Wiener Universität an, nämlich der von Pfeiffer nicht besonders geschätzte, aber von der Fakultät, die zum ersten Mal in ein germanistisches Nachbesetzungsverfahren involviert war, in Vorschlag gebrachte Wilhelm Scherer. Vor allem der zu diesem Zeitpunkt erst 27 Jahre alte Scherer sollte der Hoffnung der Fakultät, dass er „in 10 bis 15 Jahren auf [der] ersten Stufe deutscher Gelehrsamkeit zu stehen erwarten läßt ${ }^{\text {"9) }}$, sowohl in fachlicher als auch wissenschaftsorganisatorischer Hinsicht mehr als gerecht werden.

1872, vier Jahre nach seinem Amtsantritt, verließ Wilhelm Scherer die Wiener Universität bereits wieder und folgte einem Ruf nach Straßburg. Daraufhin unterbreitete die Fakultät dem Ministerium eine Viererliste, auf der sie an erster Stelle den früheren Grazer und danach Kieler Ordinarius Karl Weinhold, an zweiter den Kärntner Matthias Lexer, der zu dieser Zeit Professor in Würzburg war, und an dritter den Königsberger Lehrstuhlinhaber Oskar Schade sowie den Grazer Ordinarius Richard Heinzel, der

6 Michler/Schmidt-Dengler: Germanistik in Österreich (2004), S. 199.

7 UAW, Phil. Fak., Zl. 412 ex 1854/55, PA 3450 Karl Tomaschek.

8 Weimar: Geschichte der deutschen Literaturwissenschaft bis zum Ende des 19. Jahrhunderts (1989), S. 429-442. - Auch wenn damit die Fächertrennung in Wien vollzogen worden war, waren beide Lehrstühle bis zum Beginn des Ersten Weltkriegs mit der Bezeichnung Deutsche Sprache und Literatur versehen. - Zur Situation der jungen Forschungsrichtung Neuere deutsche Literaturgeschichte vgl. jüngst Müller/Nottscheid (Hg.): Disziplinentwicklung als „community of practice“" (2016).

9 Karl Tomaschek in seinem, dem Ministerium übermittelten Kommissionsbericht über die Nachbesetzung der Lehrkanzel, o.D.; UAW, Phil. Fak., Zl. 407 ex 1867/ 68, PA 3282 Wilhelm Scherer. 
sich in Wien habilitiert hatte, in Vorschlag brachte. Da das Ministerium seit Ende des Deutschen Bundes 1866 der Praxis folgte, nur mehr Österreicher und unter ihnen vor allem Katholiken zu berufen, zog es den Erstgereihten Weinhold erst gar nicht in Betracht und entschied sich nach der Absage Lexers für den einzig übrig gebliebenen Österreicher Richard Heinzel. ${ }^{10}$ Heinzel hatte gemeinsam mit Wilhelm Scherer bei Pfeiffer studiert, bezeichnete sich selbst aber, obwohl drei Jahre älter als Scherer, „als dessen ältesten und ersten Schüler "11 und war Scherers ausdrücklicher Wunschkandidat für die Wiener Professur. Damit entsprach die Berufung Heinzels nicht nur den nationalen Anforderungen des Ministeriums, sondern leitete auch einen Berufungsmechanismus ein, nach dem der Favorit des scheidenden Lehrstuhlinhabers dessen Nachfolge antrat.

Der nächste Lehrstuhl, der zu besetzen war, war der Karl Tomascheks, der im September 1878 starb. Dieser, obwohl ebenso wie der andere Lehrstuhl mit der Bezeichnung Deutsche Sprache und Literatur versehen, sollte jedoch nicht mit einem Altgermanisten, sondern erneut mit einem Vertreter der Neueren deutschen Literaturgeschichte besetzt werden. In dieser Hinsicht stand die Wiener und mit ihr die gesamte österreichische Germanistik jedoch vor dem Problem, dass es sich um „eine junge Wissenschaft" handelte und deshalb „die Zahl ihrer Vertreter beschränkt" ${ }^{\text {“12 }}$ war. Vor allem Richard Heinzel, der sich auf das ältere Gebiet spezialisiert hatte, war daran interessiert, dass der zweite germanistische Lehrstuhl von einem Wissenschaftler besetzt wurde, der die vom Ministerium geförderte Lehre in der neueren Abteilung übernehmen konnte. Gegenüber Fakultät und Ministerium setzte sich Heinzel in einer ausführlichen Programmschrift für das von ihm nicht vertretene neuere Fach ein, in der er unter den Prämissen unbedingt philologischer Ausrichtung dessen wissenschaftlichen Anspruch und dessen universitäre Notwendigkeit betonte. ${ }^{13}$ In der für die Frage der Nachbesetzung im Dezember 1878 einberufenen Kommis-

10 Wiesinger/Steinbach: 150 Jahre Germanistik in Wien (2001), S. 46.

11 Heinzel: Rede auf Scherer (1886), S. 802. - Zur Beziehung zwischen Scherer und Heinzel vgl. Heinzel/Scherer: Die Korrespondenz Richard Heinzels mit Wilhelm Scherer [in Vorbereitung].

12 Richard Heinzel im Bericht der Kommission über die Besetzung der erledigten Lehrkanzel für deutsche Sprache und Literatur, o.D.; UAW, Phil. Fak., Zl. 4347 ex 1878/79, PA 3328 Erich Schmidt.

13 Vgl. Heinzel im Bericht der Kommission über die Besetzung der erledigten Lehrkanzel für deutsche Sprache und Literatur, o.D.; UAW, Phil. Fak., Zl. 4347 ex 1878/79, PA 3328 Erich Schmidt. 
sion schlug Heinzel auf Empfehlung Wilhelm Scherers dessen ,Meisterschüler' Erich Schmidt vor.

Der aus Jena stammende Erich Schmidt hatte nach Graz in Straßburg studiert und ebendort 1877 den Lehrstuhl Scherers übernommen, als dieser nach Berlin wechselte. Die Kommission konnte sich jedoch nicht eindeutig zwischen dem Grazer Ordinarius Anton Schönbach, einem Altgermanisten, und dem Neugermanisten Erich Schmidt entscheiden, ${ }^{14}$ und die Wiener Professur blieb vorerst vakant. ${ }^{15}$ Der Minister für Kultus und Unterricht Conrad von Eybesfeld, der von Heinzel über den knappen Vorsprung Schönbachs informiert wurde - in der Sitzung des Professorenkollegiums am 15. März 1879 hatte Schönbach 14 und Schmidt nur zwölf Stimmen erhalten -, war aber geneigt, Heinzels Wunsch zu entsprechen: Wie der Minister in seinem Bericht an den Kaiser betonte, wollte er nicht „Schönbach, der nur in altdeutscher Philologie wissenschaftliche Leistungen aufzuweisen hat", sondern mit Schmidt „einen Mann gewinnen, der sich in der strengen Schule altdeutscher Philologie jene Methode der Forschung angeeignet hat, welche erst seit einigen Jahrzehnten auf die Behandlung der neueren Literatur Anwendung gefunden hat“ ${ }^{16}$

Das einzige Problem blieb, dass Schmidt nicht ohne Weiteres als österreichischer Wissenschaftler durchgehen konnte. Mit welcher durchaus eigenwilligen Interpretation der Minister und mit ihm der Kaiser dieses Problem lösten, berichtete Schmidt seinem „freundlichste[n] Nothelfer

14 Scherer selbst mischte sich aus Berlin nicht offiziell in die Nachbesetzung ein, veröffentlichte aber am 10. Jänner 1879, kurz nach der ersten Kommissionssitzung, in der Neuen Freien Presse einen Artikel, in dem er zwar nicht direkt auf die vakante Wiener Lehrkanzel einging, aber ein Plädoyer für die institutionelle Stärkung der Neueren deutschen Literaturgeschichte hielt und auf die Verantwortung des Ministeriums in dieser Hinsicht hinwies. Scherer: Die deutsche Literatur an den österreichischen Universitäten (1879).

15 Den universitären Unterricht in Neuerer deutscher Literatur deckte ab Sommersemester 1879 der Privatdozent Josef Seemüller ab, dessen Spezialgebiet jedoch die Ältere deutsche Literatur war. Abhilfe für die Lehre erhoffte sich Heinzel zwischenzeitlich vom Neugermanisten August Sauer, der bei ihm und Tomaschek in Wien und bei Wilhelm Scherer in Berlin studiert hatte. Sauer habilitierte sich auch tatsächlich im Juni 1879 in Wien, wurde aber noch im Sommer desselben Jahres an die Universität Lemberg berufen. Fuchs: Geschichte der germanistischen Lehrkanzel von ihrer Gründung im Jahre 1850 bis zum Jahre 1912 (1967), S. 69-73. Zu Sauer vgl. auch Höhne (Hg.): August Sauer (2011).

16 Zit. n. Fuchs: Geschichte der germanistischen Lehrkanzel von ihrer Gründung im Jahre 1850 bis zum Jahre 1912 (1967), S. 79. 
und Berater ${ }^{\text {17 }}$ Scherer, mit dem er während der gesamten Nachfolgeverhandlungen Informationen über die „Wiener Angelegenheit" ${ }^{\text {18 }}$ austauschte, in einem Brief vom 16. August 1880:

Ich schreibe jetzt so viel durcheinander, daß ich gar nicht weiß, ob ich Ihnen nach der Audienz beim Minister schon eine Meldung gemacht habe. Excellenz Conrad, der eine rührende Naivität in Bezug auf Universitätssachen verrät, hat mir alles zugestanden, was der gute David ${ }^{19}$ mit mir ausgemacht. C., der echte steirische Großgrundbesitzer mit bequemen Formen, Bonhomme, sehr ungebildet, als Minister für Cultus und Unterricht wäre er komisch, müßte man sich nicht ärgern über seine Beschränktheit.

[...] Er sprach weise Worte über schriftstellerische Arbeit und Lehrtätigkeit, ferner, daß er das Hauptgewicht auf Seminar lege, (hatte keine Ahnung davon, was ein Seminar ist), daß man mit Ausländern neuerdings üble Erfahrungen gemacht, daß er mich als halben Oesterreicher betrachte und von meiner großen Anhänglichkeit an Oesterreich gehört habe; ob ich in Graz vom juridischen Studium ausgegangen sei. Ein kundiger Thebaner. In Wien verrate ich dies Gespräch nicht.

Der Kaiser sei jetzt schwierig in Bestätigung von Nichtoesterreichern, aber bei mir altem Grazer etc. ${ }^{20}$

Nachdem der Minister und der Kaiser einander versichert hatten, dass Schmidt aufgrund seiner Grazer Studienzeit ,ja kein eigentlicher Ausländer sei “21 $^{\text {' }}$ wurde er mit Dekret vom 27. August 1880 zum außerordentlichen Professor für Deutsche Sprache und Literatur in Wien bestellt und ein Jahr später zum ordentlichen Professor ernannt. ${ }^{22}$ Damit waren beide Lehrstühle an der Wiener Germanistik mit Wissenschaftlern besetzt, die Österreicher waren oder zumindest als solche präsentiert werden konnten und aus der Lehre oder zumindest dem Einflussbereich Wilhelm Scherers kamen.

17 Scherer/Schmidt: Briefwechsel (1963), S. 144 (Brief von Schmidt an Scherer vom 1. August 1880).

18 Scherer/Schmidt: Briefwechsel (1963), S. 140 (Brief von Schmidt an Scherer vom 28. Mai 1880).

19 Benno von David war Ministerialdirektor und Sektionschef für das Hochschulwesen im Ministerium für Kultus und Unterricht, außerdem ein ehemaliger Mitschüler Scherers und dessen Kontaktmann im Ministerium. Vgl. Scherer/ Schmidt: Briefwechsel (1963), S. 110 (Brief von Scherer an Schmidt vom 25. September 1879).

20 Scherer/Schmidt: Briefwechsel (1963), S. 146-147 (Brief von Schmidt an Scherer vom 16. August 1880).

21 Scherer/Schmidt: Briefwechsel (1963), S. 146 (Brief von Schmidt an Scherer vom 12. August 1880).

22 UAW, Phil. Fak., PA 3328 Erich Schmidt. 
In die Zeit der gemeinsamen Leitung des Seminars für Deutsche Philologie in Wien durch Heinzel und Schmidt fielen die Gründung und der Ausbau des Seminars für Neuere deutsche Literatur und damit die endgültige institutionelle Etablierung der neueren Abteilung, die ab 1881 selbständig und mit demselben Gewicht neben der älteren existierte. ${ }^{23}$ Schmidt selbst blieb aber nur fünf Jahre in Wien, da er 1885 aufgrund der Vorbereitung Scherers ${ }^{24}$ zunächst als Direktor an das neu eröffnete GoetheArchiv in Weimar wechselte und nach Scherers Tod 1888 dessen Lehrstuhl in Berlin übernahm. Diese Laufbahn war, wie aus einem Brief Scherers an Schmidt vom 30. Mai 1880 hervorgeht, bereits vor und mit Schmidts Wiener Amtsantritt beabsichtigt: „Sie können von Wien leichter nach Berlin kommen, als von Straßburg." 25

Ähnlich geplant und komplikationslos verlief auch die Nachbesetzung von Schmidts Lehrstuhl in Wien. Noch bevor seine eigene Entlassung vom Kaiser bestätigt wurde und demnach auch vor der Bildung einer Berufungskommission für seine eigene Nachfolge informierte Schmidt am 24. Juni 1885 seinen Wunschkandidaten Jakob Minor:

Ich gehe definitiv im October nach Weimar u. lege mein Scepter in Ihre Hände. Das unterliegt gar keinem Zweifel; habs auch David heut früh (gleich nach meiner Rückkehr) gesagt und er billigt die Wahl, die in der Comm. ganz sicher auf Sie primo wenn nicht unico loco fällt. Sie würden schon zum Herbst herberufen werden; zunächst als Eo. [Extraordinarius, E.G.] wie ich $1880{ }^{26}$

Jakob Minor gehörte zum engeren Kreis der von Scherer beobachteten germanistischen Nachwuchswissenschaftler. ${ }^{27}$ Er hatte in Wien studiert und 1878 promoviert, war danach mit einem Stipendium zu Scherer und Karl Müllenhoff nach Berlin in die Lehre gegangen und nach seiner Wiener Habilitation 1882 zum außerordentlichen Professor an der Universität

23 Zur Etablierung des neueren Fachs vgl. Egglmaier: Entwicklungslinien der neueren deutschen Literaturwissenschaft in Österreich in der zweiten Hälfte des 19. Jahrhunderts und zu Beginn des 20. Jahrhunderts (1994).

24 Vgl. Scherer/Schmidt: Briefwechsel (1963), S. 202-204 (Brief von Scherer an Schmidt vom 21. Mai 1885).

25 Scherer/Schmidt: Briefwechsel (1963), S. 141 (Brief von Scherer an Schmidt vom 30. Mai 1880).

26 Castle: Zu Jakob Minors 100. Geburtstag (1955), S. 84 (Brief von Schmidt an Minor vom 24. Juni 1885).

27 So wollte Scherer z. B. für die Weimarer Goethe-Ausgabe „alles junge Volk anstellen: Seuffert, Minor, Sauer, Waldberg, Weilen, Burdach, Schröder“. Scherer/ Schmidt: Briefwechsel (1963), S. 141 (Brief von Scherer an Schmidt vom 21. Mai 1885). 
Prag bestellt worden. ${ }^{28}$ Minor passte als österreichischer Neugermanist ganz ausgezeichnet in das Berufungskonzept des Ministeriums und auch in die Pläne Scherers, die in wissenschaftsorganisatorischer Hinsicht vor allem darin bestanden, alle wichtigen Lehrstühle im deutschsprachigen Raum mit Vertrauten, Schülern und Anhängern zu besetzen - was in erstaunlich hohem Ausmaß auch gelang. ${ }^{29}$ Darüber hinaus konnte Minor mit der Zustimmung der Berufungskommission und des Professorenkollegiums rechnen, da er zum einen aus der eigenen Fakultät kam, zum anderen aufgrund seiner Tätigkeit in Prag dem Laufbahnmodell von Bewährung und Rückgewinnung entsprach.

Tatsächlich benötigte die Kommission nur eine einzige Sitzung, um zu einem Entschluss zu kommen. Am 6. Juli 1885 entschied sie: „primo loco Dr. Jacob Minor, außerordentlicher Professor an der Prager Universität; secundo und tertio loco ex aequo Dr. Bernhard Seuffert, Privatdocent an der Universität zu Würzburg und Dr. August Sauer, außerordentlicher Professor an der Universität Graz. " ${ }^{30}$ War bei den Nachfolgeverhandlungen Tomascheks, bei denen 1880 nach eineinhalb Jahren schließlich Schmidt berufen wurde, noch eine Diskussion darüber entbrannt, ob ein Alt- oder Neugermanist den zweiten Lehrstuhl bekommen sollte, und die Fakultät deshalb unentschieden, ob sie Anton Schönbach oder Erich Schmidt in Vorschlag bringen sollte, so war die Sachlage jetzt klar. Noch am Tag der Kommissionssitzung schrieb Schmidt an Minor:

Brennen Sie die ersten Böller ab!

Eben aus der Sitzung.

Heinzels Antrag: neuere Litteratur (also nicht Schönbach etc.) 1 einstimmig angenommen

Meine Terna: Minor I. ${ }^{\circ}$ Seuffert, Sauer aequo. 1. einst. angen.

Der Facultät sind wir nun sicher. ${ }^{31}$

28 Zu Minor vgl. Faerber: Ich bin ein Chinese (2004).

29 In Österreich waren Ende des 19. Jahrhunderts alle neugermanistischen und teilweise auch die altgermanistischen Lehrstühle mit Schülern Scherers der ersten oder zweiten Generation besetzt: Richard Heinzel und Jakob Minor in Wien, Anton E. Schönbach und Bernhard Seuffert in Graz, Josef Eduard Wackernell in Innsbruck, Richard Maria Werner in Lemberg und August Sauer in Prag. - Zu Scherers und seiner Schüler Bemühungen um die Ausgestaltung der Neueren deutschen Literaturgeschichte vgl. Müller/Nottscheid (Hg.): Disziplinentwicklung als „community of practice“ (2016).

30 Protokoll der Kommissionssitzung zur Nachbesetzung der Lehrkanzel nach Erich Schmidt vom 6. Juli 1885, zit. n. Faerber: Ich bin ein Chinese (2004), S. 121.

31 Castle: Zu Jakob Minors 100. Geburtstag (1955), S. 87 (Brief von Schmidt an Minor vom 6. [Juli] 1885). - Der betreffende Brief ist nicht vollständig datiert und 
Die Gewissheit Schmidts hinsichtlich der Fakultät sollte sich in vollem Maße bestätigen. Bereits fünf Tage später, am 11. Juli, wurde dieser Vorschlag, nachdem Schmidts Vertrauensmann und „beste[r] College von der Welt “32 Richard Heinzel aus „Opportunitätsgründen“"33 als Referent fungiert hatte, vom Professorenkollegium der philosophischen Fakultät einstimmig bestätigt. Und am 23. August 1885 berief der Kaiser Jakob Minor zum außerordentlichen Professor der Deutschen Sprache und Literatur an der Universität Wien. ${ }^{34}$ Die „Wünsche“ Schmidts „erfüllt[en]“ sich, wie er selbst feststellte, so „prächtig“ und „glatt“, dass das gesamte Berufungsverfahren „[o] [hne jede Debatte ${ }^{\text {“35 }}$ verlief und in einer Kürzestzeit von nicht einmal acht Wochen, in denen die Entscheidungsträger aller Instanzen problemlos überzeugt werden konnten, beendet war.

Das Prinzip, dass der scheidende Ordinarius seinen Nachfolger auswählte, konnte bei der nächsten Berufung nur indirekt angewendet werden. Richard Heinzels Lehrstuhl wurde nämlich vakant, weil er sich im April 1905 das Leben nahm. Trotzdem wurde sich die am 25. Mai 1905 zum ersten Mal tagende Kommission in nur einer einzigen Sitzung einig. Sie nannte für den Dreiervorschlag, der dem Ministerium zu übermitteln war, an erster Stelle Josef Seemüller, an zweiter Carl von Kraus und an dritter Konrad Zwierzina. ${ }^{36}$ Alle drei Wissenschaftler hatten in Wien studiert, promoviert und sich habilitiert und zählten zu den erfolgreichsten und von Heinzel am nachdrücklichsten geförderten Schülern der Wiener Altgermanistik. Konrad Zwierzina ging nach seiner Wiener Habilitation 1897 als Privatdozent nach Graz und war seit 1899 ordentlicher Professor an der einzigen katholischen Universität der Schweiz, in Fribourg. Carl von Kraus hatte 1894 seine Habilitationsschrift in einer längeren Widmung seinem Lehrer Heinzel zugeeignet, ${ }^{37}$ war daraufhin in Wien als Privatdo-

hier als Nr. 20 fälschlicherweise nach Nr. 19 (Brief vom 26. Dezember 1885) eingereiht, gehört aber zwischen Nr. 16 (Brief vom 4. Juli 1885) und Nr. 17 (Brief vom 12. Juli 1885).

32 Castle: Zu Jakob Minors 100. Geburtstag (1955), S. 85 (Brief von Schmidt an Minor vom 12. Juli 1885).

33 Castle: Zu Jakob Minors 100. Geburtstag (1955), S. 87 (Brief von Schmidt an Minor vom 6. [Juli] 1885).

34 Faerber: Ich bin ein Chinese (2004), S. 121, S. 123.

35 Castle: Zu Jakob Minors 100. Geburtstag (1955), S. 85 (Brief von Schmidt an Minor vom 12. Juli 1885).

36 Protokoll der Kommissionssitzung zur Besetzung der Lehrkanzel nach Herrn Hofrat Prof. Heinzel vom 25. Mai 1905; UAW, Phil. Fak., Zl. 3529 ex 1904/05, PA 3135 Josef Seemüller.

37 Kraus (Hg.): Deutsche Gedichte des zwölften Jahrhunderts (1894), S. III. 
zent und außerordentlicher Professor tätig, bevor er 1904 als Ordinarius für Ältere germanische Sprachen und Literatur an die Deutsche Universität in Prag ging. Der Erstgereihte Josef Seemüller, der mit kaiserlichem Dekret vom 1. August 1905 und mit Rechtswirksamkeit vom 1. Oktober desselben Jahres zum Ordinarius berufen wurde, ${ }^{38}$ war 1879 der erste Habilitand Heinzels und nach seiner Wiener Privatdozententätigkeit seit $1890 \mathrm{zu}-$ nächst außerordentlicher und dann ordentlicher Professor an der Universität Innsbruck. Die gesamte Liste - allen voran Josef Seemüller, der zum Wintersemester 1905 die Nachfolge Heinzels antrat - entsprach also einem Berufungsmodus, bei dem im Sinne problemfreier Kontinuität allein die jeweiligen Schüler des scheidenden Ordinarius als dessen Nachfolger in Betracht gezogen wurden.

Die letzte Lehrstuhlbesetzung, die an der Wiener Germanistik dieser Reihe der aufgebauten und gefestigten Ordnung der professoralen Erbfolge entsprach, war die Nachfolge Josef Seemüllers 1912. Seemüller ließ sich mit 1. April 1912 in den ständigen Ruhestand versetzen, ${ }^{39}$ hatte aber schon fast ein Jahr zuvor erste Vorbereitungen für seine eigene Nachfolge getroffen. Am 22. Mai 1911 schrieb er an seinen früheren Wiener Kollegen Carl von Kraus, der mittlerweile eine Professur in Bonn innehatte:

Meinem Urteil nach können nur Sie zur Nachfolge in betracht kommen. [...] Minor hatte Sie nach Heinzel an 2. Stelle genannt: er muß Sie nun wol an $1^{\mathrm{e}}$ ziehen, in der Fakultät haben Sie, das weiß ich, warme Freunde.

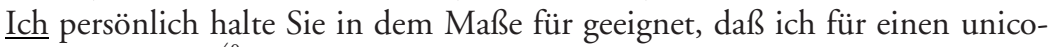
Vorschlag wäre. ${ }^{40}$

Die Kommission, die zur Wiederbesetzung der Lehrkanzel vom Professorenkollegium der philosophischen Fakultät am 11. Mai 1912 einberufen wurde, holte zunächst schriftliche Gutachten von Jakob Minor, dem „Vertreter des nächstangrenzenden Faches ${ }^{\text {“41 }}$, der aus Krankheitsgründen

38 Brief des Ministeriums für Kultus und Unterricht an das Dekanat der philosophischen Fakultät der Universität Wien vom 8. August 1905; UAW, Phil. Fak., Zl. 4349 ex 1904/05, PA 3135 Josef Seemüller.

39 Brief des Ministeriums für Kultus und Unterricht an das Dekanat der philosophischen Fakultät der Universität Wien vom 24. März 1912; UAW, Phil. Fak., Zl. 1128 ex 1911/12, PA 3135 Josef Seemüller.

40 Brief von Seemüller an Kraus vom 22. Mai 1911; BSB München, Nachlass Carl von Kraus, Krausiana I.

41 Bericht der Kommission zur Nachbesetzung der Lehrkanzel nach Josef Seemüller vom 4. Juli 1912 (Referent: Rudolf Much); ÖStA, AVA, Unterricht allgemein, Professoren und Lehrkräfte: Anstellungen, Rang, Entlassungen 1912-1914, MCU, Zl. 33439 ex 1912. 
nicht an den Sitzungen teilnehmen konnte, und von Josef Seemüller selbst ein. Beide Gutachten sprachen sich, wie es verabredet war, für Carl von Kraus an erster Stelle aus. Die Kommission, die für die Besetzungsangelegenheit nur deshalb statt einer zwei Sitzungen anberaumte, um auf die Gutachten zu warten, folgte diesen Empfehlungen mehr als vorbildlich. Sie schlug Carl von Kraus nicht nur als Erstgereihten, sondern sogar sine et unico loco vor. In ihrem Bericht vom 4. Juli 1912 begründete sie das folgendermaßen:

Ohne dass dies in einem besonderen Beschluss zum Ausdruck gekommen wäre, war doch der Wunsch der Kommission deutlich erkennbar, dass der Zusammenhang mit der grossen Vergangenheit der Altgermanistik an unserer Universität gewahrt und wiederum ein Schüler Heinzels auf dessen Lehrstuhl berufen werden sollte. [...]

Gerade an C. v. Kraus zunächst zu denken, lag deshalb schon nahe, weil er bereits nach Heinzels Tode für die Neubesetzung der altgermanistischen Lehrkanzel an zweiter Stelle durch die Fakultät in Vorschlag gekommen war. [...]

Es ist endlich begreiflich, dass in Erinnerung an die ehrenvolle Stellung, die durch die überragende Persönlichkeit Heinzels der österreichischen Germanistik gesichert war, es schmerzlich empfunden werden muss, dass wir den anerkannt tüchtigsten seiner Schüler dem Auslande überlassen sollen. ${ }^{42}$

Das Ministerium nahm daraufhin sogleich Kontakt zu Carl von Kraus auf und wollte ihn noch mit Wintersemester 1912 als Ordinarius nach Wien bestellen. Kraus zeigte sich zwar geneigt, bat aber in einem Brief vom 7. August um Verschiebung der Berufung auf das Sommersemester 1913, um der Bonner Universität und dem preußischen Ministerium genügend Zeit für eine Nachbesetzung seines dortigen Lehrstuhls zu geben. ${ }^{43}$ Einen Tag später informierte das preußische Kultusministerium das Wiener Ministerium für Kultus und Unterricht, dass es „versuchen werde[ ], den verdienten Gelehrten zu veranlassen, seinem derzeitigen Wirkungskreise

42 Bericht der Kommission zur Nachbesetzung der Lehrkanzel nach Josef Seemüller vom 4. Juli 1912 (Referent: Rudolf Much); ÖStA, AVA, Unterricht allgemein, Professoren und Lehrkräfte: Anstellungen, Rang, Entlassungen 1912-1914, MCU, Zl. 33439 ex 1912.

43 Brief von Kraus an Carl von Kelle (Sektionschef im Ministerium für Kultus und Unterricht) vom 7. August 1912; ÖStA, AVA, Unterricht allgemein, Professoren und Lehrkräfte: Anstellungen, Rang, Entlassungen 1912 - 1914, MCU Z1. 33439 ex 1912. 
treu zu bleiben “44, was vor allem bedeutete, dass Kraus in der Lage war, für die Zusage in Wien Bedingungen zu stellen.

Und das tat er auch: Wie das Unterrichtsministerium dem Finanzministerium mitteilte, forderte Kraus zusätzlich zu den „höchsten systemmäßigen Ordinariatsbezügen von $13.840 \mathrm{~K}$ “ und „der mit der Lehrkanzel verbundenen Seminarremuneration von 800 K" eine „Personalzulage“ von weiteren „11.500 K“, außerdem die vollständige Anrechnung seiner im Inland wie im Ausland verbrachten Dienstjahre für die Pensionsbemessung, die Befreiung von der Diensttaxe, die Übernahme der Übersiedlungskosten von Bonn nach Wien, die Entschädigung für die seinerzeitige Übersiedlung von Prag nach Bonn, die er dem preußischen Ministerium zurückzahlen musste, „2000 K [...] zum Zwecke der Ergänzung der Seminarbibliothek" und weitere 1.000 Kronen für deren „dringend nötige Neukatalogisierung“. „Außerdem würde er noch“, so das Unterrichtsministerium weiter, „Wert legen auf eine Erweiterung der Seminarlokalitäten [...] und endlich auf die Errichtung einer besonderen Seminarabteilung für germanische Altertumskunde“, deren Leitung Kraus' ehemaliger Studienkollege und nunmehriger Wiener Professor für Germanische Sprachgeschichte und Altertumskunde Rudolf Much ${ }^{45}$ übernehmen sollte. Im Unterrichtsministerium musste man zwar zugeben,

daß die gestellten Forderungen ziemlich bedeutend sind [...], nichtsdestoweniger muß die Unterrichtsverwaltung mit allem Nachdrucke für deren Gewährung eintreten, da es sich um die Rückgewinnung eines ganz hervorragenden Gelehrten handelt, von dem zu erwarten ist, daß er die altberühmte Wiener germanistische Schule, aus welcher er selbst hervorgegangen ist, nicht nur auf ihrer Höhe erhalten, sondern ihr neuen Glanz und neue Anziehungskraft verleihen werde. ${ }^{46}$

Das Ministerium und das Professorenkollegium waren sich, wie die vorangegangenen Zitate zeigen, darin einig, dass es sich bei dieser Berufung um die Fortführung einer Wiener germanistischen Tradition und die

44 Brief des preußischen Kultusministeriums an das Ministerium für Kultus und Unterricht in Wien vom 8. August 1912; ÖStA, AVA, Unterricht allgemein, Professoren und Lehrkräfte: Anstellungen, Rang, Entlassungen 1912-1914, MCU, Zl. 33439 ex 1912.

45 Zu Much vgl. Kap. IV.1.

46 Alle Zitate: K.K. Ministerium für Kultus und Unterricht: Referenten-Erinnerung betr.: Univ. in Wien, Wiederbesetzung der nach Hofrat Seemüller erledigten ordentlichen Lehrkanzel der deutschen Sprache und Literatur vom 28. August 1912; ÖStA, AVA, Unterricht allgemein, Professoren und Lehrkräfte: Anstellungen, Rang, Entlassungen 1912-1914, MCU Zl. 40042 ex 1912. 
wichtige Rückgewinnung eines österreichischen Gelehrten handelte, die es mit allen, auch finanziellen Mitteln durchzusetzen galt. Das Finanzministerium versuchte jedoch, die Ausgaben zu beschränken, und „beehrt[e] sich“,

vor allem zu bemerken, daß die Bewilligung derart exorbitanter Begünstigungen [...] h.o. Wissens in letzter Zeit [...] überhaupt nicht vorgekommen ist. So wurden denn auch sogar anläßlich der im Jahre 1902 erfolgten Rückberufung Boltzmann's an die Universität viel weniger weitgehende Begünstigungen bewilligt. ${ }^{47}$

Doch „angesichts des besonderen Wertes, welchen das k.k. Ministerium der Berufung des Dr. Karl von Kraus [...] beilegt", war das Finanzministerium „ausnahmsweise“ bereit, die „Weiterführung der Verhandlungen“ zu erlauben, wenn es gelänge, „eine beträchtliche Reduktion der gestellten überaus hoch gespannten Mehransprüche zu erzielen". ${ }^{48}$ In der Folge einigten sich von Kraus, das Unterrichts- und das Finanzministerium zwar auf eine Reduktion, so beträchtlich, dass von Kraus weniger verdiente als der in dem Schreiben erwähnte Physiker Ludwig Boltzmann, war sie aber nicht. ${ }^{49}$ Damit zählte mit Carl von Kraus bei seinem Amtsantritt im Sommersemester 1913 ein Germanist zu den bestbezahlten Ordinarien der Wiener Universität.

Mit Blick auf die Lehrstuhlbesetzungen an der Wiener Germanistik bis 1912 ist hinsichtlich der Ordnung der Professorenfolge Folgendes zu bemerken: Nach einer (semiprofessionellen) Konsolidierungsphase, in der

47 Brief des Finanzministeriums an das Ministerium für Kultus und Unterricht vom 25. Oktober 1912; ÖStA, AVA, Unterricht allgemein, Professoren und Lehrkräfte: Anstellungen, Rang, Entlassungen 1912-1914, MCU Zl. 48224 ex 1912. - Die Abkürzung „h.o." steht in der österreichischen Amtssprache für ,hierorts' bzw. ,hierortig'.

48 Brief des Finanzministeriums an das Ministerium für Kultus und Unterricht vom 25. Oktober 1912; ÖStA, AVA, Unterricht allgemein, Professoren und Lehrkräfte: Anstellungen, Rang, Entlassungen 1912 - 1914, MCU Zl. 48224 ex 1912. - Carl von Kraus schrieb sich selbst zunächst ,Karl'. Als sein Namensvetter Karl Kraus in Wien aber die satirische Zeitschrift Die Fackel herauszugeben begann und dort häufig über die Wiener Germanistik herzog, änderte er die Schreibweise in ,Carl'.

49 Im Vergleich zu den gestellten Forderungen verringerte sich lediglich die Personalzulage um 2.000 Kronen auf 9.500 Kronen jährlich, seine Privatdozentenzeit wurde nicht für die Pension angerechnet und die Übersiedlungskosten von Prag nach Bonn wurden nicht bezahlt. Brief des Finanzministeriums an das Ministerium für Kultus und Unterricht vom 25. Oktober 1912; ÖStA, AVA, Unterricht allgemein, Professoren und Lehrkräfte: Anstellungen, Rang, Entlassungen 19121914, MCU Zl. 48224 ex 1912. 
die Entscheidung über Lehrstuhlbesetzungen allein beim Unterrichtsministerium lag und ausschließlich Privatgelehrte oder fachfremde Wissenschaftler berufen wurden, entwickelte sich ein Berufungsmechanismus, der schließlich zum ,Normalmodell' avancierte. Beteiligt an der Entscheidungsfindung waren dabei der Vorgänger des zu Berufenden sowie die Kommission und das Professorenkollegium der Fakultät, das dem Ministerium den jeweiligen Besetzungsvorschlag unterbreitete. Das Ministerium wiederum mischte sich ab 1868 in die Wahl nicht mehr ein, sondern folgte - vor allem nachdem bei der Berufung Erich Schmidts endgültig klargestellt worden war, dass von den beiden germanistischen Lehrstühlen einer mit einem Altgermanisten und der andere mit einem Neugermanisten zu besetzen war - der Fakultätsentscheidung. In der Altgermanistik ist ein klares Lehrer-Schüler-Verhältnis auszumachen, wobei „die jeweiligen Schüler in der Nachfolge von Ordinarien gezielt etabliert wurden “50. Berufen wurden nur Wissenschaftler, die ihre ,Lehrjahre' an der Wiener Universität verbracht hatten und dem Professorenkollegium bekannt waren. Als weitere Anforderung kann die Absolvierung einer ,Professorenerprobungsphase' bezeichnet werden. Damit ist gemeint, dass die zu Berufenden nach der Habilitation in Wien ihre erste Zeit als außerordentliche oder ordentliche Professoren an einem anderen, meist kleineren Institut im In- oder Ausland verbracht hatten und erst danach ,zurückgeholt' wurden. In der Neugermanistik wurden ab der Amtszeit Wilhelm Scherers, der in Wien die altgermanistische Abteilung geleitet hatte, ausschließlich Fachvertreter berufen, die bei ihm studiert hatten und die, wie die Berufungen Schmidts und Minors zeigen, von ihm auch für den Wiener Lehrstuhl gewünscht wurden. ${ }^{51}$ In beiden Fachbereichen wurde der Nachfolger vom jeweiligen Vorgänger, so dieser nicht verstorben war, gezielt ausgesucht; außerdem hatte er Österreicher zu sein und musste einem von der Fakultät vertretenen Konzept der schulischen Kontinuität entsprechen. Bis zum Jahr 1912 und der Berufung von Carl von Kraus stand an der Wiener Germanistik also alles im Zeichen konfliktfreier Traditionsbewahrung. Dies änderte sich jedoch grundlegend, nachdem im selben Jahr auch der

50 Höppner: Eine Institution wehrt sich (1993), S. 376. Die Diagnose Wolfgang Höppners über die Berliner Germanistik bis zum Beginn des 20. Jahrhunderts lässt sich auch auf die Wiener anwenden.

51 Die engen persönlichen Verbindungen in der Abfolge Scherer-Schmidt-Minor zeigen sich in außeruniversitärer Hinsicht auch darin, dass sie nacheinander dieselbe Wohnung in der Landstraßer Hauptstraße 88 im dritten Wiener Gemeindebezirk bezogen. Faerber: Ich bin ein Chinese (2004), S. 119. 
neugermanistische Lehrstuhl durch den Tod Jakob Minors neu zu besetzen war.

\section{I.2. Der Bruch - Die Verhandlungen um die Nachfolge für den neugermanistischen Lehrstuhl nach dem Tod Jakob Minors 1912}

Wenige Monate nach der altgermanistischen wurde 1912 in Wien auch die neugermanistische Lehrkanzel vakant. Ihr Vertreter Jakob Minor starb am 7. Oktober 1912 im Alter von 57 Jahren noch während seiner Amtszeit. Bereits im Juli desselben Jahres hatte Minor ein ausführliches, mehrteiliges Testament verfasst, in dem er präzise Regelungen bezüglich seines wissenschaftlichen Nachlasses und des Umgangs mit seinem Oeuvre getroffen hatte. ${ }^{52}$ Hinweise auf einen von ihm gewünschten Nachfolger als Professor für Deutsche Sprache und Literatur finden sich darin jedoch nicht. Und auch abseits dieser letzten Verfügungen hatte sich Minor - anders als die meisten seiner Kollegen und Vorgänger - zu Lebzeiten nicht um die eigene Erbfolge an der Universität gekümmert. Einer seiner ehemaligen Schüler, Eduard Castle, meinte 1955 rückblickend, dass Minor, „so wenig er sonst Scharfblick für die realen Verhältnisse aufbrachte", dieses Ansinnen schon immer für aussichtslos gehalten habe und ihnen, „seinen Adepten“, bereits zu seinem 50. Geburtstag, als er erstmals „erwog [...], seinen Platz zu räumen“, vorausgesagt habe, „daß keinem seine Nachfolgerschaft zufallen werde“. .53

Das Problem der Wiener Neugermanistik, dass es zu wenige Fachvertreter gab, um einen Österreicher berufen zu können, das sich bei der Nachfolge Tomascheks 1878 noch gestellt hatte, existierte aber nicht mehr. Ganz im Gegenteil: Die Anzahl der germanistischen Promovenden, die eine Universitätslaufbahn eingeschlagen und sich auf Neuere deutsche Literatur spezialisiert hatten, war so hoch wie nie zuvor. Die Germanistik, vor allem die neuere Abteilung, gehörte zu jenen Fächern, die am Ende des 19. und zu Beginn des 20. Jahrhunderts den stärksten Zuwachs an Studierenden zu verzeichnen hatten. ${ }^{54}$ Minor selbst hatte seit seinem Amts-

52 Das Testament ist abgedruckt bei Faerber: Ich bin ein Chinese (2004), S. $558-$ 563.

53 Castle: Zu Jakob Minors 100. Geburtstag (1955), S. 77.

54 Zur Bildungsexpansion um die Jahrhundertwende und zum starken Anstieg der Hörerzahlen an den philosophischen Fakultäten vgl. detailliert Cohen: Education and Middle-Class Society in Imperial Austria 1848-1918 (1996). 
antritt im Wintersemester 1885 im Schnitt 14 Dissertationen pro Jahr betreut $^{55}$ und insgesamt fünf neugermanistische Habilitationen abgenommen: 1887 die Habilitation Alexander von Weilens, 1893 die Oskar Walzels, 1900 die Robert Franz Arnolds, 1905 die Stefan Hocks und 1907 die Eduard Castles. ${ }^{56}$ Diese fünf Wissenschaftler lehrten 1912 als Privatdozenten, außerordentliche oder ordentliche Professoren in Wien bzw. an einer deutschen Hochschule ${ }^{57}$ und hätten die Voraussetzungen für die Minor-Nachfolge erfüllt, wäre das Auswahlverfahren dem bisher praktizierten Berufungskonzept gefolgt, das vor allem der Aufrechterhaltung einer nationalen und schulischen Kontinuität geschuldet war. Auch hatten sich alle fünf mit einem Nachruf auf Jakob Minor als dessen Schüler präsentiert und sich somit für seine Nachfolge in Stellung gebracht. ${ }^{58}$ Darüber hinaus gab es noch zwei weitere Germanisten, die für den prestigeträchtigen Wiener Lehrstuhl in Frage gekommen wären und bereits 1885 bei der Berufung Minors ex aequo an zweiter und dritter Stelle ge-

55 Insgesamt betreute Minor in Wien 361 Doktorarbeiten als Referent und etwa ebenso viele als Koreferent. Bis 1901 wurden jährlich bis zu acht Arbeiten bei ihm eingereicht, 1903 sind es zehn, 1904 13, 1905 22, 190640 und 1910 bereits 54. Faerber: Ich bin ein Chinese (2004), S. 155. - Auch der Privatdozent Stefan Hock wies in seinem Nachruf darauf hin, dass Minor, der vor „Tausenden von Studenten“ gelehrt habe, sich oft darüber beklagte, „daß die Ueberfüllung der Wiener Hochschule, zumal der philosophischen Fakultät, und hier wiederum die germanistischen Kollegien, notwendig eine Art Massenbetrieb bedinge“. Hock: Jakob Minor [Nekrolog] (1912), S. 33.

$56 \mathrm{Zu}$ den einzelnen Habilitationsverfahren vgl. Faerber: Ich bin ein Chinese (2004), S. $157-168$.

57 Alexander von Weilen war Titularprofessor für Neuere deutsche Literaturgeschichte in Wien, Oskar Walzel ordentlicher Professor für Literatur und Kunstgeschichte an der Technischen Hochschule in Dresden, Robert Franz Arnold außerordentlicher Titularprofessor für Neuere deutsche Literaturgeschichte in Wien, Stefan Hock und Eduard Castle waren Privatdozenten für Neuere deutsche Literaturgeschichte in Wien.

58 Alexander von Weilen am prominentesten und bereits einen Tag nach Minors Tod in der Neuen Freien Presse, aber auch im Jahrbuch der Grillparzer-Gesellschaft und als offizieller Vertreter der Wiener Universität in deren jährlichem Berichtsorgan Die feierliche Inauguration des Rektors. Weilen: Jacob Minor [Nekrolog] (1912); ders.: Jakob Minor [Nekrolog] (1913); ders.: Jacob Minor [Nekrolog] (1913/ 1914). - Oskar Walzel etwas weiter abseits in der Frankfurter Zeitung. Walzel: Jakob Minor [Nekrolog] (1912). - Robert Franz Arnold in der von August Sauer herausgegebenen germanistischen Fachzeitschrift Euphorion. Arnold: Jacob Minor [Nekrolog] (1913). - Stefan Hock im Literaturblatt der Neuen Freien Presse und Eduard Castle in der populärwissenschaftlichen Zeitschrift Das Wissen für alle. Hock: Jacob Minor [Nekrolog] (1912); Castle: Jacob Minor [Nekrolog] (1912). 
nannt worden waren, die also nicht zu Minors Schülern, sondern zu seinen Altersgenossen gehörten: den Grazer Ordinarius Bernhard Seuffert und den Prager Professor August Sauer, der gemeinsam mit Minor in Wien und bei Scherer in Berlin studiert hatte und der trotz mehrerer vergeblicher Versuche, wieder stärker ins Zentrum der Monarchie zu rücken, immer noch an der akademischen Peripherie Österreich-Ungarns sein Amt versah. $^{59}$

Die Kommission, die über die „Besetzung der zur Erledigung gelangten germanistischen Lehrkanzel“"zu beraten hatte, wurde unter dem Vorsitz des Dekans und Indologen Leopold von Schroeder am 9. November 1912 einberufen. ${ }^{60}$ Sie bestand aus den Professoren Jakob Schipper (Anglistik), Josef Strzygowski (Kunstgeschichte), Hans von Arnim (Klassische Philologie), Philipp August Becker (Romanistik), Oswald Redlich (Geschichte), Guido Adler (Musikwissenschaft), Richard Wettstein (Botanik), Karl Luick (Anglistik), Wilhelm Meyer-Lübke (Romanistik) und Rudolf Much (Germanistik). Da zu dieser Zeit aufgrund der Emeritierung Josef Seemüllers neben der zu besetzenden neugermanistischen auch die zweite, altgermanistische Professur vakant war, war Much als Altertumswissenschaftler der einzige Germanist in der Kommission.

Bereits in der ersten Sitzung am 27. November 1912 zeigte sich die abwartende und wenig entscheidungsfreudige Haltung der Kommissionsmitglieder, die das Besetzungsverfahren noch die nächsten sechs Monate bis zum Amtsantritt des Seemüller-Nachfolgers Carl von Kraus im April 1913 prägen sollte. So wurde zwar ein Brief Erich Schmidts, des Berliner Scherer-Nachfolgers und Wiener Minor-Vorgängers, verlesen, in dem dieser für den Dreiervorschlag an erster Stelle August Sauer, an zweiter Oskar Walzel und an dritter Alexander von Weilen empfahl, eine weitere Diskussion über etwaige Kandidaten fand aber nicht statt. Vielmehr beschloss man, ein Gutachten des emeritierten Altgermanisten Josef Seemüller einzuholen, und vertagte daraufhin die Sitzung. ${ }^{61}$ Das Gutachten

59 Sauer lehrte als Nachfolger Jakob Minors seit 1886 als außerordentlicher und seit 1892 als ordentlicher Professor für Deutsche Sprache und Literatur an der Deutschen Universität in Prag. - Zu Sauer vgl. Sauer/Seuffert: Der Briefwechsel zwischen August Sauer und Bernhard Seuffert (1880-1926) [in Vorbereitung].

60 Protokoll der 1. Sitzung des Professorenkollegiums der philosophischen Fakultät am 9. November 1912; UAW, Phil. Fak., PH 31.11, fol. 420.

61 Protokoll der 1. Sitzung der Kommission zur Beratung über die Besetzung der germanistischen Lehrkanzel nach Hofrat Professor Minor am 27. November 1912; UAW, Phil. Fak., Zl. 495 ex 1912/13, PA 1113 Walther Brecht. - Der Origi- 
Seemüllers führte nahezu dieselben Namen an wie der Brief Erich Schmidts und stimmte in seiner Argumentation exakt mit den traditionellen Berufungskriterien des Fachs überein. Seemüller sprach sich „unter den österreichischen Gelehrten", die allein er in Betracht zog, primo loco ebenfalls für August Sauer aus. Sauer sei, so Seemüller, „heute der anerkannte Vertreter der speziell österreichischen Literaturgeschichte“, stehe aber ebenso „in Mitte des Betriebes der allgemeinen deutschen Literarhistorie". Secundo loco nannte Seemüller den in Graz lehrenden Professor Bernhard Seuffert, dessen Arbeiten, wie er betonte, „wie die Sauers (und unseres verstorbenen Jakob Minor) unter dem Einflusse Wilhelm Scherers“ stünden. Für den dritten Platz, doch nur wenn „die Kommission der Fakultät einen Ternar vorzulegen wünsche[]“, schlug Seemüller Oskar Walzel vor, an dem er hervorhob, dass er „ein Schüler Minors und Erich Schmidts“ sei. ${ }^{62}$

Mit diesen ersten Vorschlägen für die Besetzung der neugermanistischen Lehrkanzel in Wien stand die Minor-Nachfolge zunächst im Zeichen problemfreier, d. h. über Jahrzehnte hinweg eingeübter Kontinuität. Sowohl Sauer und Walzel als auch Weilen hatten sich an der Wiener Germanistik habilitiert; Sauer 1879 noch bei Richard Heinzel, Weilen 1887 und Walzel 1894 bereits bei Jakob Minor. Nur Seuffert absolvierte seine akademischen Qualifikationsprüfungen nicht in Wien, sondern in Würzburg. Dort aber bei Erich Schmidt, der wiederum von 1880 bis 1885 , also vor Jakob Minor, den Wiener neugermanistischen Lehrstuhl innehatte. Außerdem war er Katholik. Alle vier vorgeschlagenen Wissenschaftler ließen sich problemlos für eine österreichische Germanistik reklamieren oder waren selbst Österreicher. Darüber hinaus gehörten alle vier der ersten (Sauer, Seuffert) oder zweiten (Walzel, Weilen) Schüler-Generation Wilhelm Scherers an, der das Fach über Jahrzehnte hinweg sowohl methodisch als auch institutionell und wissenschaftspolitisch bestimmt hatte. Für Walzel und Weilen sprach im Sinne einer Aufrechterhaltung der bislang selbstverständlichen professoralen Erbfolge außerdem, dass sie sich bei Jakob Minor habilitiert hatten. Doch der traditionelle Berufungsmechanismus, demzufolge ein Schüler des scheidenden Ordinarius zu dessen Nachfolger gewählt wurde, ließ sich nach dem Tod Jakob Minors nicht mehr reproduzieren. Auch eine Berufung anhand der beiden anderen

nalbrief von Schmidt befindet sich nicht bei den Unterlagen, sein Inhalt geht aber aus dem Protokoll hervor.

62 Gutachten Seemüllers über die Nachfolge nach Hofrat Minor vom 29. Dezember 1912; UAW, Phil. Fak., Zl. 494 ex 1912/13, PA 1113 Walther Brecht. 
bislang maßgeblichen Auswahlkriterien (Scherer-Schule, Österreicher) sollte gänzlich scheitern.

In der zweiten Sitzung der Kommission am 11. Jänner 1913 wurde zwar das Gutachten Seemüllers verlesen, über mögliche Minor-Nachfolger aber erneut nicht diskutiert. Diesmal verzögerte man die Beratung mit der Begründung, dass der mittlerweile zu erwartende Seemüller-Nachfolger Carl von Kraus ebenfalls ein Gutachten verfassen sollte. ${ }^{63}$ Kraus kam diesem Ansuchen, das ihm von Rudolf Much übermittelt wurde, ${ }^{64}$ jedoch nicht nach, sondern forderte die Kommission auf, die weiteren Verhandlungen bis zu seinem Amtsantritt zu vertagen, ${ }^{65}$ was ihm vom Dekan und Vorsitzenden der Berufungskommission Leopold von Schroeder auch anstandslos bewilligt wurde:

Daß die Besetzung der Stelle nach Minor sich so stark verzögert, ist mir leid. Doch jetzt ist die Zeit schon so weit vorgeschritten, daß es in der That wohl angezeigt sein dürfte zu warten, bis Sie hier am Orte sind und uns berathen können, worauf die Kollegen allgemein das größte Gewicht legen. ${ }^{66}$

Diese Zusage bedeutete nicht nur einen Aufschub der Verhandlungen um weitere drei Monate, sondern führte schließlich auch zur deutlichen $\mathrm{Zu}$ rücksetzung des bisherigen Favoriten August Sauer. Hinzu kam, dass sich die publizistische Öffentlichkeit in das Berufungsverfahren einzumischen begann und inneruniversitär Intrigen gesponnen wurden. Während die Neue Freie Presse noch im Jänner 1913 kolportierte, dass Sauer „in erster Reihe [...] als Nachfolger Minors genannt ${ }^{\star 67}$ werde, wurde an der Universität selbst bereits gegen ihn polemisiert. Stefan Hock, Privatdozent an der Wiener Germanistik, verfasste nämlich eine „gegen Sauer gerichtete Schrift“, die „unter den Mitgliedern der Besetzungs-Kommission circu-

63 Protokoll der 2. Sitzung der Kommission zur Beratung über die Besetzung der germanistischen Lehrkanzel nach Hofrat Professor Minor am 11. Jänner 1913; UAW, Phil. Fak., Zl. 495 ex 1912/13, PA 1113 Walther Brecht. - Carl von Kraus war zwar noch nicht offiziell berufen, die Verhandlungen mit dem Ministerium waren aber bereits zu einem erfolgreichen Abschluss gekommen, worüber nicht nur die Kommission informiert war, sondern auch die Tagespresse schon am 14. Jänner berichtet hatte. [Anonym:] Eine Neuberufung an die Wiener philosophische Fakultät (1913).

64 Brief von Much an Kraus vom 21. Jänner 1913; BSB München, Nachlass Carl von Kraus, Krausiana I.

65 Brief von Kraus an Rudolf Much (für die Kommission) vom 30. Jänner 1913 (Abschrift); BSB München, Nachlass Carl von Kraus, Krausiana I.

66 Brief von Schroeder an Carl von Kraus vom 12. Februar 1913; BSB München, Nachlass Carl von Kraus, Krausiana I.

67 [Anonym:] Vom Wiener germanistischen Seminar (1913). 
lierte ${ }^{\text {668 }}$ und einiges Aufsehen verursachte. Die Schrift selbst ist nicht erhalten, aus den Reaktionen auf sie lässt sich aber ersehen, welche Positionen die einzelnen Kommissionsmitglieder, deren Haltung bisher - zumindest in den Protokollen - nicht erkennbar war, einnahmen. So informierte Richard Wettstein August Sauer am 16. Februar über das „Hock'sche Pamphlet“, versicherte ihm, dass „er eine solche Kampfesart für absolut unakademisch halte“, und unterrichtete ihn „bei diesem Anlasse [...] gleich, allerdings streng vertraulich, über die Sachlage“:

Von den Commissions-Mitgliedern sind für Sie außer mir Adler, Redlich, Much und Seemüller, der allerdings nicht Mitglied ist, sondern nur als Beirat

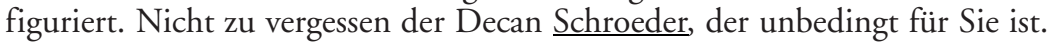
Eine mir ganz unverständliche Haltung nimmt Meyer-Lübke ein, dessen Einfluß es bisher gelang, die Sache immer wieder zur Vertagung zu bringen. Er scheint die Berufung verschieben zu wollen, bis Kraus hier ist. Die übrigen Commissions-Mitglieder scheinen verschiedene Meinungen $\mathrm{zu}$ vertreten. Strzygowski ist für Seuffert, [?] für den Germanisten aus Dresden (Namen mir momentan entfallen) ${ }^{69}$, Schipper, Becker unentschieden, Arnim ist gegen Sie, doch weiß ich nicht für wen er eintritt.

Sehr stark für Sie tritt Adler ein, doch trachte ich unter uns gesagt, ihn tunlichst abzuhalten, zu sehr hervorzutreten. Er ist in der Fakultät sehr unbeliebt und kann eher schaden als nützen.

Im Allgemeinen halte ich Ihre Chancen für günstig, einigermaßen besorgt bin ich nur für den Fall, daß Kraus eine Ihnen unerfreuliche Haltung einnimmt. ${ }^{70}$

Der Germanist Rudolf Much beschrieb die Situation Ende Jänner 1913 in einem Brief an Carl von Kraus, den er bereits seit Beginn der Berufungsverhandlungen über jede Einzelheit der Kommission, vor allem auch über das Gutachten Seemüllers und die bisherige Favorisierung August Sauers informiert hatte, folgendermaßen:

Für Minor ist nichts weiter geschehen als daß Hock Material gegen Sauer in Circulation gebracht hat, das vielfach Eindruck macht! Aber auch an Walzel findet man nicht recht Geschmack. Selber getraue ich mir, wenn ich erst mit mir einig geworden, zu, für den einen oder anderen oder auch für Seuffert den Anschlag zu geben, aber um die Kommission für einen andern ferner stehenden zu gewinnen habe ich nicht Einfluß genug. Anders stünde die Sache allerdings, wenn wir erst Ihrer sicher sind, und Sie sich für eine bestimmte Person einsetzen. [...] Zu Gunsten der Kandidatur Sauers könnte man sagen,

68 Brief von Richard Wettstein an den Dekan Leopold Schroeder, o.D.; UAW, Phil. Fak., PA 1113 Walther Brecht.

69 Wettstein meinte Oskar Walzel, der zu dieser Zeit Professor für Literatur- und Kunstgeschichte an der Technischen Hochschule in Dresden war.

70 Brief von Wettstein an Sauer vom 16. Februar 1913; Wienbibliothek im Rathaus, Handschriftensammlung, H.I.N. 184.963. 
daß sie nur das Interim bedeuten würde, denn er hat jetzt schon die vollen Dienstjahre und wird die schwere Last, die grade auf dem Wiener Neugermanisten liegt, gewiß nicht allzu lange tragen, vielmehr den Ruf nach Wien als ehrenvollen Abschluß seiner Karriere betrachten. Und nach ein paar Semester wird sich wohl eine gute junge Kraft leichter finden als es jetzt der Fall ist. ${ }^{71}$

Die von Wettstein geäußerte Befürchtung, dass Kraus gegenüber August Sauer ablehnend gesinnt sein könnte, bestätigte sich nach dessen Amtsantritt im Sommersemester 1913 in vollem Maße. Bereits in der ersten Nachfolgesitzung, der er beiwohnte, am 3. Mai 1913, trat Kraus gegenüber seiner durchweg unentschiedenen Kollegenschaft sogleich als Wortführer auf. Aus seiner Abneigung gegen den bisherigen Favoriten Sauer machte er keinen Hehl und „wünschte, [ihn] in dem Vorschlage nicht zu nennen“. Diese Einschätzung untermauerte Kraus laut Sitzungsprotokoll mit einer unerwartet drastischen und umfassenden wissenschaftlichen Diskreditierung Sauers:

In der Jugend hat er einige hübsche Abhandlungen veröffentlicht, späterhin nicht eigentlich viel mehr von Bedeutung.

Er ist Herausgeber und Bibliograph. Als Herausgeber hat er eine weitumfassende Thätigkeit entfaltet - außer Grillparzer und Stifter noch sehr viel Andres. Als Bibliograph werthvoll, in seinem „Euphorion“, wie auch im "Goedeke". Viel Arbeitsenergie u. Fleiß. Aber es fehlt ihm das Methodische, Methoden Andrer ahmt er sklavisch nach, oft wo sie keine Berechtigung haben [.] Spezialwörterbuch zu Stifter ist in dieser Richtung voll des Guten zu viel. Aehnliches gilt auch von andern Arbeiten Sauers: historisch-kritische Ausgabe Stifters, [...] u.s.w. Stoffanhäufung ohne disciplinierende Beschränkung ist da charakteristisch. Die Sichtung und Bearbeitung fällt dann Anderen zu (cf. die Grillparzer-Gespräche). Der „Euphorion“ ist [!] in Deutschland keinen guten Ruf, weil er 3 oder $4 \mathrm{Mal}$ so viel enthält, wie er enthalten sollte - Hypertrophie des Inhalts. Dies auch für die Schülerarbeiten sehr bedenklich. Massenhafte Produktion ohne gehörige Ausreifung. Auch andre Thätigkeiten noch nehmen die Arbeitskraft Sauers in Anspruch - eine Vielgeschäftigkeit, wodurch die ernste Vertiefung unmöglich wird. Dabei hält er sich doch einige Pagen. Mit Metrik hat er sich nie beschäftigt, nie darüber gelesen. Ein Interpretationscolleg hat er kaum jemals gelesen. Es mangelt ihm an innerster ästhetischer Bildung, er ist kein Humanist im höchsten Sinn des Wortes.

Aber auch für die drei anderen Genannten konnte sich Kraus nicht erwärmen. Vielmehr hatte er eine für die Wiener Verhältnisse überraschende Lösung parat, der zufolge „[e]ine einzige Persönlichkeit [...] allen Anforderungen, die in diesem Falle zu stellen sind“, genüge: „und zwar Prof.

71 Brief von Rudolf Much an Carl von Kraus (Fragment), o.D. [Ende Jänner 1913]; BSB München, Nachlass Carl von Kraus, Krausiana I. 
Köster in Leipzig“. ${ }^{72}$ Albert Köster hatte zunächst in Leipzig Geschichte und danach Deutsche Philologie bei Erich Schmidt in Berlin studiert, er war seit 1899 ordentlicher Professor in Leipzig, 1912 Dekan der philosophischen Fakultät und ab 1914 Rektor der Universität Leipzig. Köster war ein ausgewiesener Theaterhistoriker, beschäftigte sich mit Edition und Textkritik (Schiller, Goethe, Storm) und gehörte in den 1910er Jahren zu den anerkanntesten Germanisten im deutschsprachigen Raum. ${ }^{73}$ Kraus charakterisierte Köster in der Kommissionssitzung mit Blick auf die innerfachliche Differenzierung der Neugermanistik als einen

Literarhistoriker, der nicht nur auf die Literaturgeschichte des $19^{ \pm}$, resp. $18^{ \pm}$ Jahrh. sich beschränkt, sondern sehr weit ausschaut. Er beherrscht die philologische Methode in souveräner, geradezu klassischer Weise. Doch ist die philologisch-kritische Arbeit nur eine Seite seiner Thätigkeit - er ist nicht minder der Meister der literarischen Charakteristik. Er verbindet den Blick für das Kleine mit dem Weitblick für das Große. Metrik, Faustsage, Theatergeschichte, die Realien der Literaturgeschichte, Methodenlehre, Interpretationscollegia (Faust, Theil II). Die Arbeiten seiner Schüler („Probefahrten“) ${ }^{74}$ legen rühmlichstes Zeugniß von seiner Lehrthätigkeit ab. Als Redner ist er einer der besten an der Univ. Leipzig. Die Gewinnung Kösters ließe sich als das "große Loos" bei dieser Besetzung bezeichnen.

Für einen möglichen zweiten und dritten Platz nannte Kraus Bernhard Seuffert und Oskar Walzel, beide jedoch nur mit Einschränkungen. So sei Seuffert zwar „sehr solid und tüchtig“ und ein „Philologe“ könne „seine Freude an ihm haben“, doch da er „,in der Produktion einigermaßen dürftig“ sei, wollte Kraus ihn nur ,in bedeutendem Abstand“ genannt wissen. Ähnlich verfuhr Kraus mit Oskar Walzel: Gewiss sei dieser „, [u]nter den Kennern der Romantik [...] weitaus der Beste“, aber eben auch „zu fein konstruktiv oft allerdings".

Ebenso überraschend wie Kraus’ Empfehlung von Köster war auch die Reaktion der Kommissionsmitglieder. Von allen Anwesenden widersprach als einziger Adler Kraus' Einschätzung von August Sauer und wies darauf hin, dass „[d] as oesterreichische Moment [...] doch auch zu beachten“ sei. Ungeachtet dieses Einwands entschied sich die Mehrheit der Kommission

72 Alle Zitate: Protokoll der 3. Sitzung der Kommission zur Beratung über die Besetzung der germanistischen Lehrkanzel nach Hofrat Professor Minor am 3. Mai 1913; UAW, Phil. Fak., Zl. 495 ex 1912/13, PA 1113 Walther Brecht.

$73 \mathrm{Zu}$ Köster vgl. Korn/Stockinger: „Ist das Gehirn so eng, daß nur eine Betrachtungsweise darin Platz hat?“ (2013); Kirschstein: „Der Berufensten einer“ (2009).

74 Mit „Probefahrten“ ist folgende Reihe gemeint: Köster (Hg.): Probefahrten. Erstlingsarbeiten aus dem Deutschen Seminar in Leipzig (1905-1930). 
ohne weitere Diskussion dafür, Köster dem Ministerium sine et unico loco in Vorschlag zu bringen. ${ }^{75}$ Doch Köster, an den gleichzeitig auch ein Ruf nach Berlin als Nachfolger Erich Schmidts ergangen war, lehnte beide Lehrstühle ab und blieb in Leipzig. ${ }^{76}$

Nach der Absage Kösters wurden die ohnehin schon langwierigen und konfliktbeladenen Debatten um die Nachfolge Jakob Minors zusehends komplizierter und verwickelter. Zwar trat Kraus in der Sitzung am 13. Juni 1913 erneut mit einem klaren Vorhaben auf und erklärte, dass es „unbedingt nothwendig [sei], nunmehr an erster Stelle Seuffert", an zweiter Oskar Walzel und an dritter Ernst Elster sowie den zu diesem Zeitpunkt zum ersten Mal in den Protokollen erwähnten Walther Brecht zu nominieren. Doch trotz der Befürwortung Seufferts durch die gesamte Kommission konnte man sich auf keinen Dreiervorschlag einigen, da abermals über die Eignung August Sauers gestritten wurde: Während Kraus, wie der Protokollant notierte, Sauer „in nahezu vernichtender Weise“ kritisierte, weigerten sich Adler, Wettstein, Redlich und Becker einem Vorschlag ohne Sauer zuzustimmen, woraufhin die Entscheidung ein weiteres Mal vertagt wurde. $^{77}$

Ohne Auflösung der Patt-Situation zwischen den Sauer-Befürwortern und Carl von Kraus begann die nächste und letzte Zusammenkunft der Kommission am 21. Juni 1913; seit dem Tod Minors waren mittlerweile mehr als sieben Monate vergangen. Kraus versuchte wiederum, diejenigen Kollegen, die der Ansicht waren, dass Sauers „Leistungen doch zu blendend sind, um ihn aus dem Vorschlage wegzulassen “78, von seinem Standpunkt zu überzeugen - diesmal mit dem Argument, dass es nicht notwendig wäre, bei der Besetzung der Professur auf die Behandlung österreichischer Li-

75 Alle Zitate: Protokoll der 3. Sitzung der Kommission zur Beratung über die Besetzung der germanistischen Lehrkanzel nach Hofrat Professor Minor am 3. Mai 1913; UAW, Phil. Fak., Zl. 495 ex 1912/13, PA 1113 Walther Brecht.

76 Vgl. Protokoll der 4. Sitzung der Kommission zur Beratung über die Besetzung der germanistischen Lehrkanzel nach Hofrat Professor Minor am 24. Mai 1913; UAW, Phil. Fak., Zl. 495 ex 1912/13, PA 1113 Walther Brecht. - Zu den gleichzeitig stattfindenden Nachfolgeverhandlungen in Berlin vgl. Höppner: Eine Institution wehrt sich (1993).

77 Protokoll der 5. Sitzung der Kommission zur Beratung über die Besetzung der germanistischen Lehrkanzel nach Hofrat Professor Minor am 13. Juni 1913; UAW, Phil. Fak., Zl. 495 ex 1912/13, PA 1113 Walther Brecht.

78 Wortmeldung des Romanisten Philipp Becker. - Protokoll der 6. Sitzung der Kommission zur Beratung über die Besetzung der germanistischen Lehrkanzel nach Hofrat Professor Minor am 21. Juni 1913; UAW, Phil. Fak., Zl. 495 ex 1912/ 13, PA 1113 Walther Brecht. 
teratur zu achten, und mit dem Anspruch, dass vor allem er mit dem zu Berufenden gut auskommen müsse:

Wir haben an Hock Castle, Hock, Weilen bereits Kräfte, die sich der österreich. Literaturgeschichte widmen. Keineswegs beansprucht Kraus, daß der neue Kollege genau zu ihm stimmen müsse. Wenn aber Jemand, wie Sauer, hauptsächlich Herausgeber, also Philologe ist, dann muß er das auch gut machen. Unmöglich wäre ein Zusammenwirken mit Sauer natürlich nicht, doch ist die Verschiedenheit des Wesens zu groß, um Gedeihliches erwarten zu können. ${ }^{79}$

In den folgenden durchweg kontrovers verlaufenden Diskussionen wurde erneut keine Einigung erzielt, da weder Kraus noch die Fraktion der SauerBefürworter von den jeweiligen Standpunkten abwichen. Aus den Verhandlungen resultierte somit nicht wie üblich eine einzige Entscheidung, vielmehr endeten sie mit insgesamt drei unterschiedlichen Vorschlägen: In einem äußerst schwachen Majoritätsvotum stimmten Kraus, Luick, Much, Meyer-Lübke und Arnim für 1. Seuffert, 2. Brecht, 3. Elster und Walzel. Redlich, Adler und Wettstein bildeten ein Minoritätsvotum für Sauer und Seuffert ex aequo an erster Stelle und Becker gab ein Separatvotum für 1. Seuffert, 2. Sauer, 3. Brecht und Elster ab. Schipper enthielt sich unter Hinweis auf seine baldige Emeritierung der Stimme. ${ }^{80}$

Genau in dieser Uneinigkeit gingen die Vorschläge zur weiteren Abstimmung in die Sitzung des Professorenkollegiums der philosophischen Fakultät am 5. Juli 1913. Dort wurde die Entscheidung jedoch keineswegs eindeutiger. „Nach mehrstündigen Diskussionen“ - die Sitzung begann um 17.15 Uhr und endete um 21.00 Uhr - wurde, wie im knapp gehaltenen Ergebnisprotokoll vermerkt ist, „die Abstimmung vorgenommen, welche folgende Resultate“ ergab:

Zunächst wird die Frage, ob SEUFFERT an erster Stelle zu nennen sei, energisch bejaht, mit 49 Ja, 2 Nein, 2 Enthaltungen, dann die Frage, ob nicht auch SAUER neben ihm ex aequo an erster Stelle zu nennen sei, verneint, mit 35 Nein, 16 Ja, 2 Enthaltungen; weiter die Frage, ob BRECHT an zweiter Stelle zu nennen sei, ebenfalls verneint, mit 29 Nein, 21 Ja, 4 Enthaltungen. Die Frage, ob ELSTER an 3. Stelle zu nennen sei, wird bejaht mit 26 Ja, 17 Nein, 3 Enthaltungen; BRECHT aber auch für die 3. Stelle / ex aequo / abgelehnt, mit 23 Nein, 18 Ja, 4 Enthaltungen.

79 Protokoll der 6. Sitzung der Kommission zur Beratung über die Besetzung der germanistischen Lehrkanzel nach Hofrat Professor Minor am 21. Juni 1913; UAW, Phil. Fak., Zl. 495 ex 1912/13, PA 1113 Walther Brecht.

80 Vgl. Protokoll der 6. Sitzung der Kommission zur Beratung über die Besetzung der germanistischen Lehrkanzel nach Hofrat Professor Minor am 21. Juni 1913; UAW, Phil. Fak., Zl. 495 ex 1912/13, PA 1113 Walther Brecht. 
Ueber WALZEL wird nicht abgestimmt, nachdem Prof. JELLINEK einen Brief von ihm vorgelegt, nach welchem er sich verpflichtet hat, in Dresden zu bleiben und keinen Ruf, auch nach Wien nicht, anzunehmen.

Somit erscheinen vorgeschlagen:

1./ primo loco: SEUFFERT Bernhard, o.ö. Professor an der Univ. Graz,

2./ secundo loco: vacat,

3./ tertio loco: ELSTER Ernst, o.o.. Professor an der Univ. in Marburg.

Professor v. KRAUS hält in einem Minoritätsvotum den Antrag aufrecht, es möge in der Liste der Vorgeschlagenen an zweiter Stelle, für die sich ein Majoritätsbeschluss in der Fakultät nicht ergeben hat, genannt werden:

Dr. Walther BRECHT, derzeit Professor an der Ritterakademie zu Posen. ${ }^{81}$

Mit diesem Resultat waren die Verhandlungen über die Nachfolge Jakob Minors, die an der Universität zu führen waren, vorerst beendet. Der Bericht, der daraufhin am 10. Juli 1913 im Ministerium eintraf, enthielt nicht nur ein dreiseitiges, handschriftliches Schreiben des Dekans, in dem dieser das oben zitierte Ergebnis der letzten Sitzung des Professorenkollegiums übermittelte, sondern darüber hinaus auch drei maschinenschriftliche Beilagen, die weitere 22 Seiten mit allen im Diskussionsprozess entstandenen Voten umfassten. ${ }^{82} \mathrm{Da}$ „vollkommene Uebereinstimmung der Anschauungen über die [...] zu präsentierenden Persönlichkeiten nicht zu erreichen ${ }^{\text {"83 }}$ war, wie im Bericht der Majorität der Kommission korrekt festgestellt wurde, geht aus dem ungewöhnlich umfangreichen Schreiben an das Ministerium als einzige Übereinstimmung hervor, dass Bernhard Seuffert primo loco gewünscht wurde.

$\mathrm{Da}$ „Seufferts Person [...] gegenwärtig stark umworben“"war und er nach der Absage Kösters nunmehr auch in Berlin an erster Stelle genannt wurde, drängte das Professorenkollegium, dass ,die Unterrichtsverwaltung tunlichst rasch und in besonders nachdrücklicher Form an ihn herantrete,

81 Protokoll der 8. Sitzung des Professorenkollegiums der philosophischen Fakultät am 5. Juli 1913; UAW, Phil. Fak., PH 31.11.

82 In den Beilagen befindet sich sowohl das Minoritätsvotum von Carl von Kraus für Walther Brecht an zweiter Stelle, das sich auf die Verhandlungen des Professorenkollegiums bezieht, als auch der Bericht der Majorität der Berufungskommission, in dem Kraus, Luick, Much, Meyer-Lübke und Arnim für 1. Seuffert, 2. Brecht, 3. Elster und Walzel plädieren, und schließlich der Bericht der Minorität der Kommission, in dem Redlich, Adler und Wettstein neben Bernhard Seuffert auch August Sauer an erster Stelle genannt wissen wollen. - Der Bericht mit allen Beilagen ist zu finden im ÖStA, AVA, MCU, Zl. 32739 ex 1913.

83 Bericht der Majorität der Berufungskommission vom 2. Juli 1913 (Abschrift); ÖStA, AVA, MCU, Zl. 32739 ex 1913, fol. 10. 
um ihn zur Uebernahme der Wiener Lehrkanzel zu bewegen “ ${ }^{84}$ Ebenfalls mit Eingangsstempel vom 10. Juli 1913 meldete sich aber auch Robert Sieger, Dekan der Grazer philosophischen Fakultät, beim Ministerium, um es - mit denselben Argumenten wie die Wiener Universität - dazu aufzufordern, „Schritte zu tun, um den Professor Seuffert unserer Universität zu erhalten“ und ihm gegebenenfalls „durch entsprechende Konzessionen das Verbleiben an der Grazer Universität [zu] ermöglichen ". ${ }^{85}$ Bernhard Seuffert war damit im Alter von bereits sechzig Jahren für kurze Zeit zum meist umworbenen Germanisten des deutschen Sprachraums geworden. Das Ministerium stand vor der Entscheidung, ihn entweder an der einen österreichischen Universität zu halten und eine weitere langwierige Diskussion um die Besetzung des Lehrstuhls an der anderen österreichischen Universität zu riskieren oder ihn umgekehrt für Wien zu gewinnen und damit eine Vakanz in Graz zu verursachen.

Aus Sicht der Unterrichtsverwaltung konnte Seuffert für eine Neuberufung aufgrund seines fortgeschrittenen Alters kein idealer Kandidat sein. Trotzdem entschloss sich das Ministerium, in Ermangelung eines von der Mehrheit getragenen Vorschlags für den zweiten Platz, mit ihm Verhandlungen aufzunehmen. Seuffert stellte jedoch, wie zu erwarten war, höhere finanzielle Ansprüche als es sonst bei Neuberufungen üblich war. Nach einem intensiven Briefverkehr zwischen Seuffert und dem Unterrichtsministerium, zwischen dem Unterrichtsministerium und dem Finanzministerium sowie einer persönlichen Besprechung von Seuffert mit dem Unterrichtsminister scheiterte die Berufung Ende Oktober 1913 schließlich am Veto der Finanzverwaltung, die - anders als bei der Berufung des Altgermanisten Carl von Kraus ein Jahr davor - nicht gewillt war, den deutlich geringeren Forderungen des Neugermanisten Seufferts zuzustimmen. ${ }^{86}$

Wie aus den Akten des Unterrichtsministeriums hervorgeht, war man daraufhin geneigt, die Angelegenheit zur erneuten Verhandlung an die Wiener Universität zurückzugeben. ${ }^{87}$ Davor besprach man sich aber noch

84 Bericht der Majorität der Berufungskommission vom 2. Juli 1913 (Abschrift); ÖStA, AVA, MCU, Zl. 32739 ex 1913, fol. 11 verso.

85 Brief des Dekanats der philosophischen Fakultät der Universität Graz an das Ministerium für Kultus und Unterricht vom 8. Juli 1913; ÖStA, AVA, MCU, Zl. 32739 ex 1913.

86 Die Briefe und Dokumente zur Verhandlung des Ministeriums mit Bernhard Seuffert befinden sich im ÖStA, AVA, MCU, Zl. 37083, Zl. 38890, Zl. 39831, Zl. 45157 und Zl. 55234 ex 1913.

87 ÖStA, AVA, MCU, Zl. 55233 ex 1913. 
mit Carl von Kraus, der dem Minister brieflich vehement davon abriet, diesen ,unter normalen Verhältnissen durchaus zweckentsprechenden Plan geltend zu machen“, da „es schon das erstemal schwierig war, einen Vorschlag zu erzielen, der in der Hauptsache die Zustimmung der Kommissionsmitglieder fand“. Vielmehr plädierte Kraus dafür, mit dem von ihm „an zweiter Stelle vorgeschlagenen Professor Dr Brecht" Verhandlungen aufzunehmen, obwohl, wie er einräumte, für diesen „die Majorität bekanntlich nicht erzielt" wurde. ${ }^{88}$ Die gegen Brecht ins Treffen geführten Argumente widerlegte Carl von Kraus in seinem zehnseitigen Schreiben, das er selbst als „Promemoria“ verstanden wissen wollte, folgenermaßen:

Zunächst erregte die verhältnismässige Jugend des 37jährigen Kandidaten Bedenken. Dieses Bedenken, das bei unbeteiligten alten Mitgliedern einer Fakultät erfahrungsgemäss ebenso leicht Eindruck macht wie bei etwa beteiligten jüngeren, wird durch die Erfahrungen, die an der Wiener Fakultät gerade mit Berufungen für das Fach der deutschen Sprache und Literatur gemacht wurden, nicht bekräftigt: Wilhelm Scherer erhielt im 27. Jahre die Berufung auf das Ordinariat unserer Universität, Erich Schmidt im 28., Jakob Minor im 30. und Richard Heinzel im selben Alter wie Brecht. Auch braucht

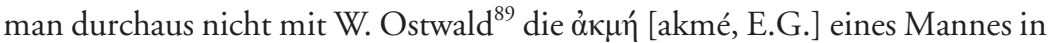
die Zeit vor seinem 30. Jahre zu verlegen, um den von vielen Seiten laut werdenden Wunsch nach Verjüngung unserer grossen Universitäten berechtigt $\mathrm{zu}$ finden und eine blühende Hoffnung für besser zu halten als eine dürre Gewisheit.

Ferner wurde der Einwand erhoben, dass von den drei im Bericht charakterisierten Arbeiten Brechts die eine (über Ulrich von Liechtenstein) dem altdeutschen Gebiet entstamme, daher für seine Wertung als moderner Literarhistoriker nicht in betracht komme. Dieser Einwand verkennt, dass die ernste Beschäftigung mit dem älteren Teil dieses oder irgend eines anderen Faches, das sich im laufe langer Jahre eine straffe Methode erarbeitet hat, für den modernen Literarhistoriker dieselbe erziehliche Bedeutung hat wie eine gute Kinderstube für den späteren Mann. So haben auch Minor, Erich Schmidt, Creizenach ${ }^{90}$, Elster und Köster ihren Ausgang abseits von ihrem eigentlichen Fachgebiete genommen; und so bildet an einer Reihe der höchst angesehenen Universitäten des Deutschen Reiches der Nachweis erfolgreicher Betätigung auf dem älteren Gebiete eine der Vorbedingungen für die Erlangung der venia docendi als moderner Literarhistoriker.

88 Brief von Kraus an das Ministerium für Kultus und Unterricht vom 15. November 1913; ÖStA, AVA, MCU, Zl. 55233 ex 1913.

89 Wilhelm Ostwald (1853-1932) war ein deutsch-baltischer Chemiker und Philosoph. Er beschäftigte sich auch mit Fragen der Wissenschaftsorganisation sowie dem Zusammenhang von Lebensalter und wissenschaftlicher Produktivität.

90 Gemeint ist der deutsche Germanist Wilhelm Creizenach (1851-1919), der bis 1913 eine Professur an der Universität Krakau innehatte. 
Wenn schliesslich geltend gemacht worden ist, dass Brecht in seiner derzeitigen Stellung kaum Gelegenheit gehabt habe, über den ganzen Umfang des von dem Wiener Literarhistoriker zu vertretenden Gebietes Vorlesungen zu halten, so darf wol darauf hingewiesen werden, dass Brecht durch die 6jährige Dozententätigkeit an der Universität Göttingen mit akademischer Tradition und akademischem Stil genau vertraut wurde, und dass sein Vortrag von Albert Köster, einem Meister akademischer Beredsamkeit, in einem brieflich abgegebenen Gutachten, das der Kommission vorgelegen hat, als ,lebhaft und anregend' gerühmt wurde. ${ }^{91}$ Wieviele der früheren Inhaber der Wiener Lehrkanzel, wieviele Professoren überhaupt, sind wol mit dem schweren Gespäck ihres ganzen Vorlesungszyklus in ihr Amt getreten? Man darf wol sagen: Berufungen, bei denen die Hoffnung auf weitere künftige Leistungen nicht mitwirkt, wären vom Standpunkt unserer Universitäten kaum zu wünschen; denn sie müssten allmählich zur Stagnation führen. ${ }^{92}$

Kraus wies den Minister darauf hin, dass „ein einheitlicher Vorschlag“ zum jetzigen Zeitpunkt „nicht [mehr] zu erreichen“ sei, und die Gefahr bestehe, dass es zu den selben „Schwierigkeiten“ kommen würde wie an der „Berliner Fakultät [...], die sich einstweilen mit dem Notbehelf eines Provisoriums abgefunden hat“. Kraus war der Meinung, dass bei erneuten Verhandlungen nicht mehr „die Fachmänner [...] die Zügel in der Hand hielten“, sondern sich „eine Liste zweiter Garnitur“, die er nicht weiter konkretisierte, durchsetzen würde:

Infolgedessen würden voraussichtlich alle Strömungen, die bei den Vorschlägen gerade dieser Lehrkanzel schon zu beobachten waren, mit verstärkter Macht wiederkehren.

Diese Strömungen sind z. T. fachlicher, z. T. politischer und persönlicher Art. Fachlicher: indem die einen vom modernen Literarhistoriker wünschen, dass er in erster Linie nach der philosophisch-ästhetischen Seite orientiert sei; andere geben der rein historischen Richtung den Vorzug; wieder andere stellen den philologischen Betrieb allen übrigen Methoden voran.

Schlimmer als die grundsätzliche Verschiedenheit der Auffassung (denen der erste Vorschlag übrigens Rechnung getragen hat, indem er keine Richtung einseitig bevorzugte) sind die Gefahren, die drohen, wenn politische Erwägungen auf den Vorschlag bestimmend wirken.

Kraus prognostizierte dem Minister, dass, sollte er erneute Verhandlungen zulassen, „die Unterrichtsverwaltung “ in Österreich „,in dieselbe peinliche Lage“ käme wie die preußische angesichts der „aus parteipolitischen Überzeugungen aufgestellte[n] Kampfkandidaten “ für die Professur an der

91 Das erwähnte Gutachten von Albert Köster findet sich weder im Universitätsarchiv noch im Staatsarchiv.

92 Brief von Kraus an das Ministerium für Kultus und Unterricht vom 15. November 1913, ÖStA, AVA, MCU, Zl. 55233 ex 1913. 
Berliner Germanistik. Er verwies auf die publizistischen Einmischungen des deutschnationalen und antisemitischen Verfassers von populären Literaturgeschichten Adolf Bartels, auf „die von anderer Seite für den Berliner Extraordinarius Richard Moses [!] Meyer ${ }^{93}$ [geschlagene] Trommel“ und auf die Wortmeldungen der „ganz rechts stehende[n] katholische[n] Kampfblätter“, die „für die Vertreter ihrer Anschauungen“ allesamt „Stimmung zu machen“ trachteten. $^{94}$

Tatsächlich waren die Nachfolgeverhandlungen um den Berliner Lehrstuhl Erich Schmidts von einer bis dahin unbekannten publizistischen Einmischung verschiedenster Blätter geprägt. Die öffentliche Aufmerksamkeit für die Nachbesetzungsverhandlungen in Wien war, wenn sie sich auch mit den Berliner Agitationen nicht gleichsetzen ließ, ebenfalls höher als bei allen anderen Berufungsangelegenheiten zuvor. Die Tagespresse berichtete kontinuierlich über den Stand der Verhandlungen, war also erstaunlich gut informiert und propagierte neben Bernhard Seuffert ${ }^{95}$ vor allem den zunächst favorisierten August Sauer. ${ }^{96}$ Sogar Karl Kraus sparte in seiner Zeitschrift Die Fackel nicht mit sarkastischen Kommentaren, mit denen er sich jedoch nicht an der Kandidatensuche beteiligte, sondern die Notwendigkeit eines Lehrstuhls für Literatur überhaupt in Frage stellte. ${ }^{97}$

Carl von Kraus zeichnete mit dem Hinweis auf die öffentlichen Aufregungen um die Berliner Besetzungsangelegenheit ein unheilvolles Bild, das er jedoch nicht mit ähnlichen Beispielen aus Österreich versah. Worum

93 Gemeint ist der jüdische Germanist Richard Moritz Meyer, dem Carl von Kraus, wie andere Kollegen auch, in antisemitischem Populismus den zweiten Vornamen Moses gab.

94 Alle Zitate: Brief von Kraus an das Ministerium für Kultus und Unterricht vom 15. November 1913, ÖStA, AVA, MCU, Zl. 55233 ex 1913.

95 So bezeichnete Robert Hohlbaum Seuffert als „jenen Mann“, „der jetzt die Führerschaft der österreichischen Literaturhistoriker übernehmen wird“. Hohlbaum: Jakob Minor (1912), S. 9.

96 Bereits drei Tage nach dem Tod Minors hatte die Neue Freie Presse von der „feststehende[n] Tatsache“ berichtet, „daß der Professor an der hiesigen deutschen Universität, Hofrat August Sauer, als Nachfolger Jakob Minors nach Wien berufen wird“. [Anonym:] Hofrat Professor Dr. Minor (1912). Ähnlich auch noch Anfang 1913, vgl. [Anonym:] Vom Wiener Germanistischen Seminar (1913). Zu den publizistisch ausgetragenen Querelen vgl. außerdem Hock: Die Nachfolge Jakob Minors (1914); [Anonym:] Die Besetzung der Lehrkanzel Minors (1914); [Anonym:] Zur Neubesetzung der Lehrkanzel Professor Minors (1914); [Anonym:] Der Nachfolger Minors in Wien (1914).

97 Karl Kraus: Wenn die Lehrkanzel nicht besetzt ist (1914); ders.: Die Katastrophe (1914); ders. : Besetzt (1914). 
es ihm eigentlich ging, war, die Berufung eines Wiener Schülers von Jakob Minor zu verhindern, wie aus dem folgenden Zitat hervorgeht:

Eine gewisse Agitation zugunsten Zweier, an unserer Fakultät seit Jahren als moderne Literarhistoriker tätigen Gelehrten hat sich schon im früheren Stadium der Verhandlungen geltend zu machen versucht. Bei der Zerklüftung der Anschauungen würde diese Agitation jetzt verschärft einsetzen und vielleicht größere Erfolge erzielen als das erstemal. Und das wäre, - bei aller Anerkennung, die man jenen in ihrem Teilgebiet sehr tüchtigen Gelehrten zollen und wünschen muss - nicht im Interesse des Faches, dessen Hauptvertreter eine starke Kraft und einen weiten Blick haben soll. ${ }^{98}$

Kraus nannte in seinem Schreiben keine Namen, doch kann es sich bei den beiden angesprochenen „moderne[n] Literarhistoriker[n]“ nur um Robert Franz Arnold und Alexander von Weilen handeln, auf die im letzten Absatz des dem Ministerium übermittelten Kommissionsberichts lobend hingewiesen wurde. ${ }^{99}$ Der anfängliche Favorit und spätere Streitfall August Sauer wird in Kraus' Brief mit keinem Wort erwähnt, wohl deshalb, weil er, betrachtet man die einzelnen Abstimmungsergebnisse genauer, in der Kommission und in der Fakultät erheblich mehr Zuspruch fand als der von Kraus gewünschte Walther Brecht. Die darauffolgenden Überlegungen im Ministerium sind aus den Akten nicht mehr rekonstruierbar. Auf der ersten Seite des Schreibens von Kraus befindet sich jedoch eine kurze handschriftliche Notiz, die lautet: „mit Brecht Verhandlungen einleiten“. ${ }^{100}$ Und tatsächlich wurde Brecht bald darauf vom Ministerium kontaktiert und bereits am 9. Dezember 1913 antwortete dieser, dass er „bereit [sei],

98 Brief von Carl von Kraus an das Ministerium für Kultus und Unterricht vom 15. November 1913; ÖStA, AVA, MCU, Zl. 55233 ex 1913.

99 Dort heißt es: „Dieser Bericht soll nicht geschlossen werden, ohne dass der Leistungen der an unserer Universität wirkender Literarhistoriker dankbar gedacht wird, die der Fakultät über die schwierige Zeit der Vakanz mit vollen Kräften hinweggeholfen haben. Sowie es dankbar begrüsst wird, dass die Unterrichtsverwaltung Prof. ARNOLD die von ihm ohne Rücksicht auf materielle Einbusse gewünschte Möglichkeit gewähren will, vom Wintersemester ab seine wertvolle Kraft ungeteilt in den Dienst der Universität zu stellen, so sei auch dem Wunsche Ausdruck gegeben, dass Prof. v. WEILEN, der gründlichste Kenner der Theatergeschichte, $[\ldots]$ auch in offizieller Form die verdiente Anerkennung zuteil werde." Bericht der Majorität der Berufungskommission vom 2. Juli 1913 (Abschrift); ÖStA, AVA, MCU, Zl. 32739 ex 1913, fol. 16.

100 Brief von Kraus an das Ministerium für Kultus und Unterricht vom 15. November 1913; ÖStA, AVA, MCU, Zl. 55233 ex 1913. 
die Lehrkanzel für deutsche Sprache und Literatur an der Universität in Wien [...] mit dem 1. April 1914 zu übernehmen“101.

Von all diesen Verhandlungen wurde das Professorenkollegium der Wiener philosophischen Fakultät weder von Carl von Kraus noch offiziell vom Ministerium unterrichtet. Am 15. Dezember 1913, sechs Tage nach Brechts Zusage, richtete der Dekan einen Brief an das Ministerium mit der Bitte, über den „Stand[ ] der Besetzung der freien germanistischen Lehrkanzel" in Kenntnis gesetzt zu werden, und forderte es dazu auf, sollten die mit Seuffert „geführten Verhandlungen gescheitert“ sein, „der Fakultät tunlichst umgehend zur Erstattung neuer Vorschläge Gelegenheit zu geben". ${ }^{102}$ Wie aus einem Vermerk der Unterrichtsverwaltung auf diesem Schreiben hervorgeht, reagierte das Ministerium auf diese Anfrage jedoch nicht.

Am 3. Februar 1914 schaltete sich aber Stefan Hock, der ein Jahr zuvor schon mit einer Streitschrift gegen August Sauer aufgetreten war, erneut in die Verhandlungen ein. In einem ausführlichen Artikel in der Neuen Freien Presse trat Hock entschieden gegen Walther Brecht und das Ansinnen des Ministeriums auf, sich über die Entscheidung der Berufungskommission hinwegzusetzen. Hock befürchtete, dass die Neuere deutsche Literaturgeschichte, die sich mit Wilhelm Scherer von der Älteren losgelöst und ihre eigenen, der „Menge und Mannigfaltigkeit des Materials“ angemessenen Methoden entwickelt habe, durch die allein vom Altgermanisten Kraus gewünschte Berufung Brechts - eines, wie Hock betonte, „Gelehrten dritten Ranges“ - erneut zu einem „Anhängsel der älteren Germanistik“ deklassiert werde. Dabei wäre es gerade jetzt, nach dem Tod Jakob Minors und Erich Schmidts, angezeigt, den „Zustand der Unruhe“ und der „Resignation“, in dem sich die Neugermanistik befände, durch die Berufung eines „Mann[es], [...] der über reiche akademische Erfahrung verfügt“, zu beenden. Brecht wäre dazu nicht in der Lage. Weder dürften seine Forschungen „Anspruch auf außergewöhnliche Bedeutung“ erheben, noch könnte er, dessen „Arbeitskraft [...] in etwa zehn Jahren [nur] zwei größere Publikationen hervorgebracht" hatte, mit den Anforderungen einer großen Universität wie der Wiener umgehen. Seine Ausführungen schloss Hock mit dem Ausdruck demonstrativer Verwunderung über das Vorgehen des Ministeriums und entschiedener Missachtung Walther Brechts: Auch

101 Brief von Brecht an das Ministerium für Kultus und Unterricht vom 9. Dezember 1913; ÖStA, AVA, MCU, Zl. 56210 ex 1913.

102 Brief von Rudolf Wegscheider an das Ministerium für Kultus und Unterricht vom 15. Dezember 1913; ÖStA, AVA, MCU, Zl. 57312 ex 1913. 
wenn er die Lehrkanzel bekäme, würde „Professor Brecht“ - schon allein aufgrund seines geringen wissenschaftlichen Formats - „nicht Minors Nachfolger werden". 103

Für Hock hatten seine öffentlichen und halböffentlichen Interventionen ein disziplinarisches Nachspiel an der Universität. ${ }^{104}$ Ungeachtet des Urteils über sein Verhalten lassen sich Hocks Sauer-Streitschrift und sein Presse-Artikel allerdings als Symptom dessen lesen, was die Nachfolgeverhandlungen für den neugermanistischen Lehrstuhl zu einer derart chaotischen und langwierigen Angelegenheit werden ließ. Zunächst zeigte sich das spezifische Wiener Problem der germanistisch äußerst schwach besetzten Kommission, das anfangs ein Machtvakuum erzeugte; gleichzeitig waren die Entscheidungsschwierigkeiten aber auch methodischen Richtungskämpfen innerhalb der Neueren deutschen Literaturgeschichte geschuldet, die zu Beginn des 20. Jahrhunderts alle Universitäten des deutschen Sprachraums beschäftigten. Mit der Ablösung von der älteren Abteilung, die sich vor allem auf Textkritik, Edition und Kommentar konzentrierte, ging im Laufe der 1880er und 1890er Jahre der neueren Abteilung die Orientierung bietende, unbedingte philologische Ausrichtung verloren. Bereits Wilhelm Scherer und nach ihm auch Jakob Minor hatten sich nicht nur um die Bewahrung, sondern auch um die Erweiterung und Erneuerung wissenschaftlicher Zugangsweisen zu literarischen Texten bemüht. ${ }^{105}$ Wirkungsvolle Experimente unternahmen dann - oftmals in falsch verstandener Opposition zu Scherer - vor allem die jüngeren Neugermanisten, die außerphilologische Konzepte der Ästhetik, der Kunstwissenschaft, der Psychologie und - im Gefolge Wilhelm Diltheys vor allem der Philosophie zur Texterklärung heranzogen. ${ }^{106}$

Diese vielfach als Krise des Fachs wahrgenommenen Veränderungen lassen sich auch als Generationenkonflikt begreifen, dem in Wien - im

103 Hock: Die Nachfolge Jakob Minors (1914).

104 Verweis für Stefan Hock wegen Vernachlässigung der Amtsverschwiegenheit; UAW, Phil. Fak., Zl. 868 ex 1913/14.

105 Vgl. u. a. Scherer: Jacob Grimm (1865); ders.: Wissenschaftliche Pflichten (1894); Minor: Centralanstalten für die literaturgeschichtlichen Hilfsarbeiten (1894); ders. : Die Aufgaben und Methoden der neueren Literaturgeschichte (1904). - Zur Wissenschaftsauffassung der Genannten vgl. Faerber: Ich bin ein Chinese (2004), S. 184-240; Michler/Schmidt-Dengler: Germanistik in Österreich (2003), S. 193-209; Müller: Wilhelm Scherer (2000).

106 Vgl. dazu u. a. Müller: Die Lebendigen und die Untoten (2007); Dainat: Von der Neueren Deutschen Literaturgeschichte zur Literaturwissenschaft (1994); König/ Lämmert (Hg.): Literaturwissenschaft und Geistesgeschichte (1993). 
Sinne eines Stabilisierungsverhaltens - mit der anfänglichen Favorisierung von zwei Vertretern der älteren Generation, August Sauer und Bernhard Seuffert, begegnet wurde. Als zusätzliche Schwierigkeit entpuppte sich das neue, aber umso intensivere Interesse der Öffentlichkeit; die Besetzung einer germanistischen Lehrkanzel wurde nicht mehr als inneruniversitäres Problem wahrgenommen, sondern, wie Hock sich ausdrückte, als „Frage [...], die für die geistige Kultur der Reichshauptstadt, ja ganz Deutschösterreichs von der größten Bedeutung “107 war. In Wien kollidierte außerdem das Selbstverständnis der neueren Abteilung als souveräner, der älteren Abteilung gleichberechtigter Teil des Fachs mit der großen Bedeutung, die man der Teilnahme des Altgermanisten Carl von Kraus an den Verhandlungen beimaß. ${ }^{108}$ Als sich dieser aber, wie zu erwarten war, als ,großer Mann' präsentierte, verweigerte ihm ein Gutteil der Kommission wiederum die Gefolgschaft. Kraus und mit ihm die Altgermanistik ${ }^{109}$ setzten sich dennoch durch. Mit einem Schreiben vom 16. März 1914 teilte das Ministerium dem Dekanat nämlich mit, dass

Seine k.u.k. Apostolische Majestät [...] mit allerhöchster Entschließung vom 9. März 1914 den Professor an der Königl. Preußischen Akademie in Posen, Dr. Walter Brecht, zum ordentlichen Professor der deutschen Sprache und

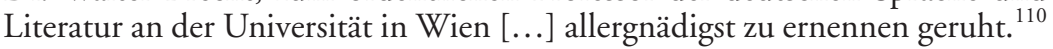

107 Hock: Die Nachfolge Jakob Minors (1914), S. 1.

108 Obwohl die neuere Abteilung gegen Ende des 19. Jahrhunderts zusehends an Attraktivität gewann und auch mehr Studierende als die ältere Abteilung aufzuweisen begann, beklagte sich Minor noch 1910, dass „die neuere deutsche Literaturgeschichte auch heute noch in den akademischen Kreisen nicht jene Stellung einnimmt, die ihr gebührt". Minor: Erich Schmidt (1910), Sp. 39.

109 Der einzige Wiener Germanist, der sich Kraus anschloss, war der Altertumskundler Rudolf Much.

110 Brief des Ministeriums für Kultus und Unterricht an das Dekanat der philosophischen Fakultät vom 16. März 1914, UAW, Phil. Fak., Zl. 495 ex 1912/13, PA 1113 Walther Brecht. 


\section{I.3. Philologie und moderate Geistesgeschichte - Walther Brecht am neugermanistischen Lehrstuhl in Wien 1914-1926}

Die Berufung Walther Brechts, der das Wiener neugermanistische Ordinariat zum Sommersemester 1914 übernahm, wurde, wenn nicht als „Katastrophe “111, so doch zumindest als „Kompromiß" ${ }^{\text {"112 }}$ wahrgenommen. Tatsächlich entsprach Brecht keinem der Kriterien, die bis 1912 bei Berufungen an der Wiener Germanistik ausschlaggebend gewesen waren: Er kam nicht aus Österreich, war nicht katholisch, er hatte nicht bei Scherer oder einem seiner österreichischen Schüler und auch nicht in Wien promoviert. Darüber hinaus war er nicht für das neuere Fach habilitiert wie seine drei Vorgänger Karl Tomaschek, Erich Schmidt und Jakob Minor. Und trotzdem wurde Brecht, der „als öffentlich Unbekannter“ nach Wien kam und bis heute als einer der „wenigst berühmt gewordenen Germanisten “113 der ersten Hälfte des 20. Jahrhunderts bezeichnet werden kann, $\mathrm{zu}$ einem ausgleichenden Vermittler österreichischer Literatur, zu einem Wissenschaftler, der die divergierenden methodischen Richtungen der $1910 \mathrm{er}$ und 1920er Jahre anzunähern trachtete, und zum ausgewiesenen Förderer einer ganzen Generation von Neugermanisten. ${ }^{114}$

111 Karl Kraus: Die Katastrophe (1914). - Die öffentliche Aufregung, die Brechts Berufung hervorrief, wurde nach einem Artikel Stefan Hocks vor allem von der Neuen Freien Presse dirigiert. Dort hieß es am 10. März 1914: „Die Unterrichtsverwaltung hat sich auch in diesem Falle über die deutlich genug geäußerten Wünsche und Ansichten des Professorenkollegiums der philosophischen Fakultät hinweggesetzt und beruft [...] Walter Brecht, dessen Eignung für die Nachfolge Jakob Minors [...] von berufener Seite in Zweifel gezogen worden ist." Hock: Die Nachfolge Jakob Minors (1914); [Anonym:] Die Besetzung der Lehrkanzel Minors (1914). - In der aggressiv antisemitischen Reichspost konnte man einen Tag später Folgendes lesen: „Es lagen wohl besondere Gründe für die Unterrichtsverwaltung vor, einen Ausländer zu wählen, nachdem im Inland hervorragende Kräfte, wie z. B. Seuffert $=$ Graz, sich finden. Das eine Gute hat die Berufung jedenfalls, daß nicht etwa ein Semit für Germanistik berufen wird.“ [Anonym:] Der Nachfolger Minors in Wien (1914).

112 So z. B. Herbert Cysarz noch 1976 über seinen Lehrer Walther Brecht: „Er war [... ] in Wien angetreten, als Kompromißkandidat am Ende harter Fakultätszwiste und langwieriger Verhandlungen“, viele hatten ihn, so Cysarz weiter, „gerade auf Minors Lehrstuhl fehl am Platz gewähnt“. Cysarz: Vielfelderwirtschaft (1976), S. 35 .

113 Cysarz: Vielfelderwirtschaft (1976), S. 34.

$114 \mathrm{Zu}$ Brecht selbst gibt es wenig Sekundärliteratur; eine Ausnahme in dieser Hinsicht stellt seine Freundschaft zu Hugo von Hofmannsthal dar, über die bereits verhältnismäßig viel geschrieben wurde. Zu Walther Brecht vgl. Erika Brecht: Er- 
Walther Brechts maßgebliche wissenschaftliche Orientierungsgeber waren der Germanist Gustav Roethe und der Kunsthistoriker Robert Vischer. ${ }^{15}$ Brecht studierte in Freiburg, Göttingen und Bonn Deutsche Philologie und Kunstgeschichte und promovierte 1903 bei Gustav Roethe in Göttingen mit einer Arbeit über die Dunkelmännerbriefe. ${ }^{116} 1906$ habilitierte er sich in Göttingen bei Roethes Freund, Schwager und Kollegen, dem Altgermanisten Edward Schröder, mit der mediävistischen Studie Ulrich von Lichtenstein als Lyriker ${ }^{117}$ und begann, nachdem er 1910 an die preußische Ritterakademie in Posen berufen worden war, auch über Neuere Literaturgeschichte zu publizieren. ${ }^{118}$ Brecht vertrat also sowohl aufgrund seiner Ausbildung als auch gemäß den Vorstellungen seines Doktorvaters Roethe, der sich stets gegen die Teilung der Germanistik ausgesprochen hatte, ${ }^{119}$ das gesamte Fach.

innerungen an Hugo von Hofmannsthal (1946); König: „Geistige und private Verbündung" (1993); Osterkamp: Formale, inhaltliche und politische Akzeptanz von Gegenwartsliteratur (1993); Bonk: Deutsche Philologie in München (1995), S. 67-72, S. 81-83, S. 240-254; König: Hofmannsthal (2001), S. 212-241; Dittmann: Walther Brecht (2003); Hofmannsthal/Brecht: Briefwechsel (2005); Oels: „... denn unsere Berufe sind doch so ineinander verhäkelt“ (2007); Oels: „Denkmal der schönsten Gemeinschaft“ (2007); Wolf: „Hybrid wie die Dichtkunst" (2012).

115 Noch 1941 bekannte Brecht: „Von meinen akademischen Lehrern haben mir Gustav Roethe und Robert Vischer in Göttingen den stärksten Eindruck gemacht, der umfassende Germanist und der künstlerische Kunsthistoriker [...]. “ Brecht: Student und Professor (1941), S. 2. - Vgl. auch Friedrich von der Leyen: Leben und Freiheit der Hochschule (1960), S. 230: „Ich war ein frisch gebackener Doktor, da kam ein dem Gymnasium eben entronnener zukünftiger Student zu mir, Walter Brecht; ein Freund meines Vaters hatte ihn mir geschickt. Er wollte Germanist werden: welche Universität ich ihm raten würde? Ich empfahl ihm, mit Erfolg, Göttingen und Gustav Roethe. Neben diesem wurde Robert Vischer sein Heiliger. Göttingen blieb für ihn die Universität, seine unvergeßliche akademische Heimat."

116 Brecht: Die Verfasser der Epistolae obscurum virorum (1904).

117 Brecht: Ulrich von Lichtenstein als Lyriker (1907).

118 Vgl. Brecht: Heinse und der ästhetische Immoralismus (1911).

119 Gustav Roethe (1859-1926) war Zeit seines Lebens daran gelegen, die Neuere deutsche Literaturgeschichte nicht aus dem Hoheitsbereich der Philologie zu entlassen; so schrieb er 1892, „daß wir Philologen die neuen Literarhistoriker nie ohne Controle lassen dürfen “, und 1906 sprach sich Roethe gegen ordentliche Professuren für das neuere Fach aus: „Die scharfe Trennung ist gewis von Übel. [...] Im Grunde halte ich, wenn schon reine neure Literarhistoriker da sein sollen, das Extraordinariat für die richtige Form: dann behält der philolog. Ordinarius die Möglichkeit einzugreifen." Roethe/Schröder: Regesten zum Briefwechsel (2000), Bd. 1, S. 433 und Bd. 2, S. 306-307. 
Brecht war durch seinen Lehrer und Förderer Roethe, auch wenn die Reaktionen auf seine Berufung nach Wien das glauben machen könnten, von der Wiener Scherer-Schule zunächst nicht sehr weit entfernt. Tatsächlich war es lange Zeit möglich, Gustav Roethe „neben Erich Schmidt“ als „bedeutendste[n] Schüler Wilhelm Scherers" zu bezeichnen. ${ }^{120} \mathrm{Als}$ Roethe 1902 an die Berliner Universität, das deutsche „Hauptquartier der Scherer-Schule “121, berufen wurde, um neben dem Neugermanisten Erich Schmidt das ältere Fach zu vertreten, rekurrierte er gerade auch auf diese Traditionslinie:

Ich denke in dieser Stunde bewegt des Mannes, der uns beiden so teuer ist und der mir der mächtigste geistige Wecker war, Wilhelm Scherers. Und wenn sich mir durch manchen ernsthaften Zweifel auch an der eigenen Kraft doch ein stolzes Glücksgefühl durchzuringen beginnt, da ich vorwärts schaue, so wurzelt es in dem Bewußtsein, daß ich zu den Männern, an deren Wirkungsstätte ich künftig lehren soll, zu Lachmann und Jac. Grimm, zu Müllenhoff und Scherer gehöre, nicht durch meine Potenz, gewiß aber durch meine Auffassung unserer Wissenschaft, durch die Ziele und Wege meiner Arbeit. ${ }^{122}$

Diese ,Ziele und Wege' sah Roethe, der sich stets „zur Freude und Strenge rein philologischer Arbeit ${ }^{\text {“123 }}$ bekannte, in einer klaren Ausrichtung der Germanistik auf Textkritik, Editionstechnik, Quellen- und Einflussforschung, Stoff- und Entstehungsgeschichte sowie Metrik und Poetik. Ab 1891 zeichnete Roethe gemeinsam mit Edward Schröder verantwortlich für die Herausgabe der Zeitschrift für deutsches Altert[h]um und deutsche Litteratur, er war ab 1890 an der Neubearbeitung der Grammatik von Jacob Grimm, an der Weimarer Ausgabe der Werke Johann Wolfgang Goethes und 1908 an der Reorganisation des Deutschen Wörterbuchs beteiligt; eigene größere Arbeiten blieben dabei jedoch aus. ${ }^{124}$ Roethes Auffassung von

120 Osterkamp: „Verschmelzung der kritischen und der dichterischen Sphäre“ (1989), S. 348. - Roethe hatte zunächst zwar nicht bei Scherer studiert, sondern in Göttingen und Leipzig, ging aber 1880 nach Berlin, wo er die „wissenschaftliche und persönliche Förderung von Wilhelm Scherer" erhielt. Gohl: Die ersten Ordinarien am Germanischen Seminar: Gustav Roethe (1987), S. 785.

121 Judersleben: Philologie als Nationalpädagogik (2000), S. 100.

122 Scherer/Schmidt: Briefwechsel (1963), S. 320 (Brief von Roethe an Erich Schmidt vom 14. Dezember 1901).

123 Roethe: Leipziger Seminarerinnerungen (1923), S. 8.

124 Bereits 1894 schrieb Roethe an Schröder: „Das ,dicke u. schöne‘ Buch bringe ich [...] eben nicht fertig." Roethe/Schröder: Regesten zum Briefwechsel (2000), Bd. 1, S. 584. - Mit dieser Einschätzung sollte Roethe auch in der Folgezeit Recht 
Wissenschaft offenbarte sich aber nicht nur in einem an Scherer, Carl Lachmann, Grimm und Müllenhoff orientierten philologischen Arbeitsprogramm, sondern auch in einem zutiefst konservativen und reaktionären Dienst-, Pflicht- und Persönlichkeitsethos, das die Abwehr demokratischer Gesellschaftsformen ebenso einschloss wie die wissenschaftlicher Neuerungen. ${ }^{125}$ Spätestens die im Jahr 2000 publizierten Regesten zum immerhin 45 Jahre umfassenden Briefwechsel mit Edward Schröder ${ }^{126}$ zeigen ihn als unbeirrbaren „Vorkämpfer des Rückschritts“127, als dezidiert antisemitischen, nationalistischen und frauenfeindlichen Wissenschaftspolitiker.

Walther Brecht gehörte zunächst zu Roethes Nachwuchshoffnungen; seine Roethe gewidmete Dissertation Die Verfasser der Epistolae obscurorum virorum (1904) stand auch noch ganz im Zeichen philologischer Literaturbetrachtung. So erklärte Brecht die Stiluntersuchung, mit der er die Autoren der Dunkelmännerbriefe ermittelte, zwar nur dann als zielführend, wenn sie vom „besonderen künstlerischen Charakter des Werkes“ ausging; diesen zu erfassen, vermöge aber, wie Brecht hervorhob, „allein die philologische Betrachtung“. ${ }^{128}$ Indem Brecht das „Kunstwerk“ ins Zentrum des Interesses rückte, betonte er „weniger die textkritische als die hermeneutische Komponente der Philologie “129 und bestimmte gleichzeitig den Unterschied zu einer rein historischen Herangehensweise:

Ich habe das Thema im engeren Sinne philologisch aufgefaßt; das heißt, ich habe, wie sich dies bei einer auf Feststellung der Verfasserschaft gerichteten Stiluntersuchung von selbst ergibt, die Epistolae wesentlich als Kunstwerk betrachtet, nicht als Zeitdokument. Vom Kunstwerke bin ich immer ausgegangen: immer habe ich die Zeit zur Erklärung des Kunstwerks herangezogen, niemals aber das Kunstwerk nur zur Illustration der Zeit, wie es der Historiker tut. $^{130}$

Brechts Arbeit über die in lateinischer Sprache verfassten Dunkelmännerbriefe verfolgte zudem den Zweck, „den deutschen Humanismus so fest wie möglich in die deutsche Litteratur- und Geistesgeschichte einzuglie-

behalten; in seinem ersten Berliner Jahrzehnt veröffentlichte er mit „Nibelungias und Waltharius“ (1909) nur einen einzigen Aufsatz.

125 Vgl. Judersleben: „Philister“ contra „Dilettant“ (1998); ders.: Philologie als Nationalpädagogik (2000).

126 Roethe/Schröder: Regesten zum Briefwechsel (2000).

127 See: Gustav Roethe und Edward Schröder (2006), S. 155.

128 Brecht: Die Verfasser der Epistolae obscurum virorum (1904), S. 2.

129 Bonk: Deutsche Philologie in München (1995), S. 246.

130 Brecht: Die Verfasser der Epistolae obscurum virorum (1904), S. VII. 
dern"131. Über die Zugehörigkeit zur deutschen Literatur entschied dabei nicht die Sprache der Texte, sondern die Herkunft der Autoren.

Für seine Habilitation wurde Brecht, der sich inzwischen mit der Schwägerin seines Doktorvaters Roethe, Adelheid von Koenen, verlobt hatte, ${ }^{132}$ von diesem an Schröder verwiesen. ${ }^{133}$ Schröder verlangte von Brecht den Nachweis, dass er "mit Texten deutscher Sprache umzugehen“ wüsste, und empfahl deshalb eine Studie über den Minnesänger Ulrich von Liechtenstein. ${ }^{134}$ Auch in dieser Arbeit ging es Brecht nicht - wie in der zeitgenössischen Mediävistik üblich - um ein zu rekonstruierendes Textdenkmal, sondern um den ,individuellen kunstcharakter“ von Ulrichs Lyrik, um „die motive, die composition, den stil des poetischen ausdrucks, die literarhistorische stellung ulrichs und seinen charakter". ${ }^{135}$ Textkritik, d.h. die sprachmaterielle Seite, spielte so gut wie keine Rolle; vielmehr bezog sich Brecht auf die 1841 von Carl Lachmann besorgte Gesamtausgabe der Werke Ulrichs, ${ }^{136}$ um sich der mittelalterlichen Lyrik interpretativ zu nähern.

Nach Abgabe der Habilitationsschrift, die dann 1907 erschien, und erfolgreich absolvierter Probevorlesung wurde Brecht im Mai 1906 an der Universität Göttingen als Privatdozent zugelassen. In seinem Habilitationsgutachten vom 23. Mai 1906 wies Schröder auf die „[s]tilistische Untersuchung und Anlage der künstlerischen Mittel“ als „die Stärke von $\mathrm{B}[\mathrm{rech} t]$ s wissenschaftlicher Arbeit" hin und prognostizierte, dass Brecht, für den die "Sprachforschung selbst [...] außerhalb seines Arbeitsfeldes“ läge, als „Literarhistoriker mit zunehmender Bevorzugung der Neuzeit“"zu sehen sein werde. ${ }^{137}$ Tatsächlich widmete sich Brecht ab diesem Zeitpunkt

131 Brief von Brecht an Carl von Kraus vom 27. Oktober 1904; BSB München, Nachlass Carl von Kraus, Krausiana I.

132 Adelheid von Koenen war die jüngere Schwester von Dorothea Roethe. Die Verlobung mit Brecht fand im Herbst 1904 statt.

133 Ab 1903 korrespondierten Roethe und Schröder intensiv über Brechts (akademische) Zukunft und bemühten sich um Stipendien für ihn. Vgl. Oels: „Denkmal der schönsten Gemeinschaft" (2007), S. 20-28.

134 Roethe/Schröder: Regesten zum Briefwechsel (2000), Bd. 2, S. 263 (Brief von Schröder an Gustav Roethe vom 23. September 1904).

135 Brecht: Ulrich von Lichtenstein als Lyriker (1907/1908), S. 1-2.

136 „Ich habe den text zu grunde gelegt, den Lachmann in seiner gesamtausgabe Ulrichs (Berlin 1841) gegeben hat. Die von bechstein in seiner commentierten ausgabe des FD (Leipzig 1888) vorgeschlagenen änderungen sind so gut wie durchweg zu verwerfen. "Brecht: Ulrich von Lichtenstein als Lyriker (1907/1908), S. 1.

137 Zit. n. Oels: „Denkmal der schönsten Gemeinschaft“ (2007), S. 24. 
ausschließlich der Erforschung Neuerer deutscher Literatur. Nach seiner Berufung auf die wenig renommierte und schlecht dotierte Professur an der Königlichen Ritterakademie in Posen erschien 1911 als nächste größere Arbeit Brechts Studie Heinse und der ästhetische Immoralismus. Darin zeigte sich zum ersten Mal deutlich Brechts methodische Positionierung zwischen Philologie und Geistesgeschichte. Neben ausgedehnten Quellenstudien, die vor allem im zweiten Abschnitt „Mitteilungen aus Heinses Nachlass“ zum Tragen kommen, widmete sich Brecht nämlich auch der Frage, „auf welchem Boden [Heinses] individualistische Ideen gewachsen" seien. Diese beabsichtigte Brecht sowohl „nach rückwärts [zu] verbinden“ als auch im „Zusammenhang mit neuesten Ideen“ zu betrachten, um den Autor in „seiner historischen Gesamtbedeutung [zu] erfassen“. ${ }^{138}$

Posen als akademische Wirkungsstätte war nicht nach Brechts Geschmack; bereits ein Jahr nach seiner Berufung beklagte er in einem Brief an Edward Schröder die „,vollständige Traditionslosigkeit“ der Hochschule, den „heterogenen Lehrkörper“ und die Niveaulosigkeit der Studenten („ziemlich übeles Material“): „Auf die Dauer möchte ich nicht hier sein. “139 Hatten sich Roethe und Schröder bis dahin stets um Brechts universitäre Karriere bemüht, Roethe Brechts wissenschaftliche Begabung zeitweise sogar als eine ihm überlegene eingestuft, ${ }^{140}$ so endete Brechts Rolle als Protegé spätestens im Winter 1912/13: Nach dem Tod Adelheid Brechts im August 1911 verlobte sich Brecht im Dezember 1912 mit Erika Leo, der Tochter des Göttinger Latinisten Friedrich Leo. Roethe war entsetzt: „Ist denn dem Menschen so ganz das Gefühl geschwunden, daß solche germ.jüdische Alliancen etwas Häßliches und Unnatürliches sind? Meine Schätzung $\mathrm{B}[\mathrm{recht}] \mathrm{s}$ ist in letzter Zeit sowieso nicht gestiegen; diese

138 Brecht: Heinse und der ästhetische Immoralismus (1911), S. VII.

139 Brief von Brecht an Schröder vom 6. Februar 1911; zit. n. Oels: „Denkmal der schönsten Gemeinschaft" (2007), S. 26.

140 So zum Beispiel in einem Brief an Edward Schröder vom 26. September 1904: „Was sich der weniger begabte und ursprünglich auch weniger selbständige Manheimer in unermüdlicher strenger höchst respectabler Selbstzucht aneignete, das fiel Brecht, der damals übrigens auch angespannt, ja enthusiastisch fleißig war, mit einer Selbstverständlichkeit zu, die ich bewundert habe und in der ich etwas mir Überlegenes empfand. [...] Ich habe an ihn die Anhänglichkeit, die ein mir im Wesentlichen überlegenes Talent erweckt [...].“ Zit. n. Oels: „Denkmal der schönsten Gemeinschaft" (2007), S. 14. - Der hier erwähnte Victor Manheimer (1877 - 1943) studierte in Berlin, Freiburg, München und Göttingen, wo er 1903 aufgrund der Arbeit Die Lyrik des Andreas Gryphius promovierte. 
egoistische Weichlichkeit ging mir doch über den Spaß. “141 Dass bereits die Großeltern von Erika Leo konvertiert waren, war für Roethe, „dessen Antisemitismus in den Zehner- und Zwanzigerjahren auch zu seinem beherrschenden wissenschaftspolitischen Argument ${ }^{\text {" } 142}$ wurde, nicht von Belang: „Mischehen [werden] durch das Taufwasser auch nicht erträglicher [...]. “143 Brechts Hoffnungen auf eine Professur in Königsberg oder Berlin wurden von Roethe ab diesem Zeitpunkt untergraben; „als Jüdinnengatte und durch seine geringe Leistungsfähigkeit ${ }^{\text {"144 }}$ kam Brecht für Roethe nicht mehr in Frage.

Nahezu zeitgleich erfuhr Brecht jedoch im Jänner 1913, dass Carl von Kraus ihn für die Wiener Professur in Betracht zog. ${ }^{145}$ Nach langen Verhandlungen, Separatvotum und der persönlichen Empfehlung durch Albert Köster, der das Wiener Ordinariat abgelehnt hatte, war die Angelegenheit, wie erwähnt, im März 1914 zugunsten Brechts entschieden. ${ }^{146}$ In Wien traf Brecht hinsichtlich der Richtungsstreitereien innerhalb der Neueren deutschen Literaturgeschichte auf eine heikle Situation; noch in den Nachrufen wurde gerade darauf hingewiesen. Bei Heinz Kindermann, Brechts Wiener Schüler und späterem nationalsozialistischen Opponenten, hieß es 1950:

Als [...] Brecht [...] 1914 als Nachfolger Jakob Minors an die Wiener Universität berufen wurde, stand er vor einer fachlich unsagbar schwierigen Aufgabe. Die Wiener Lehrkanzel für neuere deutsche Literaturgeschichte galt seit den Zeiten Scherers und Erich Schmidts als Hochburg des Positivismus. Auch Minor war neuerlich ein hervorragender Vertreter der positivistischphilologischen Methode gewesen. Indessen aber hatte sich im übrigen deutschen Sprachgebiet seit dem Vorstoß Diltheys und Ungers vieles verändert. Die geistesgeschichtliche Richtung der Literaturwissenschaft war in voller Entwicklung. So betrachtete es Brecht, der selbst einer ästhetischen Forschungsweise zuneigte, als eine seiner wichtigsten Aufgaben, den Übergang vom Positivismus zur geistesgeschichtlichen Literaturbetrachtung zu schaffen. Ohne das gesicherte philologische Fundament zu verlassen, eröffnete er in

141 Roethe/Schröder: Regesten zum Briefwechsel (2000), Bd. 2, S. 619 (Brief von Roethe an Schröder vom 16. Dezember 1912).

142 Oels: „Denkmal der schönsten Gemeinschaft“ (2007), S. 28

143 Brief von Roethe an Schröder vom 16. Dezember 1912; zit. n. Oels: „Denkmal der schönsten Gemeinschaft" (2007), S. 28.

144 Roethe/Schröder: Regesten zum Briefwechsel (2000), Bd. 2, S. 636 (Brief von Roethe an Schröder vom 7. Mai 1913).

145 Brief von Brecht an Edward Schröder vom 7. Jänner 1913; zit. n. Oels: „Denkmal der schönsten Gemeinschaft" (2007), S. 29.

146 Vgl. Kap. I.2. 
seinen Vorlesungen und Übungen die ganze Weite des neuen, philosophisch und kulturhistorisch unterbauten Blickfeldes. ${ }^{147}$

Josef Nadler, der von 1931 bis 1945 die Wiener neugermanistische Lehrkanzel innehatte, auf den Brecht jedoch nicht viel hielt, ${ }^{148}$ bemerkte in seinem Nachruf, dass Brecht, der „zwischen zwei wissenschaftlichen Generationen“ anzusiedeln sei, „in der glücklichen Lage [war], die ältere zu beerben und die jüngere anzuleiten“: „Die Schule, die er genossen hat, befähigte ihn, das Vertrauen der älteren Generation zu rechtfertigen und das der jüngeren zu gewinnen. " ${ }^{149}$

Brecht selbst äußerte sich öffentlich nie zu dieser innerfachlichen Methoden- und Generationenproblematik, in einem Brief an seinen späteren Wiener Nachfolger Paul Kluckhohn reflektierte er 1922 jedoch seine Herangehensweise:

Ich fasse die Litt.Gesch. als Geistesgeschichte aber ebenso sehr als Kunstgeschichte auf, d.h. als eine Entwicklungsgeschichte geistiger, ich betone fast noch mehr, auch seelischer Werte in Gestaltungen [...]; daher gehe ich immer vom Kunstwerk aus und gehe von dort zum Dichter als dem Hervorbringer und als dem Träger der oder der Zeitströmung. Weder also ist mir die Biographie das erste wie Minor, noch sind mir Dichtungen nur Entwicklungsdokumente einer Zeit, analog philosoph. Gedankenbildgen abstrakter Natur, wie nicht selten bei Dilthey. Bei Walzel waren oft die Dichter nicht viel [mehr] als (notwendig) schlechte Philosophen, als bildliche Menschen, die sie sind. Auf diese Weise verbindet sich mir der geistesgeschichtliche Standp. mit einem ästhetisch-philologischem. Und diesen letzteren möchte ich durchaus nicht missen, schon wegen des soliden Fundamentes der philologischen Einzeluntersuchung. ${ }^{150}$

Brecht verstand also die Dichtung explizit als Kunstwerk, von dem es stets auszugehen galt. Dabei ließen sich seines Erachtens sowohl das Einzel- als auch das Gesamtwerk als Ausdruck der unverwechselbaren Persönlichkeit des Dichters lesen, der zusammen mit seinem Werk wiederum die Möglichkeit kultur- und geistesgeschichtlicher Rekonstruktionen bot. Diese geistesgeschichtlichen Erkenntnisse müssten aber auf der Grundlage philologischer Detailstudien erfolgen. Damit nahm Brecht eine Position ein, die die philologische Herangehensweise eines Jakob Minor genauso zu integrieren vermochte wie philosophische, kunsttheoretische und formal-

147 Kindermann: Walther Brecht [Nekrolog] (1950), S. 413.

148 Vgl. Kap. I.4.

149 Nadler: Walther Brecht [Nekrolog] (1952), S. 375.

150 Brief von Brecht an Kluckhohn vom 15. Juli 1922; DLA Marbach, Bestand: Deutsche Vierteljahrsschrift. 
ästhetische Ansätze sowie dezidiert geistesgeschichtliche Arbeitsweisen. Hatte sich Minor - trotz zunehmender Skepsis - stets an das Programm der Philologie gehalten, ${ }^{151}$ so öffnete Brecht seine wissenschaftlichen Interessen nach allen Seiten, was, wie noch zu zeigen sein wird, auch die Auswahl der von ihm geförderten Germanisten beeinflusste.

Brechts erste Wiener Veröffentlichung Deutsche Kriegslieder sonst und jetzt, die 1915 im Berliner Weidmann-Verlag erschien und die er nur wenige Monate nach Beginn des Ersten Weltkriegs verfasst hatte, ${ }^{152}$ steht ganz im Zeichen deutscher Siegesgewissheit. Der Text ging aus einem Vortrag hervor, den Brecht im März und April 1915 in Wien und Naumburg/Saale gehalten hatte, ${ }^{153}$ und verbindet sein wissenschaftliches Programm der (formal-)ästhetischen und historischen Betrachtung mit einer - an Roethes im Jahr zuvor publizierten Rede Wir Deutschen und der Krieg angelehnten $-{ }^{154}$ deutschnationalen Kriegsbegeisterung. Brecht durchmisst darin deutschsprachige Kriegslyrik vom Mittelalter bis zur unmittelbaren Gegenwart, um die Voraussetzungen für das „moderne ethische Kriegslied, wie wir es allein wünschen“, zu ermitteln: „Vaterland, als real erlebtes Ideal; höchstausgebildetes Individuum: so reif entwickelte Individualität, daß sie auch den Gedanken fassen kann, sich aufzugeben, sich zu opfern für die Gesamt-Volksindividualität, die Nation, das Vaterland. “155 Im Unterschied zur Kriegslyrik des Deutsch-Französischen Kriegs von 1870/71, der die „patriotische Leidenschaft“ gefehlt habe, zeige laut Brecht „die Produktion von 1914 ein auffallend hohes Niveau", womit er sich vor allem auf die Lyrik von Ludwig Thoma, Richard Dehmel, Albrecht Schaeffer und Rudolf Alexander Schröder bezog. ${ }^{156}$ Den Krieg und die Kriegslyrik begrüßte Brecht „als Befreiung aus ästhetischer Isoliertheit“, als „Ausfüllung theoretischer Lehre“, als Erlösung durch „gemeinsames Handeln“, 157 das einen neuen „Aufschwung" bringen werde, wie es auch 1813 der Fall gewesen sei, als ,eine neue Frömmigkeit begann nach all den Orgien der Aufklärung “. ${ }^{158}$ Die Versicherung der moralischen,

$151 \mathrm{Zu}$ Minor vgl. Faerber: Ich bin ein Chinese (2004).

152 Brecht schloss die Arbeit an diesem Text am 12. Juni 1915 ab. Brecht: Deutsche Kriegslieder sonst und jetzt (1915), S. 47.

153 Vgl. Oels: „Denkmal der schönsten Gemeinschaft“ (2007), S. 31.

154 Roethe: Wir Deutschen und der Krieg (1914); zu Brechts Reaktion auf Roethes Rede vgl. Oels: „Denkmal der schönsten Gemeinschaft“ (2007), S. 32-33.

155 Brecht: Deutsche Kriegslieder sonst und jetzt (1915), S. 16.

156 Brecht: Deutsche Kriegslieder sonst und jetzt (1915), S. 27 und S. 38.

157 Brecht: Deutsche Kriegslieder sonst und jetzt (1915), S. 39-40.

158 Brecht: Deutsche Kriegslieder sonst und jetzt (1915), S. 44-45. 
ethischen und ästhetischen Bedeutsamkeit des Kriegs verband Brecht mit einer, aus antienglischem Ressentiment gewonnenen Beschreibung ,deutscher Kultur', in der er sich vor allem dagegen verwehrte, dass deutscher ,Idealismus' mit deutschem ,Militarismus' nicht einhergehen könne:

Was tat England unterdessen? Es rechnete, rechnete fieberhaft. Es rechnete, ob das neue, kriegerische Geschäftsunternehmen auch wirklich profitabel wäre; es rechnete damit es profitabel würde. Es will aushalten „bis zum letzten Penny"; wir bis zum letzten Mann.

England rechnet, Deutschland dichtet. Es dichtet im ungewissen Beginn des furchtbarsten Krieges, den es je gegeben. Dieselben Menschen, die sich rüsten, sind es vielfach, die jetzt dichten. Das allein widerlegt bündig den törichten Wahn, als sei der deutsche „Militarismus" etwas anderes als der alte deutsche „Idealismus" Schillers und Goethes. Nein, gerade das zeigt: wir sind noch dieselben! $!^{159}$

Mit seiner Kriegsbegeisterung und der Oppositionsstellung von englischem Merkantilismus und deutschem Idealismus stand Brecht, der 1914 sehnlichst wünschte, nicht in Österreich, sondern in Deutschland zu sein, ${ }^{160}$ bei Weitem nicht allein. Während deutsche Hochschullehrer bereits im September 1914 eine Erklärung unterschrieben, mit der sie aus „deutschem Nationalgefühl“ englische Auszeichnungen zurück gaben, ${ }^{161}$ fand Brecht in Österreich vor allem in Hugo von Hofmannsthal, den er 1917 kennenlernte und mit dem ihn eine lebenslange Freundschaft verbinden sollte, in der symbolischen Aufladung des Ersten Weltkriegs einen Verbündeten. ${ }^{162}$

Brecht selbst äußerte sich nach Deutsche Kriegslieder sonst und jetzt nicht mehr publizistisch zum Ersten Weltkrieg und verfasste auch sonst keinen propagandistischen Text mehr, seine politische Gesinnung blieb jedoch ambivalent. Joseph Roth, der von 1914 bis 1916 in Wien Germanistik studiert hatte, also zu Brechts ersten Wiener Studenten gehörte, ${ }^{163}$ cha-

159 Brecht: Deutsche Kriegslieder sonst und jetzt (1915), S. 3-4.

160 „Wir bedauern sehr nicht in Deutschland zu sein u. ein so großes Erlebnis zu verlieren. “ Brief von Brecht an Gustav Roethe vom 3. Oktober 1914; zit. n. Oels: „Denkmal der schönsten Gemeinschaft“ (2007), S. 33.

161 Vgl. Kellermann: Der Krieg der Geister 1914 (1915), S. 29.

$162 \mathrm{Zu}$ Hofmannsthals Kriegsbegeisterung vgl. seine politischen Schriften aus dem Ersten Weltkrieg in: Hofmannsthal: Sämtliche Werke. Bd. 34 (2011); außerdem Schumann: „Mach mir aber viel Freude“ (2000).

163 Roths Freund und Studienkollege Józef Wittlin erinnerte sich 1944: „Zum erstenmal begegnete ich Roth im Jahre 1915 auf der Wiener Universität. [...] Wir besuchten zusammen die Vorlesungen über deutsche Literatur von Professor Walther Brecht. [...] Es stellte sich heraus, daß Roth Lieblingsschüler von Professor 
rakterisierte seinen verehrten Lehrer 1926 in einem Brief an Benno Reifenberg, den Feuilletonchef der Frankfurter Zeitung, folgendermaßen:

Ich habe etwas Unerhörtes erlebt: Hören Sie: Mein lieber Professor der Germanistik Dr Brecht, der jetzt nach Breslau geht, hat mir schon 6 Jahre nicht geschrieben. Als ich noch sein Schüler war, war ich deutschnational, wie er. Ich glaube natürlich, daß er infolge meiner Publikationen mich aus seinem Herzen gewischt hat. Ich lese aber im Kaukasus in einer alten Zeitung, daß er 50 Jahre alt geworden ist. Gratuliere ihm. Und heute schickt mir die F.Z. seinen Brief: Er schickt mir seine Photographie. 1912/13 ${ }^{164}$ war ich sein Schüler. Er sieht genau so aus, wie damals. Und er hat mich soeben einer Preisstiftung für junge Autoren eingereicht. Er hat alles von mir gelesen. Er ist eben beim Aufräumen und packt - meine ersten Arbeiten, die ich noch im germanistischen Seminar geschrieben habe. Er packt sie ein! Er nimmt sie mit nach Breslau! Er hat mich damals für Stipendien eingegeben und heute für Preise. Ein deutschnationaler Mann! Sohn eines Professors, Schwiegersohn eines Professors, war ein Freund von Roethe! Das ist ein deutscher Professor. ${ }^{165}$

Mit dem soziologischen Scharfblick eines Autors, der auch die familiäre Komponente universitärer Aufstiegsmechanismen mitbedenkt, zeigte sich Roth begeistert und gleichzeitig verwundert über das Wohlwollen eines Mannes, der seine deutschnationale Gesinnung auch in der Lehre zum Ausdruck brachte, diese aber nicht - wie bei Gustav Roethe - als kulturpolitisches Hauptmovens fungierte. Tatsächlich dürfte sich Brecht ohne Schwierigkeiten in die konservative und deutschgläubige Grundstimmung unter den österreichischen Germanisten eingeordnet haben, ohne jedoch den zu Beginn des 20. Jahrhunderts an Schärfe gewinnenden Antisemitismus mitzutragen. ${ }^{166}$

Das Selbstverständnis der österreichischen Deutschen Philologie äußerte sich in den 1920er Jahren weniger in explizit programmatischen Texten als in Berufungskommissionen ${ }^{167}$ sowie Vorworten und Festreden. So hieß es 1925 in der Einleitung zur Festschrift des Wiener Akademischen

Brecht war, den er häufig besuchte. Er zeigte ihm dann seine Gedichte, die der Professor sehr lobte." Wittlin: Erinnerungen an Josef Roth (1949), S. 49-52.

164 Joseph Roth irrt sich im Jahr. Brecht kam erst im Sommersemester 1914 nach Wien.

165 Brief von Brecht an Benno Reifenberg [von Oktober 1926]; zit. n. Eckert/Berthold: Joseph Roth (1979), S. 45.

166 Zur politischen Ausrichtung der Wiener Germanisten im späten 19. und im ersten Drittel des 20. Jahrhunderts vgl. Kap. I.4. und Kap. IV.1.; darüber hinaus Michler: Lessings „Evangelium der Toleranz“ (2003); Meissl: Germanistik in Österreich (1981).

$167 \mathrm{Zu}$ Brechts (politischem) Vorgehen in dieser Hinsicht vgl. Kap. I.4. 
Germanistenvereins, für die auch Brecht einen Beitrag verfasste, ${ }^{168}$ dass „gerade die der romantischen Vorstellungs- und Empfindungswelt entspringende Nationalphilologie dazu berufen sei, gegenwärtig die wichtigsten Dinge zu leisten“, weshalb es von besonderer Bedeutung sei, „die wissenschaftlichen Erkenntnisse des germanistischen Studiums auf dem Gebiete der Volkserziehung und Pflege des Heimatgedankens nutzbar zu machen“. ${ }^{169}$ Und als im Wintersemester 1924/25 auf Drängen der Deutschen Studentenschaft, einer Dachorganisation klerikalkonservativer und deutschvölkischer Studenten, unter dem Titel „Wesen und Entwicklung des deutschen Geistes" ein Vorlesungszyklus für Hörer aller Fakultäten über ,Deutschtumskunde' eingerichtet wurde, war Brecht mit einem Vortrag über „Deutsche Dichtung“ von Beginn an beteiligt. ${ }^{170}$ Brecht selbst schrieb noch 1941, nachdem er in München wegen seiner „nichtarische[n] Ehefrau “"171 zwangspensioniert worden war, dass es darauf ankomme, „die strömende Fülle und endlose Weite des deutschen Wesens zu unmittelbarer Anschauung“ zu bringen, und dass „Männer da sind, die einen Kosmos, einen deutsch gesehenen Kosmos in sich tragen", um „durch ihr Beispiel auf diejenigen [zu] wirken, die vor ihnen sitzen“. ${ }^{172}$

Während sich in der politischen Gesinnung Brechts über Orts- und Regimewechsel hinweg eine Kontinuität ausmachen lässt, fällt seine Wiener Berufung mit einer Zäsur hinsichtlich seiner wissenschaftlichen Ausrichtung zusammen. Hatte Brecht bislang - mit Ausnahme seines Buchs über Wilhelm Heinse - seinen Forschungsschwerpunkt auf die Literatur des Mittelalters und des 16. Jahrhunderts gelegt, spezialisierte er sich nun zusehends im Bereich Neuerer und neuester deutscher Literatur. In seiner zweiten selbständigen Wiener Veröffentlichung nach Deutsche Kriegslieder sonst und jetzt beschäftigte sich Brecht 1918 erneut mit Lyrik, diesmal aber mit Conrad Ferdinand Meyer. Brecht zeigte in seinem Buch Conrad Ferdinand Meyer und das Kunstwerk seiner Gedichtsammlung, dass die Anordnung und Kompositionsprinzipien, die Meyer seinem Ge-

168 Brecht: Heine, Platen, Immermann (1925).

169 Akademischer Verein der Germanisten in Wien (Hg.): Germanistische Forschungen (1925), S. 1 (Vorwort der Herausgeber).

170 Höflechner: Die Baumeister des künftigen Glücks (1988), S. 346-347.

171 UAM, PA Walther Brecht; zit. n. Oels: „Denkmal der schönsten Gemeinschaft“ (2007), S. 80.

172 Brecht: Student und Professor (1941), S. 2. 
dichtband von $1882^{173}$ angedeihen ließ, ein zweites „unsichtbares Kunstwerk [hervorbrachten], das in und zwischen den einzelnen Gedichten sein Leben führt ${ }^{\text {"174 }}$. Dabei ging Brecht davon aus, dass durch den kunstvollen Aufbau des Lyrikbands das einzelne Gedicht „an spezifischer Schwere“ gewann, da es in Korrespondenz zu den unmittelbar nach- und vorgereihten Gedichten modifiziert erschien und darüber hinaus sein „Sinn innerhalb des Ganzen“ hinzukam, der den „Einzelsinn“ noch unterstrich. ${ }^{175}$ Nicht um die Genese einzelner Gedichte, nicht um eine rein formalistische oder biographistische Lesart war Brecht in seiner Kompositionsanalyse bemüht, sondern um den Ausgleich zwischen zeitgenössisch widerstreitenden Herangehensweisen. Zu seiner Auffassung der Deutschen Philologie heißt es in der Vorrede des Buches:

[D] as Werk ist und bleibt die Hauptsache, worauf es ankommt; denn des Werkes wegen beschäftigen wir uns mit dem Dichter. Es sollte kaum nötig sein, das noch zu sagen. Aber das kann nicht ausschließen, daß wir, wie natürlich, auch mit unserer sonstigen Kenntnis der Persönlichkeit des Dichters wie mit der seiner anderen Werke, auch an dieses Werk herantreten [...]. Den Dichter vom Kunstwerk überhaupt zu trennen und das Kunstwerk allein zu betrachten, wie es manche heute für die ästhetische Kenntnis verlangen, wäre jedenfalls dem hier vorliegenden Ziele gegenüber sinnwidrig und unmöglich, denn der spezielle Charakter der Komposition einer bestimmten Gedichtsammlung, ihr "So und nicht anders" kann nur aus dem Charakter dieses bestimmten Autors hervorgehen. ${ }^{176}$

Brecht erteilte in seiner Erklärung sowohl den biographisch-monographischen Großunternehmungen des 19. Jahrhunderts als auch den formalästhetischen, allein auf das Werk konzentrierten Herangehensweisen, wie sie in den 1910er und 1920er Jahren prominent von Fritz Strich und Oskar Walzel propagiert wurden, eine Absage. ${ }^{177}$ Jedoch war diese Absage weder in die eine noch in die andere Richtung eine derart entschiedene, dass er ohne Bedenken als ausgewiesener Vertreter einer be-

173 Meyers Gedichtband von 1882 wurde vom Autor selbst bis zur fünften Auflage 1892 immer wieder bearbeitet und erweitert und war 1917 bereits in der 80. Auflage erschienen.

174 Brecht: Conrad Ferdinand Meyer und das Kunstwerk seiner Gedichtsammlung (1918), S. 209.

175 Brecht: Conrad Ferdinand Meyer und das Kunstwerk seiner Gedichtsammlung (1918), S. 207-208.

176 Brecht: Conrad Ferdinand Meyer und das Kunstwerk seiner Gedichtsammlung (1918), S. X.

177 Zur zeitgenössischen formalästhetischen Literaturforschung vgl. Benda: Der gegenwärtige Stand der deutschen Literaturwissenschaft (1928), S. 38-46. 
stimmten Wissenschaftsauffassung gelten kann. Zeitgenössisch führte diese Zwischenstellung dazu, dass er je nach Selbstverständnis der Beurteiler für verschiedene Standpunkte in Anspruch genommen wurde. Dass diese Vereinnahmungsversuche nicht immer ohne Ambivalenzen möglich waren, zeigt eine ausführliche Rezension von Brechts Buch über Conrad Ferdinand Meyer in der Zeitschrift für Ästhetik und Allgemeine Kunstwissenschaft. Darin nennt Alfred Baeumler Brechts Studie nicht nur „einen beachtlichen Fortschritt [...] [i]nnerhalb der neueren, aufs Objekt gerichteten wissenschaftlichen Bestrebungen“, er bezeichnet sie sogar als „Höhepunkt der objektivistischen Methode“, da Brecht zeige, „daß unsere ästhetische Kritik den toten Biographismus innerlich überwunden hat", indem er „das Biographische [...] in die Form aufhebt ${ }^{\text {“ }}{ }^{178}$ Gleichzeitig und im Widerspruch zu seiner bisherigen Beurteilung der Studie warf Baeumler Brecht aber auch vor, noch tief in einer auf der Sammlung von Fakten beruhenden, d.h. in einer positivistischen Wissenschaftsauffassung verwurzelt zu sein, weshalb seine Studie, wie Baeumler abwertend feststellte, vor allem „als Quelle der Belege“ wertvoll sei:

Es ist kein Buch, was uns vorliegt, sondern nur das Material zu einem. [...] Sie [die Untersuchung, E.G.] gibt zu viel unaufgelösten Stoff. Die philologische Treue läßt sich wahren, auch wenn man zusammenfaßt. Brechts Werk hätte ein Buch für die Gebildeten werden können, es ist ein Buch für Philologen geworden. ${ }^{179}$

Einen besonderen Platz unter Brechts Wiener Publikationen nehmen seine Arbeiten zur österreichischen Literatur, vor allem zu Hugo von Hofmannsthal, ein. Mit österreichischer Literatur hatte sich Brecht vor seiner Berufung nach Wien 1914 nicht beschäftigt. Über österreichische Literatur zu publizieren, begann Brecht mit seinem Aufsatz „Wesen und Werden der deutsch-österreichischen Literatur" von $1920{ }^{180}$ Die österreichische Literaturgeschichte war eine der Herausforderungen, mit denen sich die Vertreter der Lehrstühle für Deutsche Philologie in der österreichischungarischen Monarchie seit der Institutionalisierung des Fachs nach der Universitätsreform von $1848 / 49$ zu befassen hatten. ${ }^{181}$ Selbst Wilhelm

178 Baeumler: Konrad Ferdinand Meyer [Rez.] (1921), S. 468

179 Baeumler: Konrad Ferdinand Meyer [Rez.] (1921), S. 470. Baeumlers „Vorschlag“, Brecht solle „das wichtigste in einem Aufsatz" zusammenfassen und in der nächsten Auflage „den Gedichten bei[geben]“, wurde schließlich realisiert, vgl. Brecht: Einleitung (1924).

180 Brecht: Wesen und Werden der deutsch-österreichischen Literatur (1920).

181 Zum Folgenden vgl. Michler: „Das Materiale für einen österreichischen Gervinus“ (1995); Zeman: Der Weg zur österreichischen Literaturforschung (1986). 
Scherer, der - unterstützt durch seine antikatholische Haltung und seine gesamtdeutsche Kulturauffassung - immer gegen die Eigenständigkeit einer spezifisch österreichischen Literaturgeschichte auftrat, publizierte, wenn auch nur in seiner Wiener Zeit während der 1860er und frühen 1870er Jahre, zu österreichischen Autoren. ${ }^{182}$ Eine systematische Erfassung der österreichischen Literatur, ihre biblio- und biographische sowie editorische Erarbeitung begann in größerem Maße aber erst mit der Schülergeneration von Scherer. Sowohl August Sauer, Richard Maria Werner, Josef Wackernell und Bernhard Seuffert als auch Jakob Minor und Josef Seemüller, die zeitgleich die Lehrstühle in Prag, Lemberg, Innsbruck, Graz und Wien innehatten, ${ }^{183}$ setzten einen "deutlichen Österreich-Akzent ${ }^{\text {“184 }}$ und prägten damit sowohl Forschung als auch Lehre an den Universitäten der Monarchie von den 1880er Jahren bis zum Ende des Ersten Weltkriegs. ${ }^{185}$ Die Konzeption einer eigenen österreichischen Literaturgeschichtsschreibung war in den Studien dieser Generation von Universitätsprofessoren wie auch in der von Privatgelehrten erarbeiteten, vierbändigen Deutsch-Österreichischen Literaturgeschichte (1899-1937) an den Gegebenheiten des Vielvölkerstaats orientiert. ${ }^{186}$ Ihre wesentliche Aufgabe sahen diese Forscher darin, die deutschsprachige Literatur innerhalb der österreichisch-ungarischen Monarchie, also innerhalb eines

182 Scherers Arbeiten sind nur mit großen Vorbehalten für die Konstitution einer österreichischen Literaturgeschichtsschreibung zu vereinnahmen; vor allem verkündeten sie nämlich, wie Michler überzeugend darstellte, „die Wanderung des deutschen Geistes aus dem österreichischen Gebiet nach Preußen“ oder waren, wie im Falle seines Grillparzer-Aufsatzes, „in Wahrheit Scherers Totalabrechnung mit den österreichischen Verhältnissen“. Michler: „Das Materiale für einen österreichischen Gervinus“ (1995), S. 181-182. - Gesammelt finden sich Scherers Arbeiten zur österreichischen Literatur bei Scherer: Vorträge und Aufsätze zur Geschichte des geistigen Lebens in Deutschland und Oesterreich (1874).

183 August Sauer war 1886-1925 in Prag, Richard Maria Werner 1884-1913 in Lemberg, Josef Eduard Wackernell 1888-1920 in Innsbruck, Bernhard Seuffert 1886-1923 in Graz, Jakob Minor 1885-1912 und Josef Seemüller 1905-1911 bzw. 1917-1920 in Wien.

184 Zeman: Der Weg zur österreichischen Literaturforschung (1986), S. 30.

$185 \mathrm{Zu}$ den Forschungsschwerpunkten der einzelnen österreichischen Germanisten dieser Generation vgl. Zeman: Der Weg zur österreichischen Literaturforschung (1986).

186 Die Herausgeber der Deutsch-Österreichischen Literaturgeschichte waren der Gymnasiallehrer Jakob Zeidler, der Gymnasiallehrer und Privatdozent Johann Willibald Nagl sowie der Gymnasiallehrer, Privatdozent und ab 1915 tit. a.o. Professor Eduard Castle. - Nagl/Zeidler/Castle (Hg.): Deutsch-Österreichische Literaturgeschichte. 4 Bde. (1899-1937). 
mehrsprachigen Spannungsfeldes, zu beschreiben und darüber hinaus ihre Eigenständigkeit gegenüber den übrigen deutschsprachigen Literaturen zu betonen. Vor allem August Sauers berühmte Prager Rektoratsrede Literaturgeschichte und Volkskunde von 1907 und auch sein Aufsatz „Die besonderen Aufgaben der Literaturgeschichtsforschung in Österreich", in dem er noch im letzten Jahr der Monarchie ein eigenes „Reichsinstitut für österreichische Literaturforschung" verlangte, waren dahingehend richtungsweisend. ${ }^{187}$

Eine wirkungsvolle Neubewertung der österreichischen Literatur forcierte zu Beginn des 20. Jahrhunderts ein Schüler August Sauers. Josef Nadler baute in seiner Literaturgeschichte der deutschen Stämme und Landschaften, deren erster Band 1912, also zwei Jahre vor der Berufung Brechts nach Wien, erschien, auf Überlegungen seines Lehrers zur Regionalliteraturforschung auf, übernahm dessen stammes- und volkskundliches Bewertungsschema, das die Literatur eines Stammes bzw. einer Landschaft in ihren regionalen, sozialen und politischen Besonderheiten bestimmbar machen sollte. Anders als sein Lehrer legte Nadler diesem Koordinatensystem aber eine geschichtsphilosophische, teleologisch auf das „Reich“ bzw. die deutsche Nation gerichtete Konstruktion zugrunde. Mit dem von ihm entworfenen Gedanken einer Sonderstellung der bairisch-österreichischen Dichtung verhalf Nadler zwar der österreichischen Literatur innerhalb einer gesamtdeutschen Darstellung zum ersten Mal zu gleichberechtigter Anerkennung, das ,alte' Interesse an der gesonderten Beschreibung der österreichischen Literatur innerhalb des Spannungsfeldes verschiedensprachiger Literaturen der Monarchie und in Abgrenzung zu den anderen deutschsprachigen Literaturen trat dabei jedoch in den Hintergrund. Nadlers Interesse zielte darauf ab, die österreichische Literaturforschung nicht mehr als eine eigenständige zu betrachten, sondern sie „in die Sehnsucht nach der Einheit der Nation, deren geistigen Raum sie mitschrieb “188, zu integrieren. ${ }^{189}$

187 Dieses „Reichsinstitut“ sollte sich der deutschen Literatur in Österreich in Zusammenhang mit den anderssprachigen Literaturen der Monarchie widmen und sie als eine, den anderen deutschen Literaturen des deutschsprachigen Raums ebenbürtige zeigen. Sauer: Die besonderen Aufgaben der Literaturgeschichtsforschung in Österreich (1917), S. 68.

188 Zeman: Der Weg zur österreichischen Literaturforschung (1986), S. 44.

$189 \mathrm{Zu}$ Sauers und Nadlers Literaturgeschichtekonzeption vgl. Ranzmaier: Stamm und Landschaft (2008); Höppner: Die regionalisierte Nation (2007); Meissl: Zur Wiener Neugermanistik der dreißiger Jahre (1985). 
Walther Brecht hätte der Nadler'schen Konzeption, betrachtet man seine kulturpolitischen Aussagen, in denen er stets für eine gesamtdeutsche Kulturauffassung eintrat und sich zudem für die Zusammenführung Deutschlands und Österreichs aussprach, eigentlich uneingeschränkt positiv gegenüberstehen müssen. Tatsächlich nahm Brecht zu dieser Forschungs- und kulturpolitischen Frage aber wechselnde Positionen ein. Sein erster Aufsatz zur österreichischen Literatur, die erwähnte Überblicksdarstellung "Wesen und Werden der deutsch-österreichischen Literatur" von 1920, stand noch ganz im Zeichen gesamtdeutscher Interessen. Darin heißt es gleich zu Beginn, dass die „deutsch-österreichische Literatur [...] ein integrierender Teil der deutschen“ sei und dass es deshalb „keine nur für sich existierende deutsch-österreichische Literatur geben " könne. Darüber hinaus sei die österreichische Literatur auch nur zu den Zeiten „gut [gewesen], wo sie mit der des übrigen Deutschland in lebendiger [...] Wechselwirkung stand“. ${ }^{190}$ Das zeige sich vor allem daran, dass der österreichischen Literatur des 16. Jahrhunderts aufgrund der „geistige[n] Abschnürung Österreichs vom übrigen Deutschland" durch die Gegenreformation ein hoher "geistige[r] und wirtschaftliche[r] Schade[n]" entstand. ${ }^{191}$ Nach einem nicht ohne Klischees auskommenden Durchgang von Walther von der Vogelweide über die Zeit Kaiser Maximilians, den österreichischen Barock und die Volksbühne des 18. und frühen 19. Jahrhunderts bis hin zu Franz Grillparzer, in dem der österreichischen Literatur eine starke „Nähe zum Volkstum “192, „Naivität“, „Verspätung im Geistigen" und eine geringere "Gefahr theoretischer Überbildung “193 attestiert wird, was sie als kongeniale Schwester der deutschen, stärker abstrakt konstruierten Literatur ausweise, kam Brecht zu folgendem Schluss:

Heutige österreichische und reichsdeutsche Literatur gehören zusammen: in natürlicher organischer Ergänzung!

Nicht gerade wie Kopf und Herz, aber wie Geist und Natur, Vernunft und Sinne, Leib und blühende Farbe, kühne Neueroberung und feste Stiltradition, Licht und Wärme. Diese Wärme Österreichs Kulturmission!

Das Österreichische ist vielleicht diejenige Form des Deutschen, in der es dem Ausländer am leichtesten, am liebenswürdigsten zugänglich wird; Grillparzer für ihn vielleicht der beste Weg zu Goethe.

Aber diesen Weg zu betreten, müssen wir ihm heute selber überlassen. Wir haben genug mit uns zu tun.

190 Brecht: Wesen und Werden der deutsch-österreichischen Literatur (1920), S. 337.

191 Brecht: Wesen und Werden der deutsch-österreichischen Literatur (1920), S. 340.

192 Brecht: Wesen und Werden der deutsch-österreichischen Literatur (1920), S. 339.

193 Brecht: Wesen und Werden der deutsch-österreichischen Literatur (1920), S. 341. 
Der Weg ist da, aber das Land, durch das er führt, wird bald unkenntlich sein. Nur als Teil des großen Mutterlandes kann Österreich sich retten; wird Österreich Österreich bleiben. ${ }^{194}$

Brechts Überlegungen zur österreichischen Literatur, die ihn hier unter dem Eindruck des Zusammenbruchs der Monarchie und in Abgrenzung zur Ersten Österreichischen Republik wie selbstverständlich den - nicht nur kulturellen - Anschluss an Deutschland postulieren ließen, bekamen elf Jahre später eine ganz andere Färbung. In dem 1931 erschienenen, seine bisherigen Erörterungen zur österreichischen Literatur zusammenfassenden Aufsatz „Österreichische Geistesform und österreichische Dichtung " ${ }^{195}$ den Brecht bereits als Ordinarius in München verfasste, änderte er seinen Blickwinkel nachdrücklich. Brecht vertrat darin nicht mehr auf ein einheitliches Deutsches Reich gerichtete Standpunkte, sondern knüpfte Nadler rückwärts überspringend - an ältere, differenziertere Forschungsparadigmen an, wie sie August Sauer und seine Generation vertreten hatten. So bestimmte er nun die Ausrichtung einer österreichischen Literaturforschung im Sinne von Sauers Charakteristik, nach der die österreichische Literatur im Spannungsfeld zwischen den anderen deutschen und den anderssprachigen Literaturen der Habsburgermonarchie beschrieben werden sollte:

Wie denn die schwierige Aufgabe einer allgemeinen österreichischen Literaturgeschichte, die vom alten Gesamtstaate ausginge, eigentlich darin zu bestehen hätte, die deutsch geschriebene, aber von andern Nationalitäten des Reiches an bestimmten Punkten vielfach tingierte Literatur der Deutschösterreicher von der fremdsprachig oder auch noch deutsch geschriebenen Literatur der „Nationalitäten“ einerseits zu unterscheiden, aber auch an den Punkten, wo diese Elemente unlöslich und ununterscheidbar sich amalgamiert haben, diese von Geschichte und Natur geschaffene Verbundenheit anzuerkennen und die so komplexen Gebilde methodisch zu untersuchen. Trifft es nicht zu, in der deutsch geschriebenen österreichischen Literatur ausschließlich die literarische Hervorbringung eines deutschen Stammes zu sehen wie andrer auch - niemand wird von ihr rein in dem Sinne sprechen wie von einer rheinländischen oder hessischen - so geht es auf der anderen Seite wohl zu

194 Brecht: Wesen und Werden der deutsch-österreichischen Literatur (1920), S. 349350.

195 In dem Aufsatz übernahm Brecht Überlegungen und Formulierungen aus Brecht: Wien und die deutsche Literatur (1924); ders.: Oesterreichische Geistesform und oesterreichische Dichtung I (1929); ders.: Die Wesensart des Oesterreichers (1929). 
weit, die österreichische Literatur einfach als eine „südeuropäische in deutscher Sprache" zu bezeichnen. ${ }^{196}$

Als Brecht 1931 diese Bestimmung der österreichischen Literaturforschung veröffentlichte, war - nach Paul Kluckhohn - gerade Josef Nadler sein Nachfolger auf dem Wiener Lehrstuhl für die neuere Abteilung der Deutschen Philologie geworden. Von den Vertretern einer eigenen österreichischen, auf empirische Einzelstudien bauenden Literaturgeschichte war nur noch Eduard Castle an der Wiener Universität tätig, sodass trotz der späten Anknüpfung Brechts an wissenschaftliche Paradigmen seiner Vorgängergeneration, an methodische Überlegungen Minors und Sauers, diese Forschungsrichtung innerhalb der Germanistik nicht fortgesetzt wurde und insgesamt ohne Echo blieb.

Wiederum anders gewendet sind Brechts Arbeiten zu Hugo von Hofmannsthal, mit dem er von Mai 1917 bis zu dessen Tod im Juli 1929 freundschaftlich verbunden war und als dessen Nachlassverwalter er zeitweilig auch fungierte. ${ }^{197}$ Das Verhältnis zwischen Brecht und Hofmannsthal war von Beginn an von gegenseitigen Ansprüchen geprägt, in denen eine Annäherung der wissenschaftlichen und der dichterischen Sphäre, also eine „Komplizenschaft zwischen Dichter und Wissenschaftler ${ }^{\text {“198 }}$ beabsichtigt wurde. ${ }^{199}$ Bereits Anfang 1919 übergab Hofmannsthal Brecht seine werkbiographischen Notizen „Ad me ipsum“, um, wie Brecht 1930 erklärte, „eine Art von innerlich authentischer Einwirkung auf die Diskussion zu nehmen“ und dadurch ,richtiger verstanden [zu] werden“. ${ }^{200}$ Hofmannsthal erwartete von ,seinem' Germanisten Brecht, wie Christoph König feststellte, „die Individualität und Einheit seines Oeuvres zu propagieren “201, und sprach prinzipiell davon, dass ihre beiden „Berufe [...] doch so ineinander verhäkelt ${ }^{\text {“202 }}$ wären. Brecht wiederum nannte Hofmannsthal einen „Philologorum poetissimus, poetarum philologissi-

196 Brecht: Österreichische Geistesform und österreichische Dichtung (1931), S. 614.

$197 \mathrm{Zu}$ den Konflikten um Hofmannsthals Nachlass vgl. Oels: „Denkmal der schönsten Gemeinschaft" (2007), S. 62-79.

198 Oels: „... denn unsere Berufe sind doch so ineinander verhäkelt“ (2007), S. 57.

199 Vgl. dazu auch König: „Geistige, private Verbündung“ (1993).

200 Brecht: Hugo von Hofmannsthals „Ad me ipsum“ und seine Bedeutung (1930), S. 319 .

201 König: Hofmannsthal (2001), S. 212.

202 Hofmannsthal/Brecht: Briefwechsel (2005), S. 146 (Brief von Hofmannsthal an Brecht vom 12. Jänner 1928). 


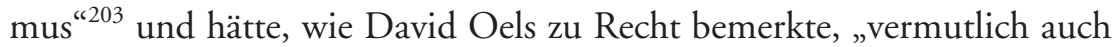
gern sich selber so bezeichnet ${ }^{\text {"204 }}$.

Tatsächlich äußerte sich Brecht bereits im Dezember 1919 in der nicht erhaltenen Rede „Hofmannsthals Märchen ,Die Frau ohne Schatten“ im Zusammenhange seines Dichtens" öffentlich zu dessen Werk, ${ }^{205} 1923$ verwendete er in seiner Publikation "Grundlinien im Werke Hugo v. Hofmannsthals“zum ersten Mal das „Ad me ipsum“ und veröffentlichte in Folge Aufsätze über „Hofmannsthals Weltbild“, den Jedermann, den literarischen Nachlass, Das Bergwerk zu Falun, Die Ägyptische Helena, seine Gespräche und Begegnungen mit dem Dichter und edierte das „Ad me ipsum “. ${ }^{206}$ Bemerkenswert an diesen Beiträgen ist neben deren Bedeutung für die Hofmannsthal-Forschung, deren Anfänge Brecht maßgeblich und nachhaltig mitprägte, ${ }^{207}$ vor allem der Stil von Brechts Wissenschaftsprosa und seine daraus resultierende Auffassung der Deutschen Philologie. Schon Brechts Beitrag zur Festschrift für Bernhard Seuffert von 1923 über die „Grundlinien im Werke Hugo v. Hofmannsthals" zeigt deutlich seine Distanzierung von wissenschaftlichen und seine Annäherung an literarische Ausdrucksformen. Bei diesem Beitrag handelt es sich nicht um eine sachlich-distanzierte Darstellung, sondern vielmehr um eine mit Zitaten aus Hofmannsthals Werk versehene und umstrukturierte Version des „Ad me ipsum", also um eine Erklärung des Dichters mit Worten des Dichters oder, wie Oels feststellte, um „dichtende Philologie ${ }^{\text {“208 }}$. Brechts Fachkol-

203 Erika Brecht: Erinnerungen an Hugo von Hofmannsthal (1946), S. 40.

204 Oels: „... denn unsere Berufe sind doch so ineinander verhäkelt“ (2007), S. 51.

205 Oels: „... denn unsere Berufe sind doch so ineinander verhäkelt“ (2007), S. 40.

206 Vgl. u. a. Brecht: Grundlinien im Werke Hugo v. Hofmannsthals (1923); ders.:

Fragmentarische Betrachtung über Hofmannsthals Weltbild (1924); ders.: Die Vorläufer von Hofmannsthals „Jedermann" (1924); ders.: Hugo von Hofmannsthals „Ad me ipsum“ und seine Bedeutung (1930); ders.: Über den literarischen Nachlaß Hugo von Hofmannsthals (1930); ders.: Über Hugo von Hofmannsthals „Bergwerk zu Falun“ (1932); ders.: Gespräch über die „Ägyptische Helena“ (1949).

207 Vgl. Osterkamp: Formale, inhaltliche und politische Akzeptanz von Gegenwartsliteratur (1993), S. 174: „Im Falle Brechts, bei dem er das größte Verständnis für sein Spätwerk vermuten durfte, hatte Hofmannsthal ganz auf den Richtigen gesetzt, als er ihm seine werkbiographische Selbstdeutung, Ad me ipsum‘ übergab: Brechts Edition und Kommentar haben, wohl ganz im Sinne des Dichters, die Deutung von Hofmannsthals Werk als eines Ganzen auf viele Jahrzehnte hin bestimmt (und dies keineswegs immer auf klärende Weise).“

208 Oels: „Denkmal der schönsten Gemeinschaft“ (2007), S. 41. - Christoph König bezeichnet den Aufsatz Brechts über das „Ad me ipsum“ sogar als „Plagiat“; König: Hofmannsthal als Interpret seiner selbst (1999), S. 62 (Anm. 3). 
lege Carl von Kraus war gelinde irritiert. Auf einen nicht erhaltenen Brief des Altgermanisten antwortete Brecht im Juli 1923:

Was Sie in u. an meinem Aufsatz, ungewöhnlich graciös' finden, kommt natürlich durchaus auf Hofmannsthals Rechnung und zwar wörtlich: denn ich habe ja nicht nur viele seiner Begriffe, Symbole, Motive, sondern auch eine Anzahl seiner besonderen Ausdrücke (z. B. „Präexistenz“, „Verschuldung“, „Süßigkeit in der Verschuldung") aus seinem mir gelegentlich überlassenen ganz privaten zerstreuten Aufzeichnungen „Ad se[!] ipsum“ herübergenommen. Es war keine Kleinigkeit, diese Geheimschrift zu deuten u. ihre Züge mit meinen seit je bestehenden Auffassungen von ihm zu einem leidlich philologisierten, nat [ürlich] noch vereinfachten u. geklärten Bilde zu vereinigen. Sie finden es, mir völlig begreiflich, graziös, er natürlich vergröbert. ${ }^{209}$

Bei Brechts Versuch, gleichzeitig sowohl literarischen als auch wissenschaftlichen Darstellungs- und Ausdrucksweisen gerecht zu werden, handelte es sich um eine Gratwanderung, die eine Annäherung der beiden Sphären im Sinn hatte und zeitgenössisch durchaus keine singuläre Erscheinung innerhalb des wissenschaftlichen Feldes war. ${ }^{210}$ Brecht verhalf diese Hinwendung zu ästhetisch und stilistisch prononcierten Darstellungsverfahren aber, wie sein Brief an Carl von Kraus zeigt, weder zu besonderer Anerkennung von Fachvertretern noch vom Dichter selbst. Ähnliches lässt sich über Brechts Beitrag zur Eranos-Festschrift anlässlich Hofmannsthals 50. Geburtstags 1924 sagen, in dem er eine „Fragmentarische Betrachtung über Hofmannsthals Weltbild“ anstellte, die auf eine einheitliche Gesamtschau von Hofmannsthals Werk abzielte. Die von Brecht angenommene Weiter- und Höherentwicklung in Hofmannsthals Oeuvre erklärte der Germanist mit folgenden - wissenschaftlich wenig erhellenden - Worten, die stilistisch offenkundig nicht Ausdruck einer an Nüchternheit und Sachlichkeit orientierten akademischen Sprache sind:

Traf man früher manchmal auf, unendlich reizvolle, Addition, wenn der vergröbernde Vergleich erlaubt ist, so herrscht jetzt Integration. Dies ist nicht nur der allgemeine menschlich-dichterische Vorgang, nicht nur Sache des Lebensalters: ein tieferes scheint sich anzuzeigen. Wer auf das „Große Welttheater", auf den „Turm" nur einen eindringenderen Blick richtet, erkennt, wie die rätselhafte Verschlungenheit aller Geschicke hier dunkelklar in bezie-

209 Brief von Brecht an Kraus vom 20. Juli 1923; BSB München, Nachlass Carl von Kraus, Krausiana I.

$210 \mathrm{Zu}$ diesem Themenkomplex vgl. Trommler: Geist oder Gestus? (1997); Osterkamp: Friedrich Gundolf zwischen Kunst und Wissenschaft (1993); Weimar: Das Muster geistesgeschichtlicher Darstellung (1993); sowie Kap. III.1. und Kap. III.2. 
hungsreichen Konfigurationen bedeutend ans Licht tritt und treten soll, als Hauptsache des Weltbildes [...]. ${ }^{211}$

„[R]ätselhafte Verschlungenheit aller Geschicke“, „dunkelklar in beziehungsreichen Konfigurationen" - das hört sich verdächtig nach einem Versuch an, sich durch dichterische Ausdrucksformen einem Sinn zu nähern, der mit dem Erkenntnisinstrumentarium der akademischen Wissenschaft nicht zu fassen war. Tatsächlich war Hofmannsthal aber auch diesmal nicht zufrieden: „Nein, Sie müssen schon bei Ihrer Weise, die Dinge darzustellen bleiben [...]. Es gibt eben jene andere Darstellungsweise, und es gibt die Ihre, beide sind giltig, und uns Deutschen ist vielleicht doch jene andere, auf die Typen und Canones ausgehende, minder gewiß." ${ }^{212}$

Ein weiteres Projekt, das ebendiese Zwischenstellung haben sollte, war Hofmannsthals Idee vom „Buch des Dichters“, das er von Brecht geschrieben haben wollte. Es sollte, wie sich Erika Brecht erinnerte, „ganz groß angelegt, ohne Zitate oder sonstigen gelehrten Apparat, ohne jeden Anklang an Biografie“ sein, demnach „ein Buch, in dem der Prozeß des dichterischen Schaffens, selbst eine Art Dichtung, in klassischer Weise dargestellt werden sollte“. ${ }^{213}$ Dieses „Hofmannsthal-Buch als Gundolfsche Gestaltmonographie“214 schrieb Brecht aber nicht mehr. Sein Dilemma bemühte sich Brecht im November 1923 Paul Kluckhohn zu erklären:

M. Gespräche mit Hofm. lassen sich nicht wiedergeben. Sie betreffen meist das Innerste des dichter. Prozesses. Sehr eigentümlich ist auch das Phänomen, wenn einer plötzlich innerlich zu dichten beginnt, numine afflatus. Ich verlasse H. dann stets. Er stirbt plötzlich der Außenwelt ab. [...] Die Philosophen u. Ästhetiker reden eigentlich nur so herum. Je mehr man davon verstehen lernt, um so mehr neigt man dazu, über diese geheimnisvollen Dinge den Schnabel zu halten. Die ältere Generation verstand freilich davon garnichts. ${ }^{215}$

Wenn Brecht in seinem Versuch, das "Innerste des dichter. Prozesses“ darzustellen, auch scheiterte, so zeigen seine Veröffentlichungen zu Hofmannsthal doch den von ihm festgestellten Unterschied zur vorherigen, dem Wissenschaftsideal strenger Philologie verpflichteten Germanisten-

211 Brecht: Fragmentarische Betrachtung über Hofmannsthals Weltbild (1924), S. 24.

212 Hofmannsthal/Brecht: Briefwechsel (2005), S. 68 (Brief von Hofmannsthal an Brecht vom 1. Juli 1924).

213 Erika Brecht: Erinnerungen an Hugo von Hofmannsthal (1946), S. 41-42.

214 Osterkamp: Formale, inhaltliche und politische Akzeptanz von Gegenwartsliteratur (1993), S. 176.

215 Brief von Brecht an Kluckhohn vom 27. November 1923; DLA Marbach, Bestand: Deutsche Vierteljahrsschrift. 
generation auf. Die Annäherung zwischen Dichter und Germanist, zwischen Kunst und Wissenschaft war kein auf Brecht und Hofmannsthal beschränktes Phänomen, sondern markiert einen „wissenschaftsgeschichtlichen Umschwung in der Deutschen Philologie der zwanziger Jahre“216, der nicht nur die Erkenntnis- und Darstellungsweise des Fachs beeinflusste, sondern auch konkrete institutionelle Auswirkungen hatte. Ein „aufschlußreiches Symptom“ dieses Wandels lässt sich nämlich, wie Ernst Osterkamp konstatierte, im Konflikt um die Nachfolge von Franz Muncker in München 1926/27 feststellen: „[N] ie zuvor wohl und auch später nicht haben bedeutende deutsche Schriftsteller in solchem Ausmaß auf die Besetzung eines Lehrstuhls für Neuere deutsche Literaturgeschichte Einfluß zu nehmen versucht [...]. "217 Nutznießer dieser Auseinandersetzung, an der sich neben Hugo von Hofmannsthal auch Thomas Mann, Rudolf Borchardt, Rudolf Alexander Schröder und Mitglieder des GeorgeKreises beteiligten, war Walther Brecht, der im Mai 1927 nach München berufen wurde. ${ }^{218}$

Uneingeschränkte Anerkennung sowohl von Hofmannsthal als auch von Vertretern des Fachs und Studierenden erhielt Brecht für seine universitäre Lehre. In den zu seinen Lebzeiten unveröffentlicht gebliebenen „Notaten für einen Aufsatz über Walther Brecht" ging Hofmannsthal anlässlich von Brechts Weggang aus Wien 1926 gerade auch auf diesen Aspekt des Aufgabenbereichs eines Universitätsprofessors ein: „Das Semester geht zu Ende. Es ist das letzte, das Professor W. Brecht lehrend an dieser Universität verbringen wird. Die Universität besitzt viele Gelehrte von Rang: in Brecht verliert sie was schlechthin niemals zu ersetzbar ist: eine Lehrerpersönlichkeit. “219 Das Gutachten, das Carl von Kraus für die Muncker-Nachfolge verfasste, konzentrierte sich ebenfalls auf Brechts Lehrtätigkeit:

Der ungewöhnliche Lehrerfolg tritt auch nach Außen hin zu Tage: in der warmen Anerkennung, mit der Studenten, Kollegen und die Oeffentlichkeit den von Wien Scheidenden bedachten, vor allem aber in der Tatsache, dass er dort vier Dozenten zurücklässt, die seine Schüler sind (Touaillon und Thalmann, Kindermann und Cysarz). Die Verschiedenheit ihrer Richtungen be-

216 Osterkamp: „Verschmelzung der kritischen und der dichterischen Sphäre“ (1989), S. 348.

217 Osterkamp: „Verschmelzung der kritischen und der dichterischen Sphäre“ (1989), S. 348.

218 Vgl. dazu Osterkamp: „Verschmelzung der kritischen und der dichterischen Sphäre" (1989); Dittmann: Carl von Kraus über Josef Nadler (1999).

219 Hofmannsthal: Notate für einen Aufsatz über Walther Brecht (2005), S. 182. 
kundet, wie mannigfaltig die Anregungen sind, die der feinorganisierte und für jede, nicht bloss für die literarische Kunst verständnisvolle Mann zu geben vermag.

Die Universität würde an ihm einen hervorragenden Lehrer und einen ebenso methodisch wie ästhetisch gebildeten Forscher gewinnen. ${ }^{220}$

Herbert Cysarz erinnerte sich 1976 an seinen „literaturhistorische[n] Lehrund Fechtmeister" Walther Brecht, bei dem er nach dem Ersten Weltkrieg studiert hatte und von dem er auch über seine Dozententätigkeit hinaus gefördert wurde, ebenfalls als „eine[n] der weitaus begabtesten [...] Germanisten“, dessen „allseitige Offenheit [...] ihn jeden Dissertanten zu dessen Bestmöglichen anspornen“ ließ und von dem „[v]iele seiner produktiven Einfälle in die Arbeiten seiner Schüler eingegangen“ waren. „[E]r half immer so freigebig wie unvermerkt" und vereinte, so Cysarz weiter, „seine philologische Gewissenhaftigkeit“ mit der Fähigkeit, „Dichtungen [...] wie ein schöpferischer Musiker Partituren" zu lesen. Welche Bedeutung Brecht für seine eigene Arbeit hatte und wie er Brechts Unterricht mit Blick auf methodische und thematische Auseinandersetzungen innerhalb des Fachs und im Unterschied zur universitären Lehre vor dessen Amtsantritt wahrnahm, erklärte Cysarz mit dem ihm eigenen Hang zum metaphernreichen Sprachgebrauch:

In meinem Fall hat Brecht mit freundwilliger Sympathie Erz und Schlacke zu scheiden, die originären Energien monoklin zu entwickeln, zugleich in Fühlung mit der Sprach- und Werk-Untersuchung zu halten getrachtet. Er hat die Ideenhistorie, die theoretischen Konvergenzen von Bild und Begriff usw., immer als eine Richtung unter anderen und als Forschungsfeld einer besonderen Anlage angesehen. Aber die Richtung dünkte ihn hier nicht nur mit überzeugender Potenz ergriffen, sondern auch entscheidender Sprengungen der amusischen Stoffhuberei, neuer Lichtungen und Leistungen fähig. Krieg und Nachkriegselend riefen nach primordialer, universeller Rechtfertigung des „Luxus" Literaturwissenschaft. Der Expressionismus, die ungeheuren Umschwünge insgemein verlangten auf viele Weisen danach, Denken und Formen in eine umfassende Esse zu werfen. Und gerade damals drohte viel hergebrachter Literatur-Unterricht in dichtungsfremde Materialienkunde und Biographik zu versacken. ${ }^{221}$

Doch nicht nur Brechts Bemühungen um einen Ausgleich zwischen verschiedenen Ansätzen in der zeitgenössischen Literaturwissenschaft und seine Fähigkeit, diplomatisch Übergänge zu schaffen, wurden gerühmt,

220 Gutachten von Carl von Kraus über Walther Brecht, o.D.; zit. n. Bonk: Deutsche Philologie in München (1995), S. 69.

221 Alle Zitate: Cysarz: Vielfelderwirtschaft (1976), S. 34-36. 
sondern auch eine ganz basale, gleichwohl nicht zu überschätzende Kompetenz, die den verständnisvollen Umgang mit verzweifelten Erstund Zweitsemestern betraf. „At the beginning I was quite lost“, schrieb der spätere Lyriker, Essayist und New Yorker Germanistikprofessor Ernst Waldinger, der 1938 aus Österreich fliehen konnte, über seinen Studienbeginn in Wien 1918:

[A] freshman at the Vienna University was in a rather difficult situation; at least during the first two semesters he was at loss and without any orientation on part of the academic authorities; this applied at least to the majority of disciplines within the Faculty of Philosophy which, except for those of science, have no regulated syllabus. Professor Brecht, one of my professors, once told us in a seminar that at the beginning of his university career he was completely at a loss when facing the extensiveless [!] of his chosen field, which seemed endless to him. ${ }^{222}$

Brechts Wiener Lehre umfasste neben den obligatorischen Vorlesungen zur Literaturgeschichte, in denen er das gesamte Spektrum der neueren Abteilung, also die Zeit vom Ende des Mittelalters bis zum Beginn des 20. Jahrhunderts abdeckte, vor allem Seminare zur Lyrik. In neun seiner insgesamt 25 Semester, in denen er an der Universität Wien Lehrveranstaltungen hielt, konzentrierte sich sein Programm auf Gedichte (Opitz, Mörike, Schiller, Goethe, Klopstock, Hölderlin, Balladen des 18. und 19. Jahrhunderts, C.F. Meyer). Daneben finden sich, was einen klar erkennbaren Unterschied zu seinem Vorgänger Jakob Minor ausmacht, deutlich mehr stilkritische als biographische Übungen. Insgesamt war Brecht in seiner zwölf Jahre dauernden Amtszeit in Wien für 63 Lehrveranstaltungen verantwortlich. ${ }^{223} \mathrm{Da}$ diese pro Semester von mehreren hundert Studierenden besucht wurden, war die Kapazität der Universitätsräumlichkeiten bei Weitem überschritten: „, $[\mathrm{M}]$ eine fast 400 Zuhörer

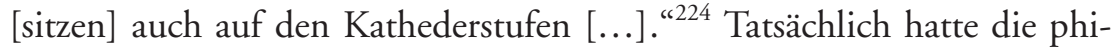
losophische Fakultät bei Brechts Amtsantritt im Sommersemester 1914 bereits 2.161 Studierende, wovon 438, also etwa ein Fünftel, Studentinnen waren. Im darauffolgenden Wintersemester 1914/15 fiel die Studierendenzahl kriegsbedingt auf 1.712, darunter nun bereits 641 Studentinnen, etwas mehr als ein Drittel; im Wintersemester 1918/19 waren an der

222 Waldinger: My Vienna University Career (1965), S. 85.

$223 \mathrm{Vgl}$. hierzu und zum Vorigen die gedruckten Verzeichnisse: Öffentliche Vorlesungen an der K.K. Universität zu Wien (1914-1918); Öffentliche Vorlesungen an der Universität zu Wien (1919-1926).

224 Brief von Brecht an Paul Kluckhohn vom 19. November 1925; DLA Marbach, Bestand: Paul Kluckhohn. 
philosophischen Fakultät 2.906 Studierende, darunter 929 Frauen, inskribiert und in Brechts letztem Wiener Semester, im Wintersemester 1925/26 gab es fast doppelt so viele Hörer und Hörerinnen wie bei seinem Amtsantritt, nämlich insgesamt 3.857, darunter 1.147 Studentinnen, also etwas weniger als 30 Prozent. ${ }^{225}$ In den Erinnerungen der männlichen Kommilitonen waren es freilich viel mehr Frauen: „[T]he lecture room where Professor Walter Brecht held his lectures on history of literature [...] was crowded, but crowded with girls", schrieb Ernst Waldinger 1965.226 Und Józef Wittlin meinte gar, dass die männlichen Studierenden in der absoluten Minderheit gewesen wären: „Die Vorlesungen von Professor Brecht, im ersten Jahr des ersten Weltkrieges, erfreuten sich großer Beliebtheit, besonders bei den Hörerinnen. Männer gab es dort wenig, es ist also nicht zu verwundern, wenn diese sofort auffielen." 227

Auch wenn sich zu den Studenten in den 1910er und 1920er Jahren nicht ganz so viele Studentinnen gesellten, wie die Erinnerungen von Waldinger und Wittlin vermuten ließen, so war das Ausmaß von Brechts Betreuungspflichten doch enorm: Während Jakob Minor in 26 Jahren insgesamt 361 Dissertationen, also im Schnitt nicht ganz 14 pro Jahr, als Referent beurteilte, ${ }^{228}$ stieg die Zahl der von Brecht betreuten Promotionen in der neueren Abteilung in den 1910er und 1920er Jahren nahezu auf das Doppelte an. In zwölf Jahren begutachtete Brecht als Referent 316 Dissertationen, also durchschnittlich 26 pro Jahr, als Koreferent noch einmal 111 Dissertationen, also durchschnittlich neun pro Jahr. ${ }^{229}$ Dabei handelte es sich um eine Arbeitsbelastung, die selbst seinen früheren Förderern Gustav Roethe und Edward Schröder Respekt abverlangte (auch wenn diese von einer etwas höheren Zahl ausgingen). Am 4. Juni 1925 schrieb Schröder an Roethe über deren ehemaligen Schützling: „[G]rausige Arbeitsüberhäufung! 600 Dissertationen in 12 Jahren!“230

225 Die angegebenen Studierendenzahlen umfassen ordentliche und außerordentliche Studierende und sind den einzelnen, semesterweisen Vorlesungsverzeichnissen entnommen, in denen sich am Ende jeweils eine „Summarische Übersicht der an der Universität Wien inskribierten ordentlichen und außerordentlichen Hörer“ befindet.

226 Waldinger: My Vienna University Career (1965), S. 84.

227 Wittlin: Erinnerungen an Josef Roth (1949), S. 49.

228 Faerber: Ich bin ein Chinese (2004), S. 155.

229 Die Zahlen wurden ermittelt nach UAW, Phil. Fak., Rigorosenprotokolle 19141926.

230 Brief von Schröder an Roethe vom 4. Juni 1925; zit. n. Oels: „Denkmal der schönsten Gemeinschaft" (2007), S. 33. 
Nichtsdestotrotz engagierte sich Brecht für seine Studierenden über die Promotion hinaus und verhandelte - teilweise mit Unterstützung von Hugo von Hofmannsthal - über Jahre hinweg mit dem Wiener Verlag Kola über eine eigene Reihe, in der Dissertationen aus der Neugermanistik veröffentlicht werden sollten. ${ }^{231}$ Diese „Sammlung à la Probefahrten “232 konnte Brecht in Wien jedoch nicht mehr realisieren. Einige der von Brecht betreuten Dissertationen erschienen aber in der Literarhistorischen Reihe des Sammelwerks Deutsche Kultur, die Brecht ab 1924 herausgab. Das Sammelwerk Deutsche Kultur, das als Publikationsorgan für Angehörige der Wiener Universität diente, betreute Brecht gemeinsam mit dem Historiker Alfons Dopsch, der für die Historische Reihe verantwortlich war. Im Verlagsprospekt hieß es 1925 zum Programm der Sammlung, dass beide Publikationsreihen, obgleich jede für sich bestünde, „ein höheres Ganzes“ bildeten: „Deutsche Kultur, sowohl die geistige als die materielle, soll Forschungsgebiet wie Idealziel beider sein. “233 Ideologisch stand dieses Unterfangen durch Dopsch, der früh für den Anschluss Österreichs an Deutschland Stimmung machte ${ }^{234}$ und wie der Altgermanist Rudolf Much dem katholisch-deutschnationalen und betont antisemitischen Verein Deutsche Gemeinschaft angehörte, dem völkischen Lager nahe. ${ }^{235}$ In der von Brecht geleiteten Literaturhistorischen Reihe erschienen aber auch Dissertationen von jüdischen Studierenden, wie die von Marianne Beyer-Fröhlich, ${ }^{236}$ einer Wiener Studentin von Brecht und späteren Mitarbeiterin des monumentalen Sammelwerks Deutsche Literatur in Entwicklungsreihen, das

231 Vgl. Brief von Brecht an Paul Kluckhohn vom 2. August 1921; DLA Marbach, Bestand: Paul Kluckhohn; Hofmannsthal/Brecht: Briefwechsel (2005), S. 40 (Brief von Hugo von Hofmannsthal an Brecht vom 8. Februar 1922); Brief von Brecht an Kluckhohn vom 16. Juli 1923; DLA Marbach, Bestand: Deutsche Vierteljahrsschrift.

232 Brief von Brecht an Paul Kluckhohn vom 2. August 1921; DLA Marbach, Bestand: Paul Kluckhohn. - Mit „Probefahrten“ nahm Brecht Bezug auf die bereits erwähnte, ähnliche Reihe Probefahrten. Erstlingsarbeiten aus dem Deutschen Seminar in Leipzig (1905-1930), die Albert Köster herausgab.

233 [Anonym/Verlagsprospekt:] Deutsche Kultur (1925), S. 257.

234 Vgl. Dopsch: Der Anschluß Deutsch-Österreichs an das Deutsche Reich (1919).

235 Vgl. Rosar: Deutsche Gemeinschaft (1971).

236 Beyer-Fröhlich: Johann Jakob Moser in seinem Verhältnis zum Rationalismus und Pietismus (1925). Weitere von Brecht betreute Dissertationen, die in dieser Reihe erschienen, sind Rudolf Henz: Die Landschaftsdarstellung bei Jean Paul (1924); Robert Hartl: Versuch einer psychologischen Grundlegung der Dichtungsgattungen (1924); Franz Horch: Das Burgtheater unter Heinrich Laube und Adolf Wilbrandt (1925); Alice Tröthandl-Berghaus: Die Dramen des Martin Hayneccius (1927). 
Brecht gemeinsam mit Dietrich Kralik und Heinz Kindermann herausgab. ${ }^{237}$

Von besonderer Bedeutung für den akademischen Betrieb und singulär im deutschsprachigen Raum war Brechts großer Erfolg bei seinem Ansinnen, ihm förderungswürdig erscheinende Dissertanten zu Akteuren in der Universitätsgermanistik zu machen. Während sich in der älteren Abteilung im selben Zeitraum nur zwei Wissenschaftler habilitierten, ${ }^{238}$ war Brecht von 1914 bis 1926 an nicht weniger als sechs Habilitationen beteiligt. Auffällig ist neben der Anzahl dabei zweierlei: zum einen die unterschiedlichen thematischen und methodischen Ausrichtungen ,seiner Privatdozenten, die auf Brechts offene wissenschaftliche Haltung zurückzuführen sind, zum anderen auch, dass sich unter den sechs Privatdozenten zwei Privatdozentinnen befanden, was jedoch nicht einer explizit frauenfreundlichen Position Brechts geschuldet war. Brechts Einstellung zu Frauen in der Wissenschaft war zwar nicht grundsätzlich ablehnend wie die vieler seiner Kollegen; mit Blick auf die Begebenheiten des akademischen Betriebs, in dem die Mitarbeit von Frauen dem Prestige eines Unterfangens nicht unbedingt förderlich war, nahm er aber eine vorsichtige bis abwehrende Haltung ein. Beispielhaft dafür ist seine Reaktion auf Paul Kluckhohns Frage, ob sie versuchen sollten, die 1920 in Freiburg promovierte Germanistin und Dilthey-Spezialistin Sigrid Gräfin von der Schulenburg als Referentin für die Deutsche Vierteljahrsschrift für Literaturwissenschaft und Geistesgeschichte zu gewinnen. Brecht antwortete: „Gegen die Schulenburg habe ich garnichts, sage nur aus Erfahrung mit Bezug auf weibliche Beteiligung: Präzedenzfall zu vermeiden! Hat der ZsfdA ${ }^{239}$ ihre schroffe Männlichkeit geschadet? “240 Dass sich bei Brecht auch zwei Wissenschaftlerinnen habilitieren konnten, war also seiner insgesamt integrativen und Unterschiede zulassenden Haltung geschuldet. Eine ,Schule' in dem

237 Das Sammelwerk Deutsche Literatur. Sammlung literarischer Kunst- und Kulturdenkmaler in Entwicklungsreihen war auf insgesamt 250 Bände konzipiert und umfasste 25 verschiedene Reihen. Marianne Beyer-Fröhlich war von 1930 bis 1936 Herausgeberin der ersten neun Bände der Reihe Deutsche Selbstzeugnisse; 1938 wurde sie entlassen und von Ernst Volkmann ersetzt. Brecht wurde ab 1937, nachdem er in München zwangsemeritiert worden war, ebenfalls nicht mehr als Herausgeber genannt. Zu Beyer-Fröhlich vgl. die Erinnerungen ihres Sohns Martin Beyer: A Wet World (1997).

238 Dietrich Kralik und Anton Pfalz.

239 Zeitschrift für deutsches Altertum und deutsche Litteratur.

240 Brief von Brecht an Kluckhohn vom 3. bis 13. Februar 1923; DLA Marbach, Bestand: Deutsche Vierteljahrsschrift. 
Sinn, dass er Nachwuchswissenschaftler um sich scharte, die methodische, thematische, habituelle und soziale Ähnlichkeiten mit ihm aufwiesen oder zumindest versuchten, sich diese Ähnlichkeiten anzueignen, hat Brecht damit nicht begründet. Seine Protegés machten - mit Ausnahme der „habilit. älteren Frau Dr. Touaillon u. Payer von Thurn“241 - trotzdem Karriere.

Nach Christine Touaillon, deren Habilitationsverfahren Brecht von seinen Grazer Kollegen übernahm und die 1921 die Venia Legendi erhielt, ${ }^{242}$ und dem hier erwähnten Bibliothekar Rudolf Payer von Thurn, der sich nur zwei Jahre vor seiner Pensionierung ebenfalls 1921 in Wien habilitierte, war Brecht noch für vier weitere Privatdozenten verantwortlich. Unter ihnen befanden sich auch (spätere) Nationalsozialisten.

So habilitierte sich 1922 unter der Ägide von Brecht Herbert Cysarz mit der Arbeit Deutsche Barockdichtung, die 1924 auch als Buch erschien und mit der sich Cysarz in die geistesgeschichtlich ausgerichtete Neubewertung der Literatur des 17. Jahrhunderts in den 1920er Jahren einschrieb. ${ }^{243}$ Cysarz erhielt 1926 den Titel eines außerordentlichen Professors in Wien, wurde 1929 als Nachfolger August Sauers nach Prag berufen und übernahm 1938 nach dessen Zwangspensionierung das Ordinariat seines Lehrers Walther Brecht in München. Cysarz, der sich stets der geistesgeschichtlich orientierten Literaturbetrachtung widmete, wurde in Prag Mitglied der Sudetendeutschen Partei und beantragte 1939 die Übernahme in die NSDAP. 1945 wurde Cysarz vom Dienst enthoben und 1946 entlassen. ${ }^{244}$

1924 habilitierten sich bei Brecht Heinz Kindermann und Marianne Thalmann. Kindermann war bereits während seiner Studienzeit in Wien ab 1915 mit der Leitung der Bibliothek des Seminars für Deutsche Philologie betraut und fungierte als studentischer Mitarbeiter von Walther Brecht. ${ }^{245}$

241 Brief von Brecht an Kluckhohn vom 2. August 1921; DLA Marbach, Bestand: Paul Kluckhohn.

$242 \mathrm{Zu}$ Touaillon vgl. Kap. II.

243 Zu Cysarz' Barockdarstellung vgl. Kiesant: Die Wiederentdeckung der Barockliteratur (1993), S. 86-87; Müller: Barockforschung (1973), S. 149-160.

244 Vgl. Müller: Das Konzept einer „Gesamtwissenschaft" bei Herbert Cysarz (2006); Bonk: Deutsche Philologie in München (1995), S. 290-321.

245 In dieser Funktion begegnete Kindermann seinen jüdischen Kommilitonen mit Ausgrenzung und Verachtung: „Der Assistent von Brecht dagegen, Dr. Heinz Kindermann, konnte Roth nicht leiden, ebenso auch uns nicht als Nicht-Germanen. Kaum, daß er sich herabließ, unsere Fragen zu beantworten. [...] Heute, von einer so entfernten Perspektive aus gesehen, erscheint mit Dr. Kindermann als 
Wissenschaftlich trat er 1918 mit einer Dissertation über Hermann Kurz, 1924 mit seiner Habilitationsschrift J.M.R. Lenz und die Deutsche Romantik und in Folge mit einer langen Reihe theaterwissenschaftlicher Texte hervor. 1927, nur drei Jahre nach Erhalt der Venia Legendi, wurde Kindermann als Nachfolger Paul Kluckhohns ordentlicher Professor in Danzig. Nach einem Lehrstuhl in Münster übernahm er 1943 die nationalsozialistische Gründung des ,Zentralinstituts für Theaterwissenschaft ${ }^{\star}$ an der Universität Wien. Kindermann war von 1918 bis 1926 Mitglied der Großdeutschen Partei in Österreich und trat früh, im Mai 1933, der NSDAP bei. Er war ein glühender Anhänger der NS-Wissenschaft, unterzeichnete 1933 das Bekenntnis der Professoren an den deutschen Universitäten und Hochschulen zu Adolf Hitler und dem nationalsozialistischen Staat, gab 1939 die ,Anschluss'-Anthologie Heimkehr ins Reich heraus und war Lektor im ,Amt Schrifttumspflege des NS-Ideologen Alfred Rosenberg. 1945 wurde Kindermann entlassen, 1954 aber wieder eingestellt und bis zu seiner Emeritierung 1969 erneut mit der Leitung des Wiener Instituts für Theaterwissenschaft betraut. ${ }^{246}$

Marianne Thalmann hatte 1918 bei Walther Brecht mit der Arbeit Probleme der Dämonie in Ludwig Tiecks Schriften promoviert, bevor sie 1923 ihre Habilitationsschrift Der Trivialroman und der romantische Roman vorlegte und 1924 als zweite Germanistin nach Christine Touaillon die Venia Legendi erhielt. Thalmann führte in ihren Forschungen nicht nur den wissenschaftlichen Terminus ,Trivialroman' in die universitäre Wissenschaft ein, sondern leistete mit ihren Studien auch einen wesentlichen Beitrag zur geistesgeschichtlich orientierten Romantikforschung in den 1920 er Jahren. Während ihrer Wiener Zeit veröffentlichte sie darüber hinaus zu formalästhetischen und von der Kunstwissenschaft beeinflussten Fragestellungen zur Gegenwartslyrik und zu Henrik Ibsen. ${ }^{247}$ Außerdem verfasste sie eine vitalistisch-biologistische Zeitdiagnose über das Drama des 19. und frühen 20. Jahrhundert. ${ }^{248} 1933$ erhielt Thalmann in Wien noch den Titel eines außerordentlichen Professors, im selben Jahr nahm sie

der ideale Prototyp eines Nazi. Und tatsächlich - er wurde Nazi.“ Wittlin: Erinnerungen an Josef Roth (1949), S. 52.

$246 \mathrm{Zu}$ Kindermann vgl. Peter: Theaterwissenschaft als Lebenswissenschaft (2009); Peter/Payr (Hg.): „Wissenschaft nach der Mode“? (2008); Kirsch: Heinz Kindermann - ein Wiener Germanist und Theaterwissenschaftler (1996).

247 Thalmann: Gestaltungsfragen der Lyrik (1925); dies.: Henrik Ibsen, ein Erlebnis der Deutschen (1928).

248 Thalmann: Die Anarchie im Bürgertum (1932). 
aber eine Berufung ans Wellesley College in den USA an, wo sie bis zu ihrer Emeritierung 1953 blieb. $^{249}$

Der letzte Wiener Privatdozent, für dessen Habilitation Brecht verantwortlich zeichnete, war Franz Koch, der bereits 1912, noch kurz vor Minors Tod, bei diesem mit der Arbeit Albert Lindner als Dramatiker promoviert hatte und danach bis 1935 als Bibliothekar in der Hofbibliothek respektive Nationalbibliothek tätig war. Nach Publikationen über die Geschichte des Burgtheaters, über Aspekte des Bibliothekswesens, über Goethe und Schiller habilitierte sich Koch 1926 mit seiner Studie Goethe und Plotin und war fortan (nebenberuflich) als Lehrbeauftragter am Seminar für Deutsche Philologie tätig. 1932 erhielt Koch den Titel eines außerordentlichen Professors, 1935 wurde er als Nachfolger Gerhard Frickes an die Friedrich-Wilhelms-Universität in Berlin berufen. Koch war wie Kindermann Mitglied der Großdeutschen Partei in Österreich und ab 1937 Mitglied der NSDAP. Während des Nationalsozialismus trat Koch außerdem als Hauptlektor des ,Amtes Schrifttumspflege' für das Fachgebiet Neuere Literatur und Geistesgeschichte, als Leiter des Wissenschaftlichen Einsatzes Deutscher Germanistik im Kriege und als Mitglied im Sachverständigenbeirat des sogenannten Reichsinstituts für Geschichte des neuen Deutschlands hervor. Koch wurde 1945 entlassen, bereits 1949 aber rehabilitiert. ${ }^{250}$

Walther Brecht litt Zeit seiner Wiener Professur, besonders nach Zusammenbruch der Monarchie unter materiellen Schwierigkeiten. Die Besoldung eines ordentlichen Universitätsprofessors in Österreich, der nicht auf ein Familienvermögen zurückgreifen konnte, reichte vor allem in Wien in den 1920er Jahren nicht aus, um ein dem Bildungsbürgertum angemessenen Lebensstil zu führen. 1918 musste Brecht seine Kinder in einem Sanatorium in Königsfeld in Baden unterbringen, da zu wenig Essen verfügbar war. ${ }^{251}$ Als Hofmannsthal von der finanziellen Lage der Brechts erfuhr, begann er, mit Kleidern und Lebensmitteln auszuhelfen. ${ }^{252} 1921$

$249 \mathrm{Zu}$ Thalmann vgl. Kap. III.

$250 \mathrm{Zu}$ Koch und den genannten Institutionen vgl. Höppner: Wissenschaft und Macht (2010); ders.: Ein „verantwortungsbewußter Mittler“ (1998).

251 Oels: „Denkmal der schönsten Gemeinschaft“ (2007), S. 34-35.

252 Vgl. Erika Brecht: Erinnerungen an Hugo von Hofmannsthal (1946), S. 60-62: „Da kam dieser [Hofmannsthal, E.G.] einmal an einem grauen Novembernachmittag [...] und bat mich um eine Erklärung. [...] So blieb mir denn nichts übrig, als auf die immer eindringlicheren Fragen endlich auch unsere ewige, jahrelange Geldnot zu erwähnen, die mit dem Heranwachsen der Kinder naturgemäß auch immer größer wurde. Als ich Zahlen nannte, fiel unser Freund fast vom Stuhl! Die 
erhielt Brecht einen Ruf an die Universität Frankfurt am Main, den er für Bleibeverhandlungen mit dem österreichischen Unterrichtsministerium nutzte. Das Ministerium bewilligte ihm daraufhin die „systemisierten Höchstbezüge" und eine jährliche Personalzulage von 20.000 Kronen, ${ }^{253}$ was insgesamt ein Jahresgehalt von 399.725 Kronen ergab. ${ }^{254}$ Trotzdem versuchte Brecht wegzukommen. Neben den Sachzwängen war vor allem die immense Arbeitsbelastung dafür verantwortlich. Am 19. November 1925 schrieb er an Paul Kluckhohn:

Es ist ein schneidend schmerzhafter Zirkel: ich bleibe in Wien, weil ich angeblich nichts produziere, und weil ich in Wien bleibe [...] und Arbeiten von Anderen begutachten muß, veröffentlichen Andere, Schüler, meine Ideen und werden bekannt und geschätzt dafür und kommen auf Grund meiner Ideen nach Deutschland womöglich. ${ }^{255}$

Brecht beklagte sich in seinen Briefen an Kluckhohn durchgehend darüber, dass er zu viel zu tun hätte. Mitte der 1920er Jahre kamen darüber hinaus Beschwerden über ,seine' Privatdozenten hinzu, denen er die Verwertung seines ,geistige[n] Eigentum[s] "256 vorwarf.

Dass Brecht ein relativ schmales Oeuvre aufwies, verringerte nicht nur seine Chancen auf eine Professur, sondern wurde auch noch posthum

,Absurdität' war ihm klar geworden, und nun wurde er ganz unglücklich: ,Aber das habe ich ja nicht geahnt, daß es Euch so schlecht geht! In der Stellung! Wer soll denn darauf kommen? [...].' [...] Wie es einem ,Festbesoldeten' auch in glänzender Stellung im Wien der Nachkriegszeit eigentlich erging, das war ihm unvorstellbar. Aber nun begriff er es auf einmal und handelte danach. [...] $\mathrm{Zu}$ Weihnachten [1925, E.G.] erschien ein Korb mit Eßwaren [...]. Dazu aber auch ein Haufen Bücher [...]. [...] Als ich das nächste Mal in Rodaun war, wurde ich von Gerty [Hofmannsthals Ehefrau, E.G.] schüchtern gefragt, ob ich wohl von abgelegten Sachen der Hofmannsthalschen Kinder [...] etwas brauchen könnte. [...] [I]ch wählte begeistert unter Bergen von Bubenmänteln, Jacken, Mützen, Mädchenkleidern und Schuhen aus, was ich brauchen konnte, und es blieb nicht viel übrig."

253 Brief des Bundesministeriums für Inneres und Unterricht an das Dekanat der philosophischen Fakultät der Universität Wien vom 22. Oktober 1921; UAW, Phil. Fak., PA 1113 Walther Brecht. - Der Ausdruck ,systemisiert' meint in der österreichischen Amtssprache so viel wie ,von der Behörde/dem System genehmigt/ zugelassen'.

254 ÖStA, AVA, Unterricht allgemein, Universität Wien, Philosophie Professoren, PA Walther Brecht.

255 Brief von Brecht an Kluckhohn vom 19. November 1925; DLA Marbach, Bestand: Paul Kluckhohn.

256 Brief von Brecht an Kluckhohn vom 19. November 1925; DLA Marbach, Bestand: Paul Kluckhohn. 
beanstandet. In den Nachrufen hieß es entweder verständnisvoll von seinem langjährigen Freund Carl von Kraus, dass ihn „,[d]ie Fülle der an ihn herandrängenden sonstigen Pflichten [...] zu[r] Verwirklichung seiner Pläne nicht kommen “257 ließ, oder süffisant von Josef Nadler, dass man „das Opfer an Zeit und Arbeit, das ihm all [seine] Unternehmungen auferlegten, [...] mitwiegen [müsse], wenn man gegenüber dem äußeren Umfang seines wissenschaftlichen Lebenswerkes gerecht sein will, wie man es muß ${ }^{\text {“258. }}$.

1925 erreichte Brecht nach Rudolf Unger nur den zweiten Platz in Göttingen, ${ }^{259}$ zum Wintersemester 1926/27 wurde er jedoch Ungers Nachfolger in Breslau. Die weit weniger renommierte Professur in Breslau zog Brecht dem Wiener Ordinariat vor. An Carl von Kraus schrieb er diesbezüglich im Oktober 1926:

Mir wird es furchtbar schwer, jetzt von Wien wegzugehn, und von Österreich, wo ich so vieles Unersetzliche zurücklasse, und eine Wirksamkeit aufzugeben, wie sie wohl nur wenigen beschieden ist. Ihre Früchte sind immer mehr in Erscheinung getreten, und wenn es äußerer Zeichen bedurft hätte, hätten die einfachen, herzlichen und mich herzlich beglückenden Kundgebungen von Schülern aus allen Generationen, und auch Kollegen, 1924 und jetzt im Abschiedssemester, auch einige Abschiedsartikel in Zeitungen, mich darüber belehren können. Diese ganze Tätigkeit ruhte auf Ihnen, nicht nur weil Sie mich ins Land gerufen haben.

Ich gebe sie auf und gehe im vollen Bewußtsein eines gefährlichen Experiments in eine nüchterne Gegend, eine glanzlose Stadt und an eine rel[ativ] enge Hochschule, weil die für mich selbst verbleibende Zeit, großenteils gerade infolge der steigenden Wirkung[,] die von der Lehrkanzel ausgeht[,] immer geringer wird und die vorwiegend mündliche Tätigkeit mich, gelinde gesagt, immer weniger befriedigt. Es ist sehr möglich, daß ich nach den großen Auditorien, an die ich jetzt so selbstverständlich gewöhnt bin, u. vor allem nach der herrlichen Aufnahmsfähigkeit der österreichischen Studenten, sowie nach der Atmosphäre des deutschen Südens das größte Heimweh empfinden werde, aber das darf keine Rolle spielen gegenüber der erkannten geistigen und sittlichen Notwendigkeit. Ich versuche, mir gar keine Illusionen zu machen über Breslau, es müßte auch nicht gerade Br. sein, es ist nur der sich gerade bietende Ort von der Art[,] daß ich hoffen kann[,] mich nicht ganz in dem Maß der letzten Jahre den Anforderungen Anderer, so vieler Dissertanten, der 6 Privatdozenten, des Volksbildungsamtes, Bundesverlages pp. hingeben zu müssen. In all solchen Dingen habe ich reichlich soviel zu thun gehabt als

257 Kraus: Walther Brecht [Nekrolog] (1950), S. 184.

258 Nadler: Walther Brecht [Nekrolog] (1951), S. 382-383.

259 Roethe/Schröder: Regesten zum Briefwechsel (2000), Bd. 2, S. 870 (Brief von Edward Schröder an Gustav Roethe vom 25. September 1925). 
beispielsweise Petersen ${ }^{260}$ der diesen Sommer 5 Dissertanten hatte, und die Technik des Urlaubnehmens war für mich schon aus pekun. Gründen hier nicht möglich.[...]

Die Zukunftsfrage für mich ist die, ob und wie rasch es mir gelingen wird, an anderem Orte, unter Verhältnissen die namentlich in materieller Hinsicht leichter, aber mir auch fremdgeworden sein werden, den nicht ausgemünzten Rohertrag dieser meiner innerlich produktivsten u. reichsten Jahre wenigstens teilweise in Buchform zu bringen. Hoffentlich bin ich nicht mittlerweile so an die Rieseneditionen und das Mitwirken an allen Kulturdingen (notgedrungen!) gewöhnt, daß es mir schwer fällt, darauf zu verzichten. Hypertroph auf der einen Seite, muß ich die andere damit wieder in Übereinstimmung bringen. Lehrer u. fertigstellender Forscher gleichmäßig ist das Gottgewollte, das ich wieder erreichen muß, womöglich auf recht günstigem Boden, wenn nicht, auf kargem. ${ }^{261}$

Lange blieb Brecht jedoch nicht in Breslau. Mit 1. Oktober 1927 wechselte er nach München, wohin er nach komplizierten Auseinandersetzungen um die Nachfolge des durch den Tod Franz Munckers vakant gewordenen Lehrstuhls unter maßgeblicher Schützenhilfe von Carl von Kraus und Hugo von Hofmannsthal berufen wurde. ${ }^{262}$ Damit war für Brecht scheinbar die ideale Wirkungsstätte gefunden, da er, wie er Kraus im März 1927 erfreut mitteilte, mit der Münchner Professur sowohl seinen „Wunsch[ ], den übergroß gewordenen Wiener Wirkungskreis [...] zu verkleinern“, erfüllt sah als auch ,in dem [ihm] lieb und vertraut gewordenem bairisch-österreichischen Milieu“ wirken konnte. ${ }^{263}$ Tatsächlich hielt sich das Ausmaß der Arbeitsbelastung in München im Vergleich zu demjenigen in Wien in Grenzen. Innerhalb von zehn Jahren hatte Brecht ,nur 52 Dissertationen zu begutachten, durchschnittlich demnach fünf pro Jahr, also nicht einmal ein Fünftel so viele wie in Wien. Mit insgesamt zwei Habilitationen ${ }^{264}$ waren auch die Betreuungspflichten Privatdozenten gegenüber nicht allzu groß. ${ }^{265}$

260 Der Germanist Julius Petersen (1848-1941) war seit 1920 der Nachfolger von Erich Schmidt an der Friedrich-Wilhelms-Universität in Berlin. Zu Petersen vgl. Boden: Julius Petersen (1994).

261 Brief von Brecht an Kraus vom 4. und 24. Oktober 1926; BSB München, Nachlass Carl von Kraus, Krausiana I.

262 Vgl. Osterkamp: „Verschmelzung der kritischen und der dichterischen Sphäre“ (1989).

263 Brief von Brecht an Kraus vom 9. März 1927; BSB München, Nachlass Carl von Kraus, Krausiana I.

264 Walther Rehm und Johannes Alt.

265 Zur Anzahl der von Brecht betreuten Münchner Dissertationen und Habilitationen vgl. Bonk: Deutsche Philologie in München (1995), S. 244-245. 
Mit dem Machtantritt der Nationalsozialisten 1933 wurde Brechts Lage jedoch zusehends schwieriger. Bereits 1934 versuchte die Hochschulkommission der NSDAP Brecht, den sie als „untragbar und nicht mehr dienstfähig “266 bezeichnete, von seiner Professur zu entfernen. Endgültig in den zwangsweisen Ruhestand versetzt wurde Brecht im Juli 1937 aufgrund des ,Gesetzes zur Wiederherstellung des Berufsbeamtentums' wegen "nichtarischer Ehefrau“. ${ }^{267}$ Brecht blieb mit seiner Frau während der Zeit des Nationalsozialismus in München, wo er am 1. Juni 1950 starb.

In Wien hatte Brecht in den 1910er und 1920er Jahren den Übergang zur Massenuniversität geleitet und dafür gesorgt, dass die methodische Ausweitung und Differenzierung des Fachs nicht zu einer zum Stillstand führenden Machtdemonstration widerstreitender Akteure wurden, indem er sich, wie selbst Nadler in seinem Nachruf zugeben musste, ,aus den völlig unergiebigen ,Richtungskämpfen' nach 1918 herausgehalten “268 hatte. Brecht trat nicht durch ein ausgeprägtes eigenes wissenschaftliches Profil hervor; er schlug sich weder auf die Seite der Wissenschaftler, die die ,alte' philologische Ausrichtung vertraten, noch auf die Seite derer, die eine unbedingt geistesgeschichtliche Neuorientierung des Fachs propagierten. Vielmehr vereinte er eine "philologische und gleichzeitig moderat geistes-

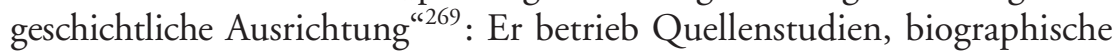
Forschungen und Textkritik, war aber an keiner der großen Autoreneditionen beteiligt und lieferte keine reinen Materialsammlungen. Zugleich war Brecht vom ersten Heft an einer der Mitherausgeber der von Paul Kluckhohn und Erich Rothacker geleiteten Deutschen Vierteljahrsschrift für Literaturwissenschaft und Geistesgeschichte, ${ }^{270}$ in der, wie es zielsetzend im Eröffnungsband heißt, „[n]eben der geistesgeschichtlichen Richtung, vornehmlich Diltheyscher Schule, [...] besonders die form- und stilanalytische gepflegt werden “271 sollte. Für die Literaturgeschichte als reine Geistesgeschichte interessierte sich Brecht aber, wie Cysarz in Bezug auf

266 Aktennotiz vom 31. Oktober 1934 (Referent Dr. v. Kloeber); zit. n. Bonk: Deutsche Philologie in München (1995), S. 82.

267 UAM, PA Walther Brecht; zit. n. Oels: „Denkmal der schönsten Gemeinschaft“ (2007), S. 80. Zu Brechts Amtsenthebung vgl. auch Bonk: Deutsche Philologie in München (1995), S. $81-83$.

268 Nadler: Walther Brecht [Nekrolog] (1951), S. 381.

269 Oels: „Denkmal der schönsten Gemeinschaft“ (2007), S. 30.

270 Brecht erscheint von 1923 bis 1936 auf dem Titelblatt der Zeitschrift.

271 [Kluckhohn/Rothacker:] Vorwort [zum ersten Heft der Deutschen Vierteljahrsschrift] (1923), S. VI. 
seine programmatische Schrift Literaturgeschichte als Geisteswissenschaft von 1926 bemerkte, „mehr rezeptiv als aktiv; sie erschien ihm zukunftshaltig, ohne daß er die Neugermanistik mit den neuen Sichten identifiziert wissen wollte “272. Über zeitgenössische Bemühungen, allein den Kunstwerkcharakter von Literatur zum Gegenstand der Forschung zu machen, schrieb Brecht 1924 an Kluckhohn: „Die meisten Kollegen sind teils modern verrannt, teils altmodisch verstockt, ich traue Wenigen ein wirklich künstlerisches Urteil zu (am wenigsten dem instinktlosen Walzel, über dessen ästhetische Bemühungen man manchmal lächeln sieht, u. nicht ganz mit Unrecht). “273

Brecht selbst nahm zumeist eine Zwischenposition ein. In seinen Beiträgen über Hugo von Hofmannsthal bemühte er sich, sowohl literarischen als auch wissenschaftlichen Erkenntnisansprüchen zu genügen; in seinem Buch Conrad Ferdinand Meyer und das Kunstwerk seiner Gedichtsammlung von 1918 versuchte er, ausgedehnte Quellenstudien und Materialsammlungen (denen zeitgenössisch zumeist ein Mangel an Synthese vorgeworfen wurde) anhand seiner These vom besonderen Bedeutungszuwachs einer Gedichtsammlung durch deren Struktur und Komposition zu einer, das gesammelte Material vereinigenden Erzählung zu verbinden. Mit Blick auf die wissenschaftsinternen Auseinandersetzungen und die Verfasstheit des Fachs Deutsche Philologie im ersten Drittel des 20. Jahrhunderts lässt sich Brecht als Übergangs- und Integrationsfigur begreifen. Besonderen Nachruhm oder Einfluss auf die Wissenschaftsgeschichte der Germanistik bescherte ihm diese Haltung nicht. ${ }^{274}$ Für die Wiener Germanistik lässt sich aber feststellen, dass bis zur Bildungsexpansion in den 1970er Jahren nicht mehr so viele und vor allem nicht so unterschiedliche Wissenschaftler innerhalb so kurzer Zeit in der neueren Abteilung habilitiert wurden und dass darüber hinaus nie wieder zwei oder mehr Privatdozentinnen der Neueren deutschen Literaturwissenschaft gleichzeitig am Institut tätig waren.

272 Cysarz: Vielfelderwirtschaft (1976), S. 37.

273 Brief von Brecht an Kluckhohn vom Ostermontag 1924; DLA Marbach, Bestand: Deutsche Vierteljahrsschrift.

274 So stellte David Oels fest, dass die „Erklärung“, warum über Brecht „in Anbetracht seines schmalen und eher unbedeutenden wissenschaftlichen Werkes" überhaupt geforscht wird, allein in seiner „Freundschaft mit Hugo von Hofmannsthal“ zu finden sei. Oels: „... denn unsere Berufe sind doch so ineinander verhäkelt“ (2007), S. 50. 


\section{I.4. Paul Kluckhohn, Josef Nadler und das Ende der Privatdozenten}

Nachdem Walther Brecht erfahren hatte, dass er für die Breslauer Professur in Betracht kam, traf er umgehend Vorbereitungen, seinen langjährigen Freund und Korrespondenzpartner Paul Kluckhohn als seinen Nachfolger auf der Wiener Lehrkanzel in Stellung zu bringen. Bereits am 31. Jänner 1926, nach Brechts Erstreihung durch die philosophische Fakultät in Breslau, aber noch bevor der definitive Ruf des preußischen Ministeriums an ihn ergangen war, schrieb er Kluckhohn: „, [I]ch [werde] alles thun was in meinen Kräften steht, um dich hierher zu bringen. " 275 Dass der scheidende Ordinarius seinen Nachfolger selbst bestimmen wollte, hatte an der Wiener Germanistik Tradition. ${ }^{276}$ Bei der Nachfolge Brechts entsprach diese Vorgehensweise aber nicht mehr dem bis zum Beginn des 20. Jahrhunderts bewährten Muster ,Österreicher - Schüler des Vorgängers - Katholik‘. Vielmehr waren Brechts erfolgreiche Bemühungen um Kluckhohn zum einen ein erneutes Beispiel seiner wissenschaftliche Haltung, die auf den Ausgleich widerstreitender fachlicher Bestrebungen zielte, zum anderen zeigen sie aber auch die zunehmende Politisierung innerhalb der Wiener Professorenschaft, die fast ausschließlich nach rechts erfolgte. ${ }^{277}$

Eine der ersten Anstrengungen, die Brecht in dieser Nachfolgeangelegenheit unternahm, zielte auch gerade darauf ab, seine Professorenkollegen an der philosophischen Fakultät von der, politischen Zuverlässigkeit seines Kandidaten, d.h. von dessen ,deutscher Haltung' zu überzeugen. Welches Selbstverständnis und welche Feindbilder die durchweg antisemitisch, antidemokratisch, antisozialistisch und reaktionär gesinnte Wiener Professorenschaft bereits Mitte der 1920er Jahre kreierte, wird aus einem Brief Brechts an Kluckhohn deutlich, in dem dieser im Frühjahr 1926 über eine von ihm organisierte konspirative Sitzung berichtete:

In einer langdauernden inoffiziellen Besprechung der mir nahestehenden nationalen Kollegen (die z.T. durch das Überhandnehmen kosmopolit.-jüdischen internation. Pazifismus erschreckt sind), Dopsch, Much, Srbik, Luick, Kralik, Pfalz, wurde, nachdem $\mathrm{m}$. Vorschläge gutgeheißen, der Sicherheit wegen verabredet, von dir, dem man höchst geneigt ist an 1 . Stelle vorzuschlagen, eine Äußerung zu erbitten, aus der hervorgeht, daß du nicht mit den

275 Brief von Brecht an Kluckhohn vom 31. Jänner 1926; DLA Marbach, Bestand: Paul Kluckhohn.

276 Vgl. Kap. I.1.

277 Vgl. dazu Meissl: Germanistik in Österreich (1981); Taschwer: Hochburg des Antisemitismus (2015). 
Vertretern jener Weltanschauung konform denkst u. dem jüdisch-sozialdemokratischen Geist entgegen bist, wie er auch bei uns in gewissen Fakultätsgruppen hervortritt. Man will natürlich vor undeutschen Überraschungen gesichert sein, hier in Wien äußerst begreiflich.

Ich habe gesagt, du hättest mir die erforderl. Garantien schriftlich u. bes. mündlich gegeben, sie möchten aber gern eine nochmalige schriftl. Äußerung von dir, wegen der anderen, nämlich der Heißsporne in der eignen Partei. Kralik hat sich erboten, dir einen Brief zu schreiben, unter meiner u. aller Anwesenden Zustimmung, diesen Brief wirst du demnächst erhalten. Du kannst ruhig und ohne Bedenken vor Gewissenszwang antworten u. mit wenigen Worten auf deine natürliche nationale Weltanschauung hinweisen. Es ist hier eben ein heißer Boden in Staat, Stadt, Univers, Kultur, u. die Kollegen, nach schlechten Erfahrgn gerade mit reichsdtschen Professoren der letzten Jahre, wollen gern sicher gehen, daß keiner kommt, der, wie Minor, einen demokrat.-jüd. Priv.dozenten nach dem andern macht oder für marxist. Schulreform, Universitätsbolschewisierung (allen Ernstes!) stimmt, sondern die Lage Wiens im gefährdeten Südosten erkennt u. e. gewissen Kulturkonservatismus einhälst [!], wie ich. Dies zur Orientierung! ${ }^{278}$

Nachdem der Altgermanist Dietrich Kralik die von Brecht angekündigten brieflichen Bestätigungen für Kluckhohns Weltanschauung eingeholt hatte, ${ }^{279}$ bedurfte es nur mehr einer einzigen offiziellen Sitzung der Berufungskommission, um Kluckhohn einstimmig an erster Stelle dem Professorenkollegium vorzuschlagen. ${ }^{280} \mathrm{Im}$ Bericht an das Ministerium, den Brecht als Referent am 5. Juni 1926 verfasste, war von den politischen Vorsondierungen freilich keine Rede mehr. Dass im Ministerium eine deutschfreundliche und der Eigenständigkeit Österreichs nicht unbedingt wohlgesonnene Haltung vorherrschte, lässt sich aus Brechts - im Vergleich zu den inoffiziellen Besprechungen - eher dezent gehaltenen Formulierungen trotzdem schließen. So wurde gleich zu Beginn des Berichts festgehalten, dass für die Wiener Professur nur ein "Gelehrter“ in Frage

278 Brief von Brecht an Kluckhohn, o.D. [Frühjahr 1926]; DLA Marbach, Bestand: Paul Kluckhohn. - Von den genannten „nationalen Kollegen“ gehörten zumindest der Historiker Heinrich Srbik sowie die Germanisten Dietrich Kralik, Rudolf Much und Anton Pfalz einem an der philosophischen Fakultät einflussreichen antisemitischen Netzwerk an, außerdem waren sie, wie auch der Historiker Alfons Dopsch, Mitglieder der deutschnationalen und antisemitischen Vereinigung Deutsche Gemeinschaft. Vgl. Taschwer: Hochburg des Antisemitismus (2015), S. 99-132; Rosar: Deutsche Gemeinschaft (1971).

279 Vgl. die Briefe von Dietrich Kralik an Paul Kluckhohn von 1926; DLA Marbach, Bestand: Paul Kluckhohn 68.812/1-4.

280 Sitzungsprotokoll der Kommission zur Beratung über die Wiederbesetzung der Lehrkanzel für deutsche Sprache und Literatur nach Professor Dr. Walther Brecht vom 21. Mai 1926; UAW, Phil. Fak., PA 2216 Paul Kluckhohn. 
komme, der zwar „innerhalb Österreichs Bescheid“ wisse und der „Verständnis [...] für die besondere Sendung Österreichs" habe, der aber vor allem „über dessen jetzige Grenzen hinausgehen“ könne, also „wie ein Gesandter der übrigen Deutschen bei diesem deutschen Stamme zu wirken im Stande" sei. ${ }^{281}$

Neben der politischen Ausrichtung ging Brecht auf die vom ihm gewünschte innerfachliche Positionierung seines potentiellen Nachfolgers ein. Dabei verfolgte Brecht seiner eigenen Auffassung entsprechend das Konzept einer diplomatischen und konsensfähigen Wissenschaftsanschauung. So sollte sein Nachfolger kein „Anhänger extremster Richtungen" sein, sondern

noch unausgegorenen extremen Lehrmeinungen fernstehend, von dem soliden Boden philologischer und historischer Auffassung und Ausbildung ausgehend, womöglich auch den Methoden der Altgermanistik nicht fremd, im Stande [sein], das Berechtigte und Unberechtigte gegenwärtig lebendiger Strömungen mit reifem Urteil zu scheiden und nur dasjenige, was seiner ruhigen Prüfung standgehalten hat, aufzunehmen und so zu einer wissenschaftlich haltbaren Synthese historischer und begrifflicher Art zu gelangen. ${ }^{282}$

Als „zweifellos hervorragendst geeignete Persönlichkeit“, die sowohl politisch als auch aufgrund ihrer Wissenschaftsauffassung allen Anforderungen gerecht würde, wurde Paul Kluckhohn präsentiert, da er sich ebenso durch „[s] eine gesamtdeutsche Einstellung“ auszeichne wie durch „seine Verbindung von Philologie und Geistesgeschichte, von neuerer mit alter Germanistik“ und durch „seine vernünftige mittlere Haltung in den gegenwärtigen Kämpfen innerhalb der Disziplin“.

Die beiden Wiener Anwärter auf die Professur Eduard Castle und Robert Franz Arnold fertigte Brecht nebenbei ab (zu „enge[ ] Spezialisten“). Ähnliches widerfuhr den beiden gefährlichsten Konkurrenten Kluckhohns

281 Bericht der Kommission betreffend der Wiederbesetzung der Lehrkanzel für deutsche Sprache und Literatur nach Professor Brecht vom 5. Juni 1926 (Abschrift); UAW, Phil. Fak., PA 2216 Paul Kluckhohn. - Politische Interessen spielten bei Wiener Lehrstuhlbesetzungen auch schon im letzten Drittel des 19. Jahrhunderts eine Rolle. Nur war man bei diesen im Gegensatz zu den 1920er Jahren noch daran interessiert, niemanden zu berufen, der ,in intime[r] Verbindung mit den hiesigen ,deutschnationalen' Burschenschaften" stand bzw. ein „politische[r] Gesinnungsverwandte[r]" Scherers war. Vgl. Scherer/Schmidt: Briefwechsel (1963), S. 155-157.

282 Bericht der Kommission betreffend der Wiederbesetzung der Lehrkanzel für deutsche Sprache und Literatur nach Professor Brecht vom 5. Juni 1926 (Abschrift); UAW, Phil. Fak., PA 2216 Paul Kluckhohn. 
Julius Petersen ${ }^{283}$ und Josef Nadler: „[A]uf den hervorragenden Vertreter des Faches in Berlin (Petersen) “ müsse, laut Brecht, von vornherein „verzichtet werden“, „um nicht unnötigen Zeitverlust durch finanziell aussichtslose Verhandlungen entstehen zu lassen“. Nadlers Name kam in dem Bericht erst gar nicht vor; in einem einzigen Satz wurde aber auch er aus der Anwärterliste gestrichen:

Die stammeskundliche Richtung innerhalb der deutschen Literarhistorie erscheint dem Referenten, wie den nahestehenden Fachgenossen, in ihren wissenschaftlichen Grundlagen nicht gefestigt genug, um sie an so verantwortungsvoller Stelle als die hier wünschenswerteste zu empfehlen. ${ }^{284}$

Dass Kluckhohn nach diesem von Brecht moderierten Schnellverfahren das Wiener Ordinariat trotzdem erst zum Sommersemester 1927 und nicht, wie geplant, zum vorhergehenden Wintersemester antrat, war keinen Einsprüchen durch Kollegen oder das Ministerium geschuldet, sondern einem Ministerwechsel, der die Erledigung der Amtsgeschäfte verzögerte. ${ }^{285}$

Paul Kluckhohn war zum Zeitpunkt seiner Berufung nach Wien ordentlicher Professor an der Technischen Hochschule Danzig. Er hatte davor in Heidelberg, München, Göttingen und Berlin Germanistik, Geschichte und Klassische Philologie studiert, 1909 mit der historischen Arbeit Die Ministerialität in Südostdeutschland vom 10. bis zum Ende des 13. Jahrhunderts bei Karl Brandi in Göttingen promoviert und sich im November 1913 in Münster für das Gesamtfach der Deutschen Philologie habilitiert. Die dafür eingereichte Arbeit Die Auffassung der Liebe in der Literatur des 18. Jahrhunderts und in der deutschen Romantik konnte kriegsbedingt erst 1922 erscheinen, erfuhr aber bereits 1931 eine zweite Auflage und etablierte zusammen mit der 1923 erfolgten Gründung der Deutschen Vierteljahrsschrift für Literaturwissenschaft und Geistesgeschichte Kluckhohns Ruf als ebenso geistesgeschichtlich wie auch philologisch versiertem Forscher. In den Nachrufen wurde gerade auch darauf hingewiesen, dass Kluckhohn nicht nur als „Hauptvertreter der sogenannten geistesgeschichtlichen Richtung“ zu sehen sei, sondern auch als „sorgfältige[r] und wohlgeschulte[r] Philologe[ ]“,286 dass ihn mithin „Offenheit

283 Zu Petersen vgl. Boden: Julius Petersen (1994).

284 Alle Zitate: Bericht der Kommission betreffend der Wiederbesetzung der Lehrkanzel für deutsche Sprache und Literatur nach Professor Brecht vom 5. Juni 1926 (Abschrift); UAW, Phil. Fak., PA 2216 Paul Kluckhohn.

285 Briefe von Brecht an Kluckhohn vom 29. Juni und 3. Juli 1926; DLA Marbach, Bestand: Paul Kluckhohn.

286 Meister: Paul Kluckhohn [Nachruf] (1961), S. 360-361. 
für jede begründete Meinung und Methode “287 auszeichnete. ${ }^{288}$ In Wien übernahm Kluckhohn neben dem Altgermanisten Dietrich Kralik sogleich die Leitung des Seminars für Deutsche Philologie, ${ }^{289}$ gab ab 1928 die erste historisch-kritische Novalis-Ausgabe heraus und war ab 1931 im Rahmen des Sammelwerks Deutsche Literatur in Entwicklungsreihen für elf Bände der Reihe Romantik als Herausgeber verantwortlich. ${ }^{290}$ In der Lehre konzentrierte sich Kluckhohn auf die Literatur der deutschen Romantik, er las aber auch über das Drama des 17. und 18. Jahrhunderts, über die Geschichte des Romans vom 16. bis zum 19. Jahrhundert und über Gegenwartsliteratur. ${ }^{291}$

Kluckhohns Amtszeit fiel in eine Phase massiver nationalsozialistisch, antisozialistisch und antisemitisch bedingter Studierendenunruhen in Wien, in denen Hakenkreuz- und Heimwehr-Studierende ihre sozialistischen und jüdischen Kommilitonen und Kommilitoninnen verfolgten, verprügelten und aus dem Universitätsgebäude vertrieben. ${ }^{292}$ Wie eng die Verbindung zwischen Studierenden und Lehrenden aus dem völkischdeutschnationalen Lager war, offenbarte sich spätestens, als der damalige Rektor der Wiener Universität Wenzel Gleispach 1930 eine neue Studentenordnung erließ. Darin wurden die Studierenden - unabhängig von ihrer Staatsbürgerschaft - nach ihrer „Volkszugehörigkeit“ bzw. „Abstammung " in die „Deutsche Studentenschaft" und die „gemischte Stu-

287 Binder: Paul Kluckhohn [Nachruf] (1958), S. 224.

$288 \mathrm{Zu} \mathrm{Kluckhohns} \mathrm{Bedeutung}$ für die zeitgenössische Romantikforschung vgl. Klausnitzer: Blaue Blume unterm Hackenkreuz (1999); zu Konzept und Geschichte der Deutschen Vierteljahrsschrift für Literaturwissenschaft und Geistesgeschichte vgl. Rothacker: Rückblick und Besinnung (1956); Dainat/Kolk: Das Forum der Geistesgeschichte (1995).

289 Ernennungsdekret des Bundesministeriums für Unterricht für Paul Kluckhohn vom 25. November 1926; UAW, Phil. Fak., PA 2216 Paul Kluckhohn.

290 Das waren: Lebenskunst (1931); Weltanschauung der Frühromantik (1932); Frühromantische Erzählungen 1 (1933); Frühromantische Erzählungen 2 (1933); Deutsche Vergangenheit und deutscher Staat (1935); Dramen der Frühromantik (1936); Vorbereitung (1937); Dramen von Zacharias Werner (1937); Dramen von Clemens Brentano und Achim von Arnim (1938); Dramen von Achim von Arnim und Joseph von Eichendorff (1938); Lustspiele (1938); Charakteristiken (1950).

291 Vgl. Öffentliche Vorlesungen an der Universität zu Wien (1927-1931).

292 Zur Studierendengeschichte in der ersten Hälfte des 20. Jahrhunderts vgl. Speiser: Die sozialistischen Studenten Wiens (1986); Lichtenberger-Fenz: „... deutscher Abstammung und Muttersprache" (1990); Zoitl: „Student kommt von Studieren!“ (1992); Posch/Ingrisch/Dressel: „Anschluß“ und Ausschluss (2008); Grabenweger: Literatur - Politik - Universität [erscheint 2016]. 
dentenschaft" unterteilt. ${ }^{293}$ Dabei handelte es sich um die Herstellung von „Zwangsgemeinschaften“294 nach völkisch-rassischen Gesichtspunkten, mithin um die Einteilung der Studierenden in ,arisch' und ,nichtarisch ‘. ${ }^{295}$ Wie aus den Erinnerungen der damaligen Germanistikstudentin und späteren Deutschlehrerin Minna Lachs hervorgeht, war auch Kluckhohns Verhalten gegenüber Studierenden nicht frei von antisemitischen oder zumindest antipolnischen Ressentiments; gleichzeitig verweigerte er aber den Schlägertruppen der deutschnationalen Studentenschaft seine Unterstützung:

Ich war im 3. Semester [Wintersemester 1928/29, E.G.], als ich mich bei Prof. Kluckhohn zu einem Kolloquium anmeldete. Er hielt die Prüfungen in Dreiergruppen ab und gestattete Studierenden zuzuhören. Ich war in einer Gruppe mit zwei ahnungslosen Studenten, die sich anscheinend auf ihre Schmisse verlassen hatten. Der eine schüttelte bei der ersten Frage den Kopf und tat den Mund fast nicht auf, und die Frage ging an den zweiten Prüfling über, der Unzusammenhängendes murmelte, und die Frage landete bei mir, ich beantwortete sie richtig und ausführlich. Das ging so eine Weile, bis sich der Professor erhob. Wir folgten ihm alle drei, von Freunden begleitet, zum Dekanat, um die Zeugnisse entgegenzunehmen. Die beiden Burschen hatten ein „Gut", und ich war nur gerade durchgekommen. „Das muß ein Irrtum sein“, sagten die beiden Kollegen, „wir warten mit Ihnen, bis der Herr Professor herauskommt und Sie ihn gleich fragen können." Nach einigem Sträuben gab ich nach. Ich hielt Prof. Kluckhohn mein Zeugnis hin und sagte: „Ich habe doch alle Fragen beantwortet, Herr Professor, ist dies nicht ein Irrtum?" Er antwortete nicht und ging hoch erhobenen Hauptes an mir vorbei, als ob ich Luft wäre. Die umstehenden waren betroffen, aber ich nicht, denn ich wußte, was es bedeutete, im Meldebuch, in der Spalte Geburtsort, "Trembowla, Polen“ stehen zu haben.

Jeden Samstag hatten die deutsch-nationalen Studenten der schlagenden Verbindungen ihren Korso in den Wandelgängen der Universität. Anschließend stürmten sie die Hörsäle mit dem Ruf: „Juden raus!“ Ich wußte von keinem Professor, der sich ihnen entgegengestellt hätte. Daher war ich auch sehr erstaunt über das Verhalten von Professor Kluckhohn, als sie in seine

293 Studentenordnung der Universität Wien vom 8. April 1930; zit. n. LichtenbergerFenz: „... deutscher Abstammung und Muttersprache“ (1990), S. 91. Zur Einführung dieser Studentenordnung, den Reaktionen darauf und zu ihrer Wiederabschaffung 1931 vgl. ebd., S. 84-138.

294 So Josef Hupka, Professor der Rechte an der Universität Wien, in der Neuen Freien Presse vom 23. April 1930. Hupka: Die Studentenordnung der Universität Wien (1930), S. 1.

295 Nach massiven Protesten und einem Verfahren vor dem Verfassungsgerichtshof wurde die Studentenordnung am 20. Juni 1931, ein Jahr nach Inkrafttreten, für ungesetzlich erklärt und aufgehoben. 
Vorlesung eindrangen. Wieder schrien sie ihr "Juden raus“. Da nahm der Professor seine Skripten und sagte ruhig und laut: „Wir gehen alle.“296

Die Privatdozenten, die sich bei seinem Vorgänger Brecht habilitiert hatten, wurden von Kluckhohn weiter gefördert. ${ }^{297} 1929$ erhielt außerdem Brechts ehemaliger Dissertant, der Frühe-Neuzeit-Forscher Hans Rupprich die Venia Legendi. ${ }^{298}$ Mit Rupprich hatten sich seit 1900 insgesamt zehn Wissenschaftler und Wissenschaftlerinnen in Wien allein für die neuere Abteilung habilitiert: drei bei Jakob Minor (Robert Franz Arnold 1900, Stefan Hock 1905, Eduard Castle 1907); sechs, darunter die ersten Frauen, bei Walther Brecht (Rudolf Payer von Thurn 1921, Christine Touaillon 1921, Herbert Cysarz 1922, Marianne Thalmann 1924, Heinz Kindermann 1924, Franz Koch 1926) und einer (Hans Rupprich) bei Paul Kluckhohn. Die ältere Abteilung (inklusive der ihr angegliederten Sprachwissenschaft) zählte seit der Jahrhundertwende immerhin fünf Privatdozenten und eine Privatdozentin (Viktor Junk 1906, Dietrich Kralik 1914, Anton Pfalz 1919, Lily Weiser 1927, Edmund Wießner 1927, Walter Steinhauser 1927). Die Attraktivität der älteren Abteilung, die gegenüber dem neueren Fach zunehmend ins Hintertreffen geriet, wurde vor allem durch den Altertumskundler Rudolf Much aufrechterhalten, der neben Josef Seemüller und später Dietrich Kralik - den beiden Ordinarien für das ältere Fach - für zwei der sechs Habilitationen (Pfalz, Steinhauser) mitverantwortlich, in zwei Fällen (Kralik, Weiser) hauptverantwortlich war. Mit vier weiteren Privatdozenten in den 1930er Jahren (Otto Höfler 1932, Rudolf Kriss 1933, Siegfried Gutenbrunner 1936, Richard Wolfram 1936) war Much unter den Wiener Altgermanisten sowohl universitätspolitisch als auch in der wissenschaftlichen Definition des Fachs der erfolgreichste. ${ }^{299}$

Während die Anzahl der Privatdozenten seit der Jahrhundertwende kontinuierlich anstieg, waren der Status und die Bedeutung der Privatdozentur einem gesellschaftlichen und universitätsorganisatorischen Abstieg unterworfen, der das Prestige und die konkrete pekuniäre Situation

296 Lachs: Warum schaust du zurück (1986), S. 151-152.

297 Vgl. die Briefe Brechts an Kluckhohn (DLA Marbach; Bestände: Paul Kluckhohn; Deutsche Vierteljahrsschrift), in denen sich die beiden Germanisten über das akademische Fortkommen der Privatdozenten austauschen.

298 Aufgrund der Arbeit Willibald Pirckheimer und Dürers erste Reise nach Italien (1930), in der Rupprich in einer ausführlichen Würdigung Walther Brecht als seinem maßgeblichen Lehrer huldigte.

299 Zu Rudolf Much und zur Wiener Altgermanistik vgl. Kap. IV.1. 
dieser Berufsgruppe ebenso betraf wie ihre Lehrverpflichtung. Bis zum Ende des 19. Jahrhunderts war die Privatdozentur nur eine Übergangsphase, auf die nach einigen Jahren unweigerlich und zumeist über den Umweg eines Extraordinariats eine besoldete ordentliche Professur folgte. Karl Tomaschek, der erste Habilitand der Wiener Germanistik, erhielt die Venia Legendi 1855 und wurde 1862 Professor in Graz; Wilhelm Scherer habilitierte sich 1864 und erhielt 1868 das Wiener Ordinariat; Josef Seemüllers Habilitation von 1879 folgte 1890 die Berufung nach Innsbruck; August Sauer habilitierte sich ebenfalls 1879, wurde 1886 Extraordinarius und 1892 Ordinarius in Prag; Jakob Minor erhielt 1880 die Venia Legendi und wurde nach außerordentlichen Professuren in Prag und Wien 1888 Ordinarius in Wien. Die beiden nächsten Privatdozenten waren die ersten Juden, die sich an der Wiener Germanistik habilitierten. Bei ihnen funktionierte der dargestellte Karriereverlauf zunächst zwar, aufgrund des bereits gegen Ende des 19. Jahrhunderts um sich greifenden universitären Antisemitismus jedoch nicht vollständig: ${ }^{300}$ Alexander von Weilen habilitierte sich 1887, erhielt 1899 den Titel eines außerordentlichen Professors, wurde 1904 zum besoldeten außerordentlichen Professor ad personam ernannt und 1909 mit dem Titel eines ordentlichen Professors ausgestattet. Der 1914 von der philosophischen Fakultät in Wien gestellte Antrag auf Ernennung von Alexander von Weilen zum ordentlichen Professor wurde jedoch nie entschieden. Max Hermann Jellinek habilitierte sich 1892, wurde 1900 zum außerordentlichen Professor ad personam ernannt und erhielt 1906 den Titel eines ordentlichen Professors. Sowohl Weilen als auch Jellinek hatten die gewohnte Privatdozentenlaufbahn des 19. Jahrhunderts durchschritten - bis zu dem Punkt, an denen ihnen ein fixes Ordinariat zugesprochen werden sollte: Beide erhielten im Unterschied zu ihren nicht-jüdischen Generationskollegen nur den Titel, nicht den Lehrstuhl eines ordentlichen Professors. ${ }^{301}$

Die letzten Wiener Habilitanden, bei denen der gewohnte Karriereverlauf noch funktionierte, waren Rudolf Much (Habilitation 1893, ordentliche Professur ad personam 1906 in Wien), Carl von Kraus (Habilitation 1894, ordentliche Professur 1904 in Prag), Oskar Walzel (Habilitation 1894, ordentliche Professur 1897 in Bern) und Konrad

$300 \mathrm{Zu}$ Judentum und Antisemitismus in der österreichischen Germanistik im 19. Jahrhundert vgl. Michler: Lessings „Evangelium der Toleranz“ (2003).

$301 \mathrm{Zu}$ den antisemitischen Ausschlussmechanismen und deren personalpolitischen Konsequenzen an der Wiener Universität nach 1918 vgl. Taschwer: Hochburg des Antisemitismus (2015); Ehs: Das extramurale Exil (2011). 
Zwierzina (Habilitation 1897, ordentliche Professur 1899 in Fribourg). Danach begann das Zeitalter der ewigen Privatdozenten bzw. der Privatdozentur als „Nebenbeschäftigung “302, die zusätzlich zu einem Brotberuf ausgeübt wurde. Rudolf Wolkan hatte sich 1896 in Czernowitz habilitiert, ließ seine Venia Legendi 1902 nach Wien übertragen und erhielt 1908 den Titel eines außerordentlichen Professors, kam über diesen Status jedoch nicht hinaus. Er finanzierte seinen Lebensunterhalt zunächst als Lehrer, danach als Bibliothekar. ${ }^{303}$ Theodor von Grienberger habilitierte sich 1898 in Wien, erhielt 1906 den Titel eines außerordentlichen Professors in Czernowitz, war aber Zeit seines Lebens hauptberuflich ebenfalls Bibliothekar. ${ }^{304}$

Ähnliches lässt sich über die nächsten vier Wiener Habilitanden sagen: Robert Franz Arnold (Venia Legendi 1900), Stefan Hock (Venia Legendi 1905), Viktor Junk (Venia Legendi 1906) und Eduard Castle (Venia Legendi 1907) bekleideten Zeit ihrer regulären Laufbahn nie einen ordentlichen Lehrstuhl. Arnold, der 1895 vom Judentum zum Protestantismus konvertierte, erhielt 1906 den Titel eines außerordentlichen Professors, seine Ernennung zum wirklichen ordentlichen Professor wurde aber zweimal (1927 und 1931) abgelehnt, 1934 wurde er im österreichischen Ständestaat zwangspensioniert. ${ }^{305}$ Hock war nach seiner Habilitation vor allem publizistisch tätig, arbeitete als Dramaturg am Wiener Burgtheater, als Mitarbeiter Max Reinhardts am Deutschen Theater in Berlin und übernahm 1934 das Wiener Raimundtheater. 1938 wurde ihm als Jude von den Nationalsozialisten die Venia Legendi aberkannt. ${ }^{306}$ Junk erhielt 1926 zwar noch den Titel eines außerordentlichen Professors, war hauptberuflich aber bereits seit 1900 bis zu seiner Pensionierung 1945 Aktuar der Wiener Akademie der Wissenschaften. ${ }^{307}$ Castle war bis 1923 Mittelschullehrer, wurde im selben Jahr außerordentlicher Professor in Wien und 1933 mit dem Titel eines ordentlichen Professors ausgestattet. 1938 wurde er von den Nationalsozialisten aus politischen Gründen entlassen. ${ }^{308}$

302 Denkschrift der Privatdozenten der Universität Wien vom 12. Jänner 1919; UAW, Phil. Fak., S 29, fol. 4.

303 Gruber: Rudolf Wolkan (2003).

304 Tatzreiter: Theodor Maria Ritter von Grienberger (2003).

305 [Redaktion:] Robert Franz Arnold (2003).

306 Haider-Pregler: Stefan Hock (1972).

307 [Redaktion:] Viktor Junk (1965).

308 Kriegleder: Eduard Castle (2003). 
Dass die Privatdozentur seit der Jahrhundertwende keine sichere Aussicht mehr auf eine ordentliche Professur darstellte und damit zusehends an Prestige und gesellschaftlicher Bedeutung verlor, hatte vor allem mit der zunehmenden Disproportion von Lehrenden und Lernenden zu tun, also mit dem Anstieg der Studierendenzahlen bei gleichzeitiger Stagnation des Stellenplans an der Universität. Während die Anzahl der Hörer und Hörerinnen an der philosophischen Fakultät sprunghaft anstieg, sich zwischen 1898 und 1932 mehr als versechsfachte, ${ }^{309}$ blieb die Anzahl der Professuren nahezu gleich: 1898 gab es 51 ordentliche Lehrkanzeln und 20 Extraordinariate an der philosophischen Fakultät, 1933 nur unwesentlich mehr, nämlich 55 Ordinariate und 34 Extraordinariate. ${ }^{310}$ Diese Entwicklung bedeutete zum einen, dass die Hauptlast der universitären Lehre von Privatdozenten getragen werden musste, dass sie mithin für die Universität unabdingbar geworden waren, da ohne sie der laufende Lehrbetrieb nicht aufrechterhalten werden konnte. ${ }^{311}$ Gleichzeitig verlor die Privatdozentur dadurch aber auch ihre alte Bedeutung als sicherer Weg zu einem Ordinariat, da es zu wenige Professuren gab. Die Privatdozentur, die seit der Universitätsreform von 1848/49 als „Ausgangspunkt für die akademische Laufbahn“ gelten sollte, wurde „für die Mehrzahl der Schluß- und Endpunkt ihres Fortkommens". ${ }^{12}$

Hinzu kam, dass die staatlichen Sparmaßnahmen in den 1920er und 1930er Jahren den Universitätsbetrieb massiv beeinträchtigten. Zwar brachte der Kampf der Hochschullehrer um materielle Besserstellung 1921 zunächst ein Besoldungsgesetz zu ihren Gunsten, bereits 1924 wurde aber ein neues Gesetz verabschiedet, in dem die ordentlichen Professoren um eine, die außerordentlichen Professoren um zwei Dienstklassen zurückgesetzt wurden und damit um einiges schlechter bezahlt wurden als noch in der Monarchie. ${ }^{313}$ Darüber hinaus wurden in den 1920er Jahren einzelne Habilitationen vom Ministerium nur dann bestätigt, wenn der Bewerber bzw. die Bewerberin eine formelle Erklärung abgab, auf jede fixe Besoldung

309 Im Sommersemester 1898 studierten 879 Hörer und Hörerinnen an der philosophischen Fakultät in Wien, im Wintersemester 1932 waren es bereits 5.287.

310 Vgl. Meister: Die staatlichen Ersparungsmaßnahmen und die Lage der Wissenschaft (1933), S. 15-16.

311 Im Studienjahr 1918/19 standen an der philosophischen Fakultät 52 ordentlichen Professoren bereits 114 Privatdozenten gegenüber. - Denkschrift der Privatdozenten der Universität Wien vom 12. Jänner 1919; UAW, Phil. Fak., S 29, fol. 1.

312 Castle: Die Lage der Hochschullehrer (1926), S. 3.

313 Vgl. Castle: Die Lage der Hochschullehrer (1926), S. 3. 
für immer zu verzichten. ${ }^{314}$ Die Habilitierten mussten trotzdem als unbezahlte Dozenten weiter lehren, um ihre Venia Legendi und die (immer unwahrscheinlichere) Aussicht auf eine Universitätskarriere nicht zu verlieren. Damit wurde die Privatdozentur, wie Eduard Castle 1921 feststellte, „geradezu ein Privileg für Kapitalisten oder Hungerkünstler “" ${ }^{\text {315. }}$.

Die finanzielle Schlechterstellung und die schwindende Wahrscheinlichkeit einer akademischen Karriere führten zu einem massiven Prestigeverlust der Privatdozentur. Gleichzeitig war dieser Prestigeverlust - gemeinsam mit der Unverzichtbarkeit der Privatdozenten für den laufenden Lehrbetrieb - aber auch mitverantwortlich dafür, dass sich in den 1920er Jahren erstmals drei Frauen an der Wiener Germanistik habilitieren konnten. Danach dauerte es fast dreißig Jahre bis erneut eine Wissenschaftlerin am Wiener Germanistikinstitut die Venia Legendi erhielt. Eine Privatdozentur, die keine Aussicht auf ein Ordinariat versprach, musste nicht mehr verteidigt werden. Ordentliche Professorinnen wurden diese Wissenschaftlerinnen in Österreich ohnehin nicht.

Paul Kluckhohn verließ die Wiener Universität 1931 nach nur acht Semestern und nahm einen Ruf an die Universität Tübingen an. Wie zuvor Walther Brecht war ihm die immense Arbeitsbelastung an der Wiener Germanistik zu viel. ${ }^{316}$ Hatte sich Brecht bei seinem Weggang noch gegen Nadler als seinen Nachfolger ausgesprochen, so stand dessen Berufung nach Wien nun nichts mehr im Wege. Die Fakultätskommission entschied sich für Josef Nadler und Günther Müller auf dem ersten Platz, für Ferdinand Josef Schneider auf dem zweiten Platz und diskutierte Brechts Schüler Herbert Cysarz, Heinz Kindermann und Franz Koch für den dritten Platz, ließ diesen schlussendlich aber frei. Vehement gegen Nadler trat Eduard Castle in einem Separatvotum auf, in dem er den „Ausschluß

314 Vgl. Castle: Die Lage der Hochschullehrer (1926), S. 3.

315 Castle: Die Not der Universität Wien und die Privatdozenten (1921), S. 3 ; zit. n. Meissl: Germanistik in Österreich (1981), S. 482. - Vgl. auch Denkschrift der Privatdozenten der Universität Wien vom 12. Jänner 1919; UAW, Phil. Fak., S 29, fol. 2: „Während früher auch Vermögenslose, die genug Mut und Idealismus hatten, sich einzuschränken und anspruchslos zu leben, den Beruf des Dozenten erwählen konnten, wird es nunmehr nur Großkapitalisten möglich sein, die akademische Laufbahn mit Aussicht auf Erfolg einzuschlagen. An die Stelle der Auslese der Tüchtigsten wird die Auslese der Reichsten treten [...].“

316 Vgl. die Briefe von Walther Brecht an Paul Kluckhohn; DLA Marbach, Bestände: Paul Kluckhohn; Deutsche Vierteljahrsschrift. - Noch in einem Nachruf auf Kluckhohn heißt es, dass Kluckhohn Wien verließ, da er sich „den sehr großen Lehr- und Prüfungsverpflichtungen [...] nicht gewachsen fühlte“. Meister: Paul Kluckhohn [Nekrolog] (1960), S. 357. 
der in Osterreich tätigen Fachvertreter" kritisierte und vor allen darauf verwies, dass "Nadlers Werk und Persönlichkeit [...] viel umstritten“ wären. Bereits in der Kommissionssitzung hatte Castle „aus Gründen des persönlichen Verhaltens" Einspruch gegen Nadler erhoben und auch Unterstützung durch „mehrere Redner“ erhalten, die zugaben, dass „Nadlers Naturell gewiss manche Härten habe“. ${ }^{317}$ In Wien trat das Ministerium zunächst an Günther Müller heran, der aber aus finanziellen Erwägungen ablehnte. Nach Interventionen beim Ministerium durch seinen Prager Studien- und Cartellverbandskollegen Josef Bick wurde Nadler schließlich zum Wintersemester 1931/32 nach Wien berufen. ${ }^{318}$

Nadler, der als schwieriger Kollege galt, der niemanden neben sich duldete, wurde bereits kurz nach seinem Amtsantritt seinem Ruf gerecht. Zunächst versuchte er, die bislang den Extraordinarien Robert Franz Arnold und Max Hermann Jellinek vorbehaltenen Proseminare an sich zu ziehen. ${ }^{319}$ Auch mit den Schülern seiner Vorgänger scheint er nicht zu Recht gekommen zu sein. Mit Ausnahme Hans Rupprichs verließen sie alle kurz nach Nadlers Amtsantritt die Wiener Universität. Mit den Anforderungen des Massenstudiums hatte Nadler hingegen keine Probleme. Er hielt seine Vorlesungen oftmals zweimal hintereinander, um dem Ansturm der Studierenden gerecht zu werden, und 1934 engagierten sich seine Hörer und Hörerinnen mit einer Unterschriftenaktion für den Bau eines eigenen Saals für seine Vorlesungen. ${ }^{320}$ Schließlich waren seine überfüllten Lehrveranstaltungen auch mitverantwortlich dafür, dass 1935 das Auditorium Maximum gebaut wurde. ${ }^{321}$ Dass er außerdem schnell und effizient bei der Beurteilung von Dissertationen war, ist vielfach in Erinnerungen ehemaliger Studierender bezeugt. ${ }^{322}$ Doch obwohl Nadler mehr Promotionen abnahm und für mehr Studienabschlüsse verantwortlich war als jeder einzelne seiner Vorgänger, hat er während seiner gesamten, immerhin

317 Alle Zitate: Kommissionsbericht betreffend die Wiederbesetzung der Lehrkanzel für deutsche Sprache und Literatur nach dem Abgang von Prof. Kluckhohn vom 25. November 1930; UAW, Phil. Fak., Zl. 370 ex 1930/31, PA 2713 Josef Nadler.

$318 \mathrm{Zu}$ den näheren Details von Nadlers Berufung nach Wien vgl. Ranzmaier: Stamm und Landschaft (2008), S. 373-378; Meissl: Germanistik in Österreich (1981), S. 481.

319 Meissl: Germanistik in Österreich (1981), S. 481.

320 [Anonym:] „Volksentscheid“ für einen neuen Hörsaal (1934), S. 5.

321 Ranzmaier: Germanistik an der Universität Wien zur Zeit des Nationalsozialismus (2005), S. 19; Schmidt-Dengler: Germanistik in Wien 1945 bis 1960 (2005), S. 211; Hopf: [Erinnerungen an Josef Nadler] (1984), S. 18.

322 Vgl. u. a. Wörster: Gedenkschrift für Josef Nadler (1984). 
14 Jahre andauernden Amtszeit nicht nur keine einzige Frau habilitiert, sondern überhaupt keinen Wissenschaftler. ${ }^{323}$

323 Die Habilitation von Schülern galt im akademischen Betrieb als Zeugnis des Lehrerfolgs eines Professors; gleichzeitig war den Professoren aber auch schon vor Nadler bewusst, dass sie sich damit zusätzliche Konkurrenten schufen. Vgl. Brief von Walther Brecht an Paul Kluckhohn vom 19. November 1925; DLA Marbach, Bestand: Paul Kluckhohn. - Zu Nadlers Position vgl. das Interview von Irene Ranzmaier mit Helmut Birkhan, in dem dieser über seine Wiener Studienzeit in den späten 1950er Jahren spricht: „[J]eder Student ist potentiell lästig, und jeder Student ist auch ein potentieller Gegner. Deshalb hat man auch nicht gerne habilitiert. Das ist ein Nadlersches Erbe, weil schon Nadler gesagt hat: Ich werde ja nicht blöd sein und mir durch Habilitation einen Konkurrenten züchten." Ranzmaier: Germanistik an der Universität Wien zur Zeit des Nationalsozialismus (2005), S. 189. 